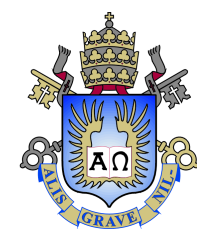

Leonardo Leyva Lamas

\title{
Áreas de Coordenação associadas a Estações Terrenas em Movimento operando no Serviço Fixo por Satélite na faixa de $27,5-29,5 \mathrm{GHz}$
}

Dissertação apresentada como requisito parcial para obtenção do grau de Mestre pelo Programa de Pós-graduação em Engenharia Elétrica do Departamento de Engenharia Elétrica do Centro Técnico Científico da PUC-Rio.

Orientador: Prof. José Mauro Pedro Fortes 


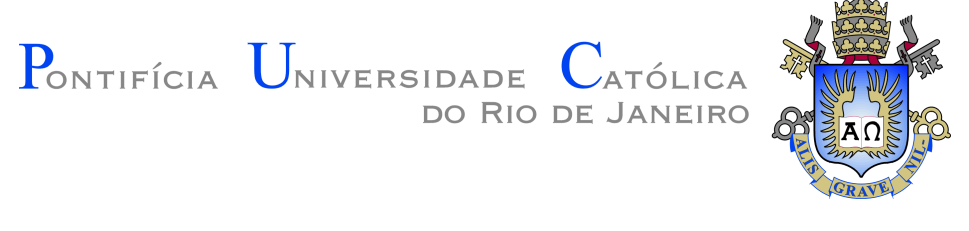

Leonardo Leyva Lamas

\begin{abstract}
Áreas de Coordenação associadas a Estações Terrenas em Movimento operando no Serviço Fixo por Satélite na faixa de $27,5-29,5 \mathrm{GHz}$
\end{abstract}

\begin{abstract}
Dissertação apresentada como requisito parcial para obtenção do grau de Mestre pelo Programa de Pós-graduação em Engenharia Elétrica do Departamento de Engenharia Elétrica do Centro Técnico Científico da PUC-Rio. Aprovada pela Comissão Examinadora abaixo assinada.
\end{abstract}

Prof. Raimundo Sampaio Neto CETUC - PUC-Rio

Prof. Paulo Roberto Rosa Lopes Nunes Instituto Militar de Engenharia - IME

Prof. Márcio da Silveira Carvalho

Coordenador Setorial do Centro Técnico Científico - PUC-Rio 
Todos os direitos reservados. É proibida a reprodução total ou parcial do trabalho sem autorização da universidade, do autor e do orientador.

\section{Leonardo Leyva Lamas}

Graduou-se em Engenharia em Telecomunicações e Eletrônica pelo Instituto Superior Politênico José Antonio Echeverría (La Habana, Cuba) em 2013.

Ficha Catalográfica

Leyva Lamas, Leonardo

Áreas de Coordenação associadas a Estações Terrenas em Movimento operando no Serviço Fixo por Satélite na faixa de 27,5-29,5 GHz / Leonardo Leyva Lamas; orientador: José Mauro Pedro Fortes. - Rio de janeiro: PUC-Rio, Departamento de Engenharia Elétrica, 2018.

v., 84 f: il. color. ; $30 \mathrm{~cm}$

Dissertação (mestrado) - Pontifícia Universidade Católica do Rio de Janeiro, Departamento de Engenharia Elétrica.

Inclui bibliografia

1. Interferência;. 2. Estações terrenas em movimento;. 3. Serviço Fixo Terrestre;. 4. Critérios de Interferência;. 5. Áreas de coordenação;. 6. Serviço Fixo por Satélite.. I. Pedro Fortes, José Mauro. II. Pontifícia Universidade Católica do Rio de Janeiro. Departamento de Engenharia Elétrica. III. Título. 


\section{Agradecimentos}

A minha família pela confiança depositada em mi quando decidi deixar meu país e meus seres amados para estudar no estrangeiro, em destaque, a minha mãe que sempre acreditou em mim, a meu pai pelos conselhos, a minha esposa por ter me dado forças em aqueles momentos mais difficiles e por todo o seu amor que tive presente apesar da distância, a meu irmão e a sua família, em destaque a minha sobrinha Amelie.

A meu orientador, o professor José Mauro Pedro Fortes, que tem sido exemplo como professor e pessoa, pela excelente orientação e dedicação sem as quais no houvesse sido possível a realização deste trabalho. Alem disso, pelo tempo e esforço dedicados no só nesta dissertação de mestrado mas desde meu começo no CETUC.

Aos colegas com que tive a sorte de compartir bons momentos: Rainel, Randy, Julio, Yuneisy, Robert, Dailys, Marcelo, Jenny, Mauricio, Jose Calpa, Juan Pablo, Alberth, Azucena, Javier, Christian, Jussif, Teddy, Americo, Laisa, Carina, David, Kirenia, Alex, Dayrene, Adrian, em fim a todos com quem convivi estes dois anos, obrigado, por vocês o tempo longe de casa não foi mais difícil.

As amizades que fiz fora do âmbito da PUC por ter acreditado em mim, por seu apoio incondicional e por ter-me dado a oportunidade de adquirir novos conhecimentos, agradeço a vocês Carlos A, Leticia, Vitor, Paulo, Douglas.

Aos professores com que passei aulas por ter-me dado a oportunidade de crescer academicamente, em destaque, ao professor Raimundo Sampaio Neto, também exemplo como professor e pessoa, obrigado por todo o que deram-me a oportunidade de aprender e conhecer.

A todo o pessoal do CETUC por ter-me brindado seu carinho e apoio em todo momento, em destaque, a Marcelo Balisteri, por seu trato cálido e amizade. Da mesma forma agradeço a Carlos por tudo o seu apoio ao longo deste dois anos.

À PUC-Rio, ao corpo de funcionários do Departamento de Engenharia, notavelmente Adriane por ter-me tido paciência e auxiliado no difícil começo. Da mesma forma agradeço o apoio financeiro provido pela CAPES, sem o qual este trabalho nem o tempo vivido em Brasil houvesse sido possível. 


\section{Resumo}

Leyva Lamas, Leonardo; Pedro Fortes, José Mauro. Áreas de Coordenação associadas a Estações Terrenas em Movimento operando no Serviço Fixo por Satélite na faixa de 27,5-29,5 GHz. Rio de Janeiro, 2018. 84p. Dissertação de Mestrado - Departamento de Engenharia Elétrica, Pontifícia Universidade Católica do Rio de Janeiro.

A prestação de serviços de comunicação utilizando plataformas móveis é realizada tradicionalmente por sistemas via satélite do Serviço Móvel por Satélite (MSS) em faixas de frequência relativamente baixas. O crescimento elevado no número de conectividades de banda larga tornou claro que o espectro do Serviço Móvel por Satélite não é suficiente para atender às novas necessidades. Este fato motivou a Conferência Mundial de Radiocomunicações 2015 (WRC-15) a solicitar, em sua Resolução 158, que Setor de Radiocomunicações da União Internacional de Telecomunicações realizasse estudos envolvendo o compartilhamento de frequências e a compatibilidade entre estações terrenas em movimento (ESIMs) operando na faixas alocadas ao Serviço Fixo por Satélite (FSS) e outros serviços. Como consequência, o assunto foi também incluído na agenda da WRC-19. O presente trabalho, aborda a proteção de receptores do Serviço Fixo Terrestre contra interferência produzidas por ESIMs e propõe, inicialmente, uma metodologia para determinar a Áreas de Coordenação em torno da área de serviço de ESIMs operando no FSS na faixa 27,5-29,5 GHz. Conforme evidenciado no trabalho, as áreas de coordenação obtidas são normalmente complexas e inadequadas para utilização em um texto regulamentar. Assim, é também proposta uma metodologia para a determinação de uma Área de Coordenação Alternativa baseada numa distância $D$ pré estabelecida. Na metodologia, a escolha da distância $D$ adequada é feita com base em curvas do tipo ROC (Receiver Operating Chracteristics), usualmente utilizadas em problemas de detecção. Finalmente, é feita uma análise da redução de potência de transmissão das ESIMs (redução que depende de sua localização na área de serviço) necessária para garantir a proteção dos receptores do Fixo Terrestre fora da Área de Coordenação Alternativa proposta.

\section{Palavras-chave}

Interferência; Estações terrenas em movimento; Serviço Fixo Terrestre; Critérios de Interferência; Áreas de coordenação; Serviço Fixo por Satélite. 


\section{Abstract}

Leyva Lamas, Leonardo; Pedro Fortes, José Mauro (Advisor). Coordination Areas for Earth Stations in Motion operating in the Fixed Satellite Service in the band 27.5-29.5 GHz. Rio de Janeiro, 2018. 84p. Dissertação de Mestrado - Departamento de Engenharia Elétrica, Pontifícia Universidade Católica do Rio de Janeiro.

The provision of communication services to mobile platforms has traditionally been accomplished by Mobile-Satellite Service (MSS) satellite systems using relatively low frequency bands. The high growth in connectivity requirements has made it clear that the spectrum allocated to the MSS is not enough to meet these new needs. This fact has motivated the World Radiocommunication Conference in 2015 (WRC-15) to invite, in its Resolution 158, Radiommunications Sector of the International Telecommunication Union (ITU-R) to carry out studies involving the frequency sharing and the compatibility between earth stations in motion (ESIM) operating within geostationary FSS allocations and other services. As a consequence, the issue was also included in the WRC-19 agenda. This paper deals with the protection of Fixed Service receivers against interference produced by ESIMs and proposes, initially, a methodology to determine the Coordination Areas around the service area of the ESIMs operating in the FSS in the range 27.5-29.5 GHz. As evidenced in the paper, the obtained coordination areas are usually complex and unsuitable for use in a regulatory text. Thus, a methodology is also proposed for the determination of an Alternative Coordination Area based on a predetermined distance $D$. In the methodology, the choice of the proper distance $D$ is made based on ROC type curves (Receiver Operating Characteristics), usually used in detection problems. Finally, an analysis of the ESIMs transmission power reduction (reduction that depends on their location in the service area) necessary to guarantee the protection of the Fixed Service receivers outside the proposed Alternative Coordination Area.

\section{Keywords}

Interference; Earth Stations in Motion; Fixed Service; Interference Criteria; Coordination Area; Fixed Satellite Service. 


\section{Sumário}

1 Introdução 14

2 Descrição do Problema $\quad 17$

3 Modelo Matemático 20

3.1 Densidade de potência interferente na entrada do receptor FS 20

3.2 Critérios de proteção contra a interferência 23

3.3 Determinação da Área de Coordenação 25

3.4 Área de Coordenação Pré Especificada 31

4 Resultados Numéricos $\quad 38$

4.1 Região Montanhosa 41

4.1.1 Zona de serviço do tipo rodovia ou linha ferroviária numa região montanhosa. 41

4.1.2 Zona de serviço definida pelo feixe de recepção de um satélite geostacionário numa região montanhosa. $\quad 47$

4.2 Região Plana 53

4.2.1 Zona de serviço do tipo rodovia ou linha ferroviária numa região predominantemente plana. 53

4.2.2 Zona de serviço definida pelo feixe de recepção de um satélite geostacionário numa região predominantemente plana. 59

5 Conclusões $\quad 65$

$\begin{array}{ll}\text { Referências bibliográficas } & 67\end{array}$

A Procedimento para determinar o valor $L$ da perda de propagação que não é excedido durante $P \%$ do tempo. $\quad 69$

$\begin{array}{lll}\text { A.1 Dados de partida } & 71\end{array}$

$\begin{array}{ll}\text { A.2 Dados radiometeorológicos } & 71\end{array}$

A.3 Análise do perfil do percurso $\quad 72$

A.4 Predição da interferência em céu claro 75

A.4.1 Propagação em visibilidade direita (incluídos os efeitos a curto prazo) 75

$\begin{array}{lll}\text { A.4.2 Difração } & 76\end{array}$

$\begin{array}{lll}\text { A.4.3 Dispersão troposférica } & 77\end{array}$

A.4.4 Propagação por dutos e por reflexão nas camadas 77

$\begin{array}{lll}\text { A.4.5 Perdas adicionais devidas à ocupação do solo } & 78\end{array}$

A.4.6 Predição Geral das perdas básicas de transmissão não excedidas $\begin{array}{ll}\text { durante o p do tempo } & 79\end{array}$

A.5 Exemplo do uso da metodologia 79

B Nível máximo admissível da densidade de potencia da antena transmissora (ESIM) a partir da Recomendação ITU-R S.524. 


\section{Lista de figuras}

Figura 2.1 Esquema ilustrativo da Área de Coordenação obtida para uma estação terrena numa localização fixa.

Figura 2.2 Esquema ilustrativo da Área de Coordenação obtida quando a mobilidade dos terminais é levada em conta.

Figura 2.3 Esquema ilustrativo dos mecanismo de propagação da interferência, visada direta, difração, propagação por dutos e espalhamento troposférico.

Figura 3.1 Esquema ilustrativo da interferência gerada por uma ESIM em $\mathbf{r} \in \Omega_{\mathbf{r}}$ na entrada de um receptor do Serviço Fixo Terrestre.

Figura 3.2 Funções Distribuição de Probabilidade Complementar da variável $i_{\mathrm{dB}}$ e critérios de proteção contra a interferência a serem satisfeitos.

Figura 3.3 Ilustração do critério de proteção contra a interferência em (3-18), $C_{i_{\mathrm{dB}}}(I)$ corresponde a Função Distribuição de Probabilidade Complementar da variável $i_{\mathrm{dB}}$ gerada na entrada de um receptor do FS.

Figura 3.4 Esquema ilustrativo da distância de coordenação $D_{\mathbf{r}}^{j}(\alpha)$, numa posição $\mathbf{r}=\mathbf{R}$ no azimute $\alpha=\mathrm{A}$

Figura 3.5 Influencia da variação da distancia entre o receptor FS e a estação interferente ESIM no formato da $C_{i_{\mathrm{dB}} \mid \mathbf{r}=\mathbf{R}, \alpha=\mathrm{A}}(I)$ para o $j$ critério de proteção sendo analisado.

Figura 3.6 Exemplo das distâncias $D_{\mathbf{R}}^{1}(\mathrm{~A})$ - longo prazo e $D_{\mathbf{R}}^{2}(\mathrm{~A})$ curto prazo prazos respectivamente num cenário real para uma ESIM numa posição $\mathbf{r}$ com latitude $\theta=40,82^{\circ} \mathrm{N}$, longitude $\phi=97,60^{\circ} \mathrm{O}$ e azimute $\mathrm{A}=90^{\circ}$.

Figura 3.7 Esquema ilustrativo do Contorno de Coordenação ao redor de uma estação terrena em movimento (ESIM) na posição $\mathbf{r}=\mathbf{R}$.

Figura 3.8 Exemplo da obtenção do $\mathcal{C}_{\mathbf{R}}^{1}$ - longo prazo e $\mathcal{C}_{\mathbf{R}}^{2}$ - curto prazo numa situação real para uma ESIM numa posição $\mathbf{R}$ com latitude $\theta=40,82^{\circ} \mathrm{N}$ e longitude $\phi=97,60^{\circ} \mathrm{O}$

Figura 3.9 Exemplo da Área de Coordenação para uma rede de ESIMs operando na região $\Omega_{\mathbf{r}}$ partindo da união das Regiões de Coordenação.

Figura 3.10 Exemplo da obtenção de $\mathcal{A}_{\Omega_{\mathrm{r}}}^{1}$ - longo prazo e $\mathcal{A}_{\Omega_{\mathrm{r}}}^{2}$ - curto prazo numa situação real para ESIM operando numa região circular de raio $30 \mathrm{~km}$ e centro na posição geográfica definida pela latitude $\theta=20^{\circ} \mathrm{S}$ e longitude $\phi=44^{\circ} \mathrm{O}$.

Figura 3.11 Áreas de Coordenação Pré-estabelecidas: (a) Região de Coordenação definida pela distância pré-estabelecida $D$ e associada à uma ESIM localizada em $\mathbf{r} \in \Omega_{\mathbf{r}}$; (b) Área de Coordenação definida pela distância pré-estabelecida $D$, associada a toda a área de serviço $\Omega_{\mathbf{r}}$. 
Figura 3.12 Ilustração da Área de Coordenação Pré Estabelecida $\mathcal{A}_{\Omega_{\mathbf{r}}}(D)$ e da Área de Coordenação Real $\mathcal{A}_{\Omega_{\mathrm{r}}}^{j}$, associada a $j$ ésima condição do critério de proteção, obtida a partir da metodologia descrita na Seção 3.3.

Figura 3.13 Exemplo de ROC obtida a partir de variar $D$ no intervalo de $[0, \infty)$ no eixo das abcissas - $P_{f a}$ e no eixo das ordenadas $P_{d}$

Figura 3.14 Esquema do comportamento da Função Distribuição de Probabilidade Complementar da densidade de potência de densidade interferente no receptor FS.

Figura 3.15 Exemplo do comportamento da densidade espectral de potência da ESIM em $\mathbf{r} \in \Omega_{\mathbf{r}}$ - rodovia, para o $j$-ésimo critério de proteção, que garante a proteção de receptores do FS em $\overline{\mathcal{A}}_{\Omega_{\mathrm{r}}}(D)$.

Figura 3.16 Exemplo do comportamento da densidade espectral de potência da ESIM em $\mathbf{r} \in \Omega_{\mathbf{r}}$ - região de serviço circular, para o $j$-ésimo critério de proteção, que garante a proteção de receptores do FS em $\overline{\mathcal{A}}_{\Omega_{\mathbf{r}}}(D)$.

Figura 4.1 Relêvo da região montanhosa localizada no estado de New Mexico, no Estados Unidos.

Figura 4.2 Parte da rodovia interestadual I-40 que cobre o percurso entre as cidades de Gallup e Albuquerque no estado de New Mexico no Estados Unidos.

Figura 4.3 Áreas de Coordenação obtidas com o procedimento da Seção 3.3, para ESIMs operando em um trecho da rodovia I-40, numa região com topografia predominantemente montanhosa. A linha vermelha corresponde ao critério de proteção de longo prazo $\left(p_{1}=0,2\right)$ e a linha preta ao critério de curto prazo $\left(p_{2}=5 \times 10^{-5}\right)$.

Figura 4.4 Curva ROC associada ao critério de longo prazo (região montanhosa e área de serviço caracterizada por trecho de rodovia). 44

Figura 4.5 Curva ROC associada ao critério de curto prazo (região montanhosa e área de serviço caracterizada por trecho de rodovia). 44

Figura 4.6 Áreas Pré-Especificada para distâncias $D=70 \mathrm{~km}$ e $D=$ $90 \mathrm{~km}$ ao redor de uma rodovia numa região predominantemente montanhosa.

Figura 4.7 Máxima densidade de potência de transmissão das ESIM ao longo do trecho da rodovia I-40 considerado. A posição $\mathbf{r} \in \Omega_{\mathbf{r}}$ é caracterizada pela distância ao longo da rodovia, medida a partir da cidade de Gallup.

Figura 4.8 Máxima densidade de potência de transmissão das ESIM ao longo do trecho da rodovia I-40 considerado. A posição $\mathbf{r} \in \Omega_{\mathbf{r}}$ é caracterizada pela distância ao longo da rodovia, medida a partir da cidade de Gallup.

Figura 4.9 Área de serviço do feixe de recepção do satélite geostacionário com centro definido pela latitude $35,4^{\circ} \mathrm{N}$ e longitude $107,6^{\circ} \mathrm{O}$ no estado de New Mexico no Estados Unidos. 
Figura 4.10 Áreas de Coordenação obtidas com o procedimento da Seção 3.3, para ESIMs operando numa região circular, com topografia predominantemente montanhosa. A linha vermelha corresponde ao critério de proteção de longo prazo $\left(p_{1}=0,2\right)$ e a linha preta ao critério de curto prazo $\left(p_{2}=5 \times 10^{-5}\right)$.

Figura 4.11 Curva ROC associada ao critério de longo prazo (região montanhosa e área de serviço caracterizada pelo feixe de recepção do satélite geostacionário).

Figura 4.12 Curva ROC associada ao critério de curto prazo (região montanhosa e área de serviço caracterizada pelo feixe de recepção do satélite geostacionário).

Figura 4.13 Áreas Pré-Especificada para distâncias $D=115 \mathrm{~km}$ e $D=130 \mathrm{~km}$ ao redor de uma região de serviço circular.

Figura 4.14 Máxima densidade de potência de transmissão das ESIM $(D=115 \mathrm{~km})$ na área de serviço (feixe recepção satélite GEO). A posição $\mathbf{r} \in \Omega_{\mathbf{r}}$ é caracterizada pela posição geográfica.

Figura 4.15 Máxima densidade de potência de transmissão das ESIM $(D=130 \mathrm{~km})$ na área de serviço (feixe recepção satélite GEO). A posição $\mathbf{r} \in \Omega_{\mathbf{r}}$ é caracterizada pela posição geográfica.

Figura 4.16 Relêvo da região plana localizada no estado de Nebraska, no Estados Unidos.

Figura 4.17 Parte da rodovia interestadual I-80 que cobre o percurso entre as cidades de Kearney e Lincoln no estado de Nebraska no Estados Unidos.

Figura 4.18 Áreas de Coordenação obtidas com o procedimento da Seção 3.3, para ESIMs operando em um trecho da rodovia I-80, numa região com topografia predominantemente plana. A linha vermelha corresponde ao critério de proteção de longo prazo $\left(p_{1}=0,2\right)$ e a linha preta ao critério de curto prazo $\left(p_{2}=5 \times 10^{-5}\right) .55$

Figura 4.19 Curva ROC associada ao critério de longo prazo (região plana e área de serviço caracterizada por trecho de rodovia).

Figura 4.20 Curva ROC associada ao critério de curto prazo (região plana e área de serviço caracterizada por trecho de rodovia).

Figura 4.21 Áreas Pré-Especificada para distâncias $D=90 \mathrm{~km} \mathrm{e}$ $D=100 \mathrm{~km}$ ao redor de uma rodovia numa região predominantemente plana.

Figura 4.22 Máxima densidade de potência de transmissão das ESIM ao longo do trecho da rodovia I-80 considerado. A posição $\mathbf{r} \in \Omega_{\mathbf{r}}$ é caracterizada pela distância ao longo da rodovia, medida a partir da cidade de Kearney.

Figura 4.23 Máxima densidade de potência de transmissão das ESIM ao longo do trecho da rodovia I-80 considerado. A posição $\mathbf{r} \in \Omega_{\mathbf{r}}$ é caracterizada pela distância ao longo da rodovia, medida a partir da cidade de Kearney.

Figura 4.24 Área de serviço do feixe de recepção do satélite geostacionário com centro definido pela latitude $40,8^{\circ} \mathrm{N}$ e longitude $97,5^{\circ} \mathrm{O}$ no estado de Nebraska no Estados Unidos. 
Figura 4.25 Áreas de Coordenação obtidas com o procedimento da Seção 3.3, para ESIMs operando numa região circular, com topografia predominantemente montanhosa. A linha vermelha corresponde ao critério de proteção de longo prazo $\left(p_{1}=0,2\right)$ e a linha preta ao critério de curto prazo $\left(p_{2}=5 \times 10^{-5}\right)$.

Figura 4.26 Curva ROC associada ao critério de longo prazo (região predominantemente plana e área de serviço caracterizada pelo feixe de recepção do satélite geostacionário).

Figura 4.27 Curva ROC associada ao critério de curto prazo (região predominantemente plana e área de serviço caracterizada pelo feixe de recepção do satélite geostacionário).

Figura 4.28 Área Pré-Especificada para distância $D=100 \mathrm{~km}$ ao redor de uma região de serviço circular.

Figura 4.29 Máxima densidade de potência de transmissão das ESIM $(D=100 \mathrm{~km})$ na área de serviço (feixe recepção satélite GEO). A posição $\mathbf{r} \in \Omega_{\mathbf{r}}$ é caracterizada pela posição geográfica.

Figura A.1 Metodologias abordadas na recomendação ITU-R P.54216.

Figura A.2 Procedimento usado para a determinação da perda básica não excedida segum a recomendação UIT P.452-16.

Figura A.3 Valor anual médio de $\Delta N$ (proporção de variação do índice de refracção no primeiro quilômetro da atmosfera).

Figura A.4 Valor meio da refracção na superfície ao nevei do mar $N_{0} .74$

Figura A.5 Exemplo de um perfil de percurso transhorizonte $\quad 75$

Figura A.6 Metodologia geral para a determinação dos parâmetros obtidos a partir do perfil do percurso

Figura A.7 Metodologia geral para a determinação das perdas devido a difração

Figura A.8 Exemplo na região metropolitana de Rio de Janeiro, transmissor localizado na PUC-Rio no bairro da Gavea e receptor no Museu Bélico localizado Niteroi.

Figura A.9 Perfil do percurso do exemplo da zona sul do Rio de Janeiro, transmissor localizado na PUC-Rio no bairro da Gavea e receptor no Museu Bélico localizado Niteroi.

Figura A.10 Função acumulativa da perda básica de transmissão $F_{l p}\left(L_{p}\right)$ entre uma estação na PUC-Rio no bairro da Gavea e outra estação no Museu Bélico em Niteroi.

Figura B.1 Condição em (B-3), são ilustrados o diagrama de radiação (Recomendação ITU-R F-1245-2 e ITU-R S.465-6) e o nível máximo admissível da densidade e.i.r.p. (Recomendação ITU-R S.524-9) em dB(W/40KHz), considerando $D=0,5 \mathrm{~m}$.

Figura B.2 Condição em (B-3), são ilustrados o diagrama de radiação (Recomendação ITU-R F-1245-2 e ITU-R S.465-6) e o nível máximo admissível da densidade e.i.r.p. (Recomendação ITU-R S.524-9) em dB(W/40KHz), considerando $D=1 \mathrm{~m}$. 


\section{Lista de tabelas}

Tabela 4.1 Parâmetros utilizados nos exemplos apresentados nas seções 4.1 e 4.2 .

Tabela 4.2 Probabilidades de falso alarme e probabilidades de detecção para as distâncias $D$ destacadas nas figuras 4.4 e 4.5.

Tabela 4.3 Probabilidades de falso alarme e probabilidades de detecção para as distâncias $D$ destacadas nas figuras 4.11 e 4.12. 50

Tabela 4.4 Probabilidades de falso alarme e probabilidades de detecção para as distâncias $D$ destacadas nas figuras 4.19 e 4.20. $\quad 57$

Tabela 4.5 Probabilidades de falso alarme e probabilidades de detecção para as distâncias $D$ destacadas nas figuras 4.26 e 4.27. 


\section{Lista de símbolos e abreviações}

$\begin{array}{ll}\text { MSS } & \text { Mobile Satellite Service } \\ \text { FSS } & \text { Fixed Satellite Service } \\ \text { ESOMP } & \text { Earth Station on Mobile Platforms } \\ \text { ESIM } & \text { Earth Station in Motion } \\ \text { FS } & \text { Fixed Service } \\ \text { ROC } & \text { Receiver Operating Characteristics } \\ \text { ITU } & \text { International Telecommunication Union } \\ \text { WRC } & \text { World Radiocommunication Conferences } \\ \text { CDF } & \text { Complementary Distribution Function } \\ \text { PDF } & \text { Probability Density Function } \\ \text { TDMA } & \text { Time Division Multiple Access } \\ & \\ & \end{array}$




\section{Introdução}

A prestação de serviços de comunicação por satélite utilizando plataformas móveis sempre foi, tradicionalmente, realizada por sistemas do Serviço Móvel por Satélite (MSS) que operam em faixas de frequência relativamente baixas (e.g. 0,5 a 1,5 GHz - Banda L e 2,0 a 4,0 GHz - Banda S). As bandas disponíveis para um usuário nestas faixas de frequência são relativamente pequenas (algumas centenas de $\mathrm{kHz}$ ), o que limita a taxa de dados que pode ser transmitida. A capacidade máxima nestas bandas de frequência é de até 700 kbit/s aproximadamente, num único canal.

Nos últimos quinze anos, houve um crescimento muito elevado no número de conectividades de banda larga. A demanda por serviços de banda larga tem sido impulsionada principalmente (mas não se limitando a) por serviços baseados na Internet, que incluem navegação na web, VoIP, comércio eletrônico, e-banking, mídia social, streaming de música, streaming de vídeo/TV e serviços na nuvem [1], consequentemente tornou-se claro que o espectro do Serviço Móvel por Satélite não era suficiente para atender a essa necessidade.

Este fato motivou a Conferência Mundial de Radiocomunicações de 2003 a considerar a utilização de estações terrenas móveis operando em faixas alocadas ao Serviço Fixo por Satélite (FSS), tradicionalmente utilizadas para comunicações entre satélites e estações terrenas fixas. Na ocasião foi adotada a Resolução 902 [2] contendo disposições regulamentares e operacionais para a utilização de estações terrenas operando a bordo de embarcações nas faixas de 5,925-6,425 GHz e 14-14,5 GHz, possibilitando a transmissão de uma maior taxa de dados.

A crescente demanda por serviços através de plataformas móveis e os avanços na tecnologia de antenas de satélite, particularmente o desenvolvimento de antenas estabilizadas de 3 eixos (capazes de manter um alto grau de precisão, no apontamento das antenas, mesmo em plataformas em movimento rápido), motivaram o desenvolvimento de estações terrenas móveis com características de apontamento muito estáveis, permitindo o uso de faixas de frequência mais elevadas (e.g. 17,3-30,0 GHz) na prestação de serviços de comunicações, atendendo assim à necessidade de maior taxas de dados [3]. Requisitos técnicos e operacionais relativos ao uso de estações terrenas em movimento 
operando na faixa de frequências 17,3-30,0 GHz podem ser encontrados no Relatório ITU-R S.2223 [3], produzido em 2011. Este relatório descreve como estações terrenas deste tipo, operando nas faixas alocadas ao FSS, podem ser projetadas e operadas satisfazendo os requisitos aplicáveis, na época, a outros tipos de estações terrenas do FSS.

No início de 2015, a partir de diversos estudos realizados, foi aprovado, no âmbito do ITU-R, o Relatório ITU-R S.2357 [4], que fornece orientações técnicas e operacionais para a utilização de estações terrena sobre plataformas moveis (ESOMP) operando em conexão com satélites geoestacionários do FSS, nas faixas de frequências 19,7-20,2 GHz e 29,5-30,0 GHz. Mais recentemente, a Conferência Mundial de Radiocomunicações de 2015 (WRC-15), em sua Resolução 158 [5], considera o uso das faixas de frequência 17,7-19,7 GHz (espaço-Terra) e 27,5-29,5 GHz (Terra-espaço) por estações terrenas em movimento (ESIM) que se comunicam com estações geoestacionárias do FSS, e solicita à União Internacional de Telecomunicações (ITU) estudos envolvendo as características técnicas e operacionais e os requisitos de usuário de diferentes tipos de estações em movimento (navio, avião, veículos terrestres) que operam ou pretendem operar nas bandas alocada ao Serviço Fixo por Satélite dentro das faixas 17,7-19,7 GHz e 27,5-29,5 GHz. Além disso, a resolução solicita estudos de compatibilidade e compartilhamento entre as estações terrenas em movimento que operam com redes geoestacionárias do FSS e as estações (existentes ou planejadas) de outros serviços que utilizam esta mesma faixa de frequências (e.g. Serviço Fixo Terrestre, Serviço Fixo por Satélite, Serviço Móvel e Serviço de Exploração da Terra [6]-[8]). Estes estudos visam à proteção adequada de cada um destes serviços, sem impor restrições indevidas aos demais. Os resultados destes estudos e análises irão fornecer subsídios técnicos para as decisões a serem tomadas na Conferência Mundial de Radiocomunicações de 2019 (WRC-19), cuja agenda contempla este tópico (Item 1.5 da agenda).

A responsabilidade desta tarefa, no momento, foi imputada ao Grupo de Trabalho 4A (WP-4A) da Comissão de Estudos 4 do Setor de Radiocomunicações da ITU. Na primeira reunião celebrada pelo WP-4A, em Abril de 2016, foram apresentados diversos trabalhos concernentes à proteção do serviço fixo terrestre da interferência gerada por estações terrenas em movimento a bordo de veículos terrestres. Na reunião, foi apresentada uma metodologia [9] para estimar a interferência produzida sobre um receptor do serviço fixo terrestre quando suas características técnicas e sua localização são conhecidas. Comentários sobre esta metodologia foram apresentados na segunda reunião do WP-4A. O assunto voltou a ser tratado na terceira reunião do WP-4A, 
celebrada em Maio de 2017, quando estudos adicionais apresentaram uma metodologia [10] para estimar a máxima densidade de e.i.r.p. transmitida pelas ESIM (dependente de sua localização) que garante a proteção dos receptores do FS localizados sobre um contorno de coordenação predefinido.

No presente trabalho, são propostas duas metodologias para a determinação de áreas de coordenação associadas às áreas de serviço de estações terrenas em movimento. Para isso, são considerados elementos como, por exemplo, o relêvo, a mobilidade das ESIM e as condições de propagação. Inicialmente, no Capítulo 2, é apresentada uma descrição sucinta do problema a ser analisado. Em seguida, no Capítulo 3, a modelagem matemática e metodologias propostas são desenvolvidas. É obtida uma expressão para a determinação das estatísticas da densidade de potência interferente gerada na entrada de um receptor do FS. São apresentados os critérios de proteção utilizados, assim como o desenvolvimento das duas metodologias propostas para a determinação de áreas de coordenação. A primeira delas considera uma densidade de potência de transmissão constante para as ESIM, e a segunda propõe uma Área de Coordenação Alternativa obtida a partir de uma distância $D$, pré-especificada e determinada de acordo com uma análise envolvendo curvas do tipo ROC. Finalmente é feita uma avaliação da redução na densidade de potência de transmissão das ESIM, requerida para garantir a proteção fora da área de coordenação alternativa por parte das ESIM. No Capítulo 4 as metodologias desenvolvidas são aplicadas a cenários particulares envolvendo diferentes tipos de relêvo e regiões de serviço. Finalmente no Capítulo 5, as conclusões resultantes do estudo realizado são apresentadas. 


\section{2 \\ Descrição do Problema}

O problema em análise neste trabalho diz respeito à proteção dos enlaces do Serviço Fixo Terrestre (FS) da interferência gerada por transmissões de estações terrenas em movimento (ESIM), mais especificamente, de estações a bordo de veículos terrestres operando na faixa de frequências 27,5-29,5 GHz. A proteção de receptores do FS da interferência provocada pela estação transmissora de outro sistema é usualmente garantida através da determinação de uma área de coordenação em torno da estação interferente. O conceito de área de coordenação não é novo e foi desenvolvido inicialmente para coordenação envolvendo estações terrenas fixas que operam com satélites geostacionários, sendo posteriormente ampliado para estações terrenas operando com satélites não-geoestacionários. De acordo com o conceito, receptores vítima localizados fora da área de coordenação são dispensados do processo de coordenação com o sistema interferente.

A determinação da área de coordenação depende diretamente do critério utilizado na proteção do sistema vítima. Uma metodologia para a determinação destas áreas de coordenação é apresentada no Apêndice 7 do Regulamento de Radiocomunicações (RR) da ITU [11]. Um exemplo típico do resultado desta metodologia é ilustrado na Figura 2.1.

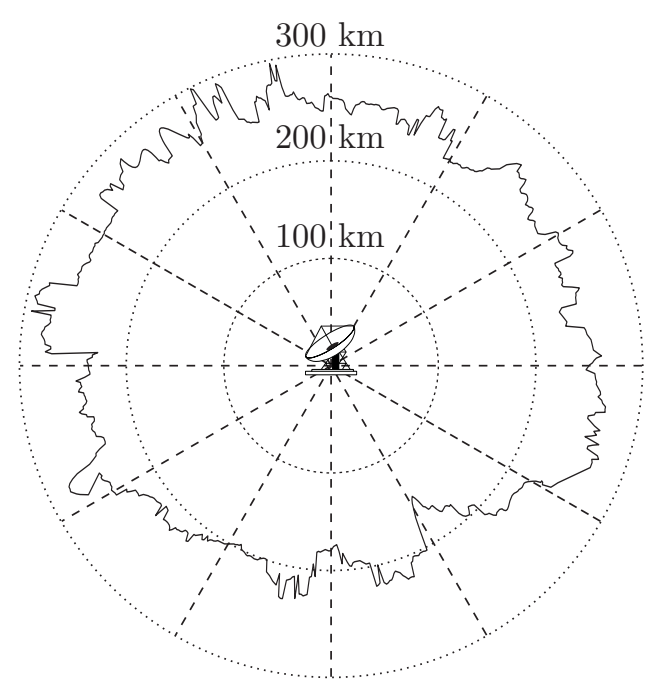

Figura 2.1: Esquema ilustrativo da Área de Coordenação obtida para uma estação terrena numa localização fixa. 
A metodologia do Apêndice 7 do RR sugere cenários e modos de propagação adaptados a cada tipo de aplicação, fornecendo um procedimento de cálculo para determinar o nível de perda de propagação que, para uma dada distância, não é excedida durante uma certa percentagem de tempo pré-especificada. A metodologia, entretanto contempla apenas áreas de coordenação associadas a estações terrenas com posição geográfica fixa.

Conforme indicado na introdução deste trabalho, a utilização de estações terrenas em movimento (ESIM), operando nas faixas alocadas ao Serviço Fixo por Satélite, é atualmente uma realidade. Em vista disso, torna-se importante o desenvolvimento de técnicas e metodologias que venham a proteger os receptores dos serviços que compartilham faixas de frequência com as ESIMs das interferências por elas geradas. Para resolver este problema, uma das possibilidades é a utilização de áreas de coordenação, agora em torno da área de serviço onde atuam as ESIMs.

Como consequência da mobilidade inerente às estações terrenas em estudo, o processo de coordenação com receptores do Serviço Fixo Terrestre pode-se tornar muito complicado uma vez que deve-se garantir a proteção do receptor FS independentemente da localização da ESIM dentro de sua área de serviço. A ideia de se determinar uma área de coordenação associada a toda a área de serviço das ESIM torna-se então bastante interessante uma vez que, independentemente da localização da ESIM, receptores do FS localizados fora da área de coordenação são dispensados do processo de coordenação. Este fato motiva o desenvolvimento de metodologias que permitam a determinação de áreas de coordenação associadas a áreas de serviço como, por exemplo, as áreas de atuação das ESIM. Este conceito é ilustrado na Figura 2.2.

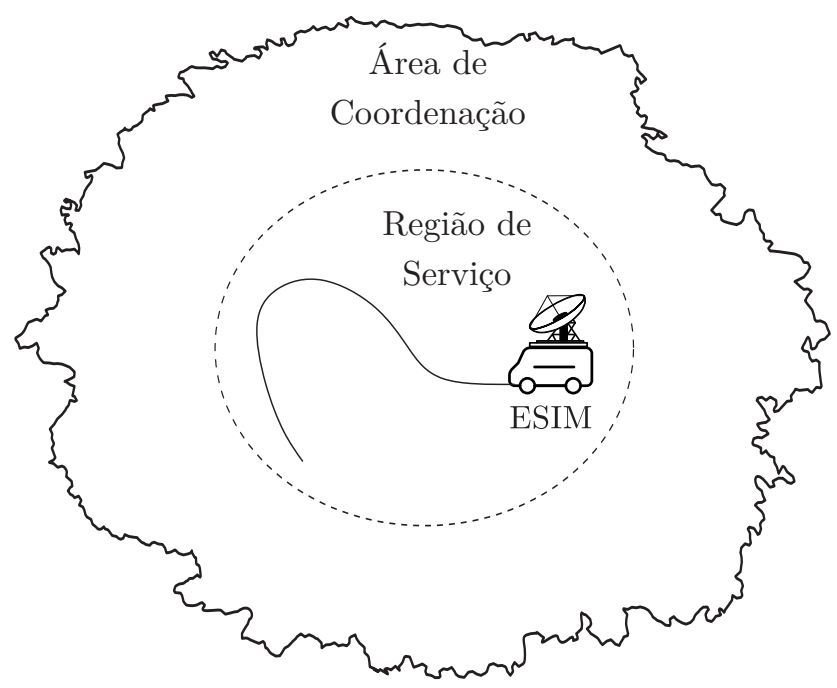

Figura 2.2: Esquema ilustrativo da Área de Coordenação obtida quando a mobilidade dos terminais é levada em conta. 
O problema da determinação de áreas de coordenação associadas às áreas de serviço das ESIM é abordado neste trabalho. Os estudos e analises aqui desenvolvidos visam o desenvolvimento de uma metodologia semelhante àquela do Apêndice 7 do RR, mas que considera estações terrenas em movimento. Como no Apêndice 7 do RR, serão considerados fatores como o relêvo do terreno e as perdas devidas a diferentes mecanismos de propagação (e.g. visada direta, difração, propagação por dutos e espalhamento troposférico), conforme ilustrado na Figura 2.3.

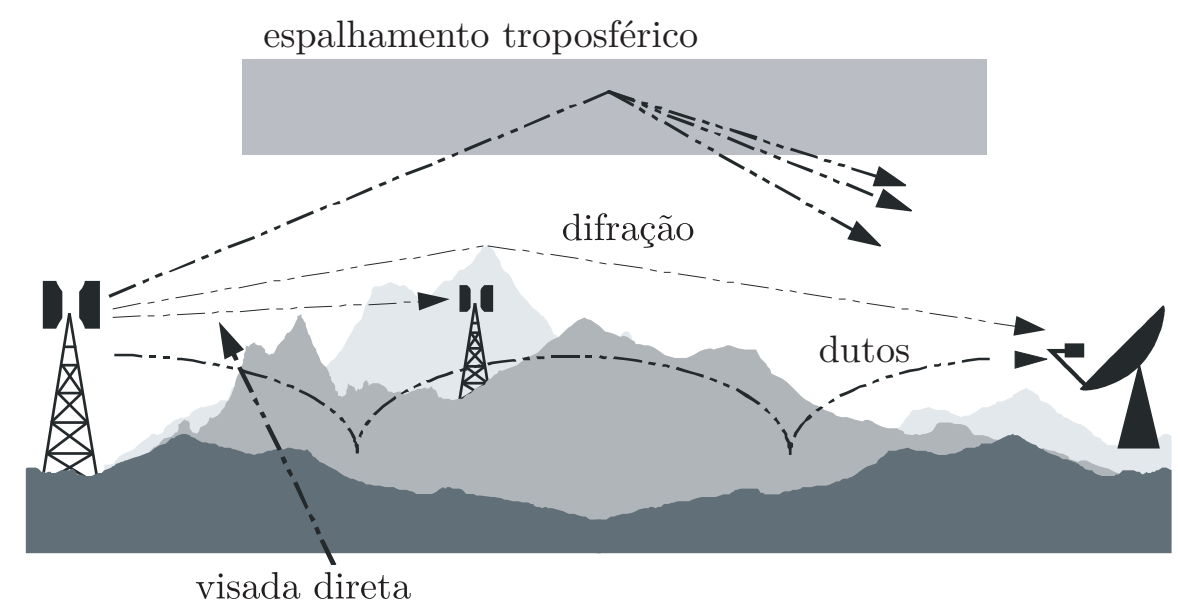

Figura 2.3: Esquema ilustrativo dos mecanismo de propagação da interferência, visada direta, difração, propagação por dutos e espalhamento troposférico. 


\section{3}

\section{Modelo Matemático}

Este trabalho abrange o desenvolvimento de um estudo de compartilhamento entre Estações Terrenas em Movimento (ESIM) que utilizam satélites geostacionários e receptores do Serviço Fixo Terrestre (FS), operando na mesma faixa de frequências. O objetivo principal do estudo é a determinação da Área de Coordenação em torno à zona de serviço das estações terrenas em movimento, fora das quais os receptores do FS estejam protegidos das interferências geradas pelas ESIMs, sem a necessidade de coordenação entre os sistemas.

Considera-se no estudo que as estações terrenas utilizam a técnica de múltiplo acesso por divisão no tempo (TDMA) e operam na faixa de frequências $27,5-29,5 \mathrm{GHz}$.

Assim, neste capitulo será abordada a formulação matemática para a obtenção da densidade de potência interferente gerada na entrada de um receptor do sistema fixo. Será explicada a metodologia usada para a obtenção da Área de Coordenação que atinja as restrições impostas pelo sistema vítima e, no final do capítulo, será abordado um estudo de proteção de mais fácil aplicação real que a Área de Coordenação obtida.

\section{1}

\section{Densidade de potência interferente na entrada do receptor FS}

Considerando-se a geometria apresentada na Figura 3.1, tem-se que a densidade de potência interferente produzida na entrada do receptor FS pela transmissão de uma estação terrena localizada na posição $\mathbf{r} \in \Omega_{\mathbf{r}}$, expressa em [W/MHz], é dada por

$$
i=\frac{p_{t} g_{t}(\theta) g_{r}(\phi)}{\ell}
$$

onde $p_{t}$ é a densidade de potência de transmissão da ESIM, dada em [W/MHz], $g_{t}(\theta)$ caracteriza o ganho da antena transmissora da ESIM na direção do receptor FS,$g_{r}(\phi)$ caracteriza o ganho da antena receptora do FS na direção da estação terrena interferente e $\ell$ é a perda de propagação sofrida pelo sinal no percurso entre a ESIM e a estação vítima do FS. 
A perda de propagação $\ell$ é modelada por uma variável aleatória, cuja Função Distribuição de Probabilidade (FDP) pode ser obtida pela metodologia descrita na Recomendação UIT-R P.452, que aborda o comportamento estatístico da perda de propagação no percurso entre duas estações (respectivamente, transmissora e receptora) situadas na superfície da Terra operando em frequências superiores a 0,1 GHz. Esta recomendação é complexa e bastante completa, abordando diversos mecanismos de propagação da interferência como: visada direta, difração, espalhamento troposférico e propagação por dutos. Um resumo da mesma é apresentado no Apêndice A.

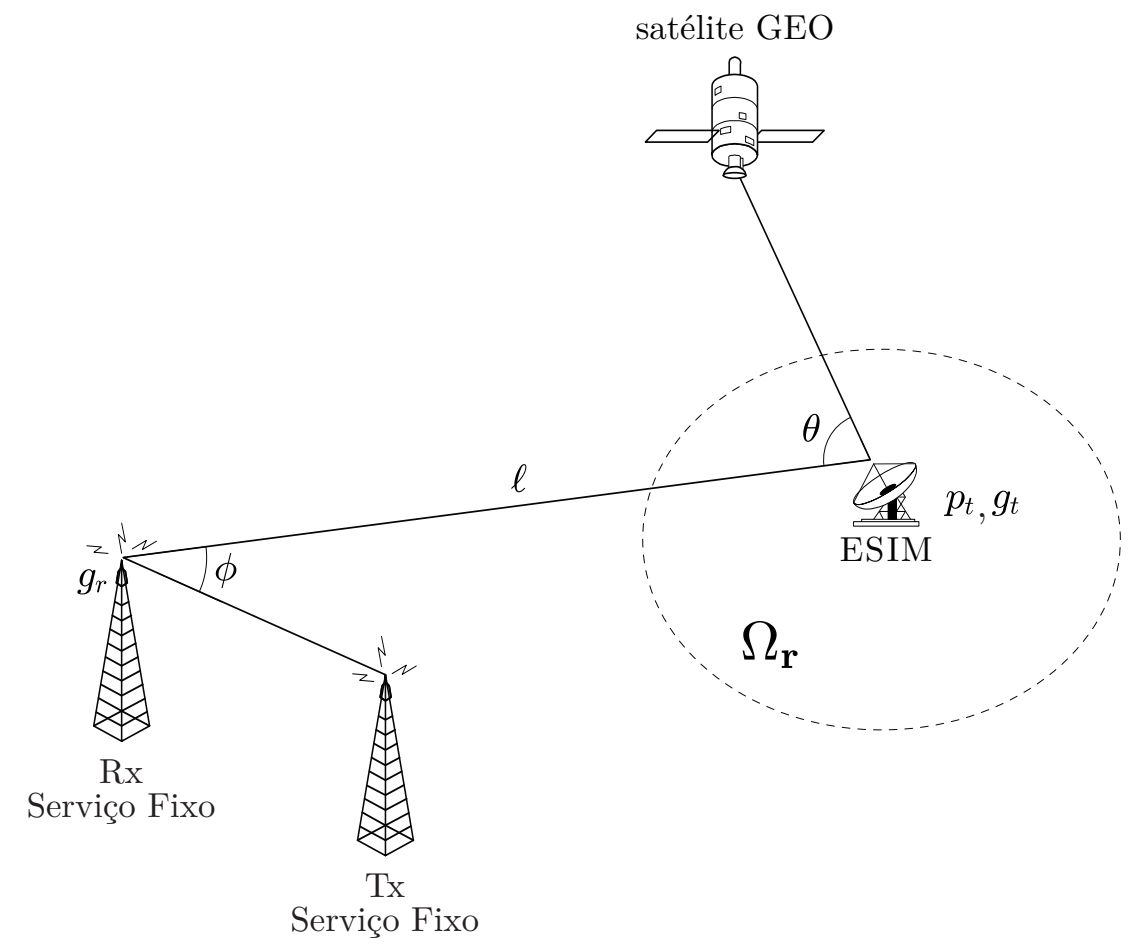

Figura 3.1: Esquema ilustrativo da interferência gerada por uma ESIM em $\mathbf{r} \in \Omega_{\mathbf{r}}$ na entrada de um receptor do Serviço Fixo Terrestre.

Neste estudo é considerada a situação de pior caso, na qual a antena receptora da estação vítima do FS aponta na direção da ESIM, ou seja,

$$
g_{r}(\phi)=g_{r}(0)
$$

onde $g_{r}(0)$ caracteriza o ganho máximo da antena receptora do sistema vitima (FS). Neste caso, (3-1), é reescrita como

$$
i=\frac{p_{t} g_{t}(\theta) g_{r}(0)}{\ell}
$$

ou, em dB,

$$
i_{\mathrm{dB}}=p_{t_{\mathrm{dB}}}+g_{t_{\mathrm{dB}}}(\theta)+g_{r_{\mathrm{dB}}}(0)-\ell_{\mathrm{dB}}
$$


Note que em (3-4), $i_{\mathrm{dB}}$ e $p_{t_{\mathrm{dB}}}$ estão expressos em $[\mathrm{dB}(\mathrm{W} / \mathrm{MHz})], g_{t_{\mathrm{dB}}}(\theta)$ e $g_{r_{\mathrm{dB}}}(0)$ expressos em [dBi] e a perda de propagação $\ell_{\mathrm{dB}}$ em $[\mathrm{dB}]$.

Para obter a FDP da variável aleatória $\ell_{\mathrm{dB}}$, note que a Recomendação ITU-R P.452 fornece, para um dado valor $P \in\left[1.0 \times 10^{-3}, 50\right]$, o valor $L$ da perda de propagação não excedida durante $P \%$ do tempo, expressa em dB. Assim, variando-se o valor de $P$, é possível construir a FDP de variável aleatória $\ell_{\mathrm{dB}}$ no intervalo $\left[L_{0.001}, L_{50}\right]$, dada por,

$$
F_{\ell_{\mathrm{dB}}}(L)=P\left(\ell_{\mathrm{dB}} \leq L\right)=\frac{P}{100} \quad ; \quad L_{0.001} \leq L \leq L_{50}
$$

com $L_{0.001}$ e $L_{50}$ denotando, respectivamente, os níveis de atenuação excedidos durante $0,001 \%$ e $50 \%$ do tempo ou, em termos da teoria de probabilidade, os níveis excedidos com probabilidades 0,00001 e 0,5, respectivamente.

Como a perda $\ell_{\mathrm{dB}}$ sofrida pela sinal é modelada por uma variável aleatória podemos, a partir de (3-4), observar que a densidade de potência interferente $i_{\mathrm{dB}}$ é também uma variável aleatória. Sua Função Distribuição de Probabilidade é dada por,

$$
F_{i_{\mathrm{dB}}}(I)=P\left(i_{\mathrm{dB}} \leq I\right)
$$

ou, considerando-se (3-4),

$$
F_{i_{\mathrm{dB}}}(I)=P\left(i_{\mathrm{dB}} \leq I\right)=P\left(p_{t_{\mathrm{dB}}}+g_{t_{\mathrm{dB}}}(\theta)+g_{r_{\mathrm{dB}}}(0)-\ell_{\mathrm{dB}} \leq I\right)
$$

fazendo-se uma manipulação de variáveis em (3-7) e supondo-se que a perda $\ell_{\mathrm{dB}}$ sofrida pelo sinal no percurso é uma variável aleatória continua, tem-se,

$$
F_{i_{\mathrm{dB}}}(I)=P\left(\ell_{\mathrm{dB}}>p_{t_{\mathrm{dB}}}+g_{t_{\mathrm{dB}}}(\theta)+g_{r_{\mathrm{dB}}}(0)-I\right)
$$

ou ainda,

$$
F_{i_{\mathrm{dB}}}(I)=1-F_{\ell_{\mathrm{dB}}}\left(p_{t_{\mathrm{dB}}}+g_{t_{\mathrm{dB}}}(\theta)+g_{r_{\mathrm{dB}}}(0)-I\right)
$$

Note que (3-9) fornece a FDP da densidade de potência interferente $i_{\mathrm{dB}}$ supondo que a estação terrena interferente está localizada numa posição geográfica conhecida $(\mathbf{r}=\mathbf{R})$, ou seja, fornece uma FDP condicional. Assim, é possível escrever,

$$
F_{i_{\mathrm{dB}} \mid \mathbf{r}=\mathbf{R}}(I)=1-F_{\ell_{\mathrm{dB}} \mid \mathbf{r}=\mathbf{R}}\left(p_{t_{\mathbf{R} \mathrm{dB}}}+g_{t_{\mathrm{dB}}}\left(\theta_{\mathbf{R}}\right)+g_{r_{\mathrm{dB}}}(0)-I\right)
$$

Os índices $\mathbf{R}$ que aparecem nas variáveis $p_{t_{\mathrm{dB}}}$ e $\theta$ foram colocados para explicitar suas dependências diretas com a posição $\mathbf{R}$ da estação terrena interferente.

Um caso particular de interesse diz respeito à situação em que a densidade de potência transmitida pela estação terrena é a mesma, independentemente de sua localização. Neste caso, $p_{t_{\mathbf{R}} \mathrm{dB}}=p_{t_{\mathrm{dB}}} \forall \mathbf{r} \in \Omega_{\mathbf{r}}$ e (3-10) se escreve, 


$$
F_{i_{\mathrm{dB}}}(I)=1-F_{\ell_{\mathrm{dB}}}\left(p_{t_{\mathrm{dB}}}+g_{t_{\mathrm{dB}}}\left(\theta_{\mathbf{R}}\right)+g_{r_{\mathrm{dB}}}(0)-I\right)
$$

\section{2}

\section{Critérios de proteção contra a interferência}

Os critérios de interferência são usualmente definidos por um conjunto de pares do tipo,

$$
\left(I_{j}, P_{j}\right) ; j=1,2, \ldots M
$$

tal que os níveis de densidade de potência interferente $\left\{I_{j}, j=1, \ldots, M\right\}$ não podem ser excedidos por mais do que o $P_{j} \%$ do tempo, respectivamente. Em termos de probabilidade, estas condições podem ser expressas como,

$$
P\left(i_{\mathrm{dB}}>I_{j}\right) \leq p_{j} \quad ; \quad j=1,2, \ldots M
$$

onde $i_{\mathrm{dB}}$ é a densidade de potência interferente gerada na entrada do receptor vítima e $p_{j}=P_{j} / 100$.

Considerando-se a Função Distribuição de Probabilidade Complementar (CDF - Complemtary Distribution Function) da variável aleatória $i_{\mathrm{dB}}$, definida por

$$
C_{i_{\mathrm{dB}}}(I)=P\left(i_{\mathrm{dB}}>I\right)=1-F_{i_{\mathrm{dB}}}(I),
$$

as restrições em (3-13) podem ser reescritas como

$$
C_{i_{\mathrm{dB}}}\left(I_{j}\right) \leq p_{j} \quad ; \quad j=1,2, \ldots M
$$

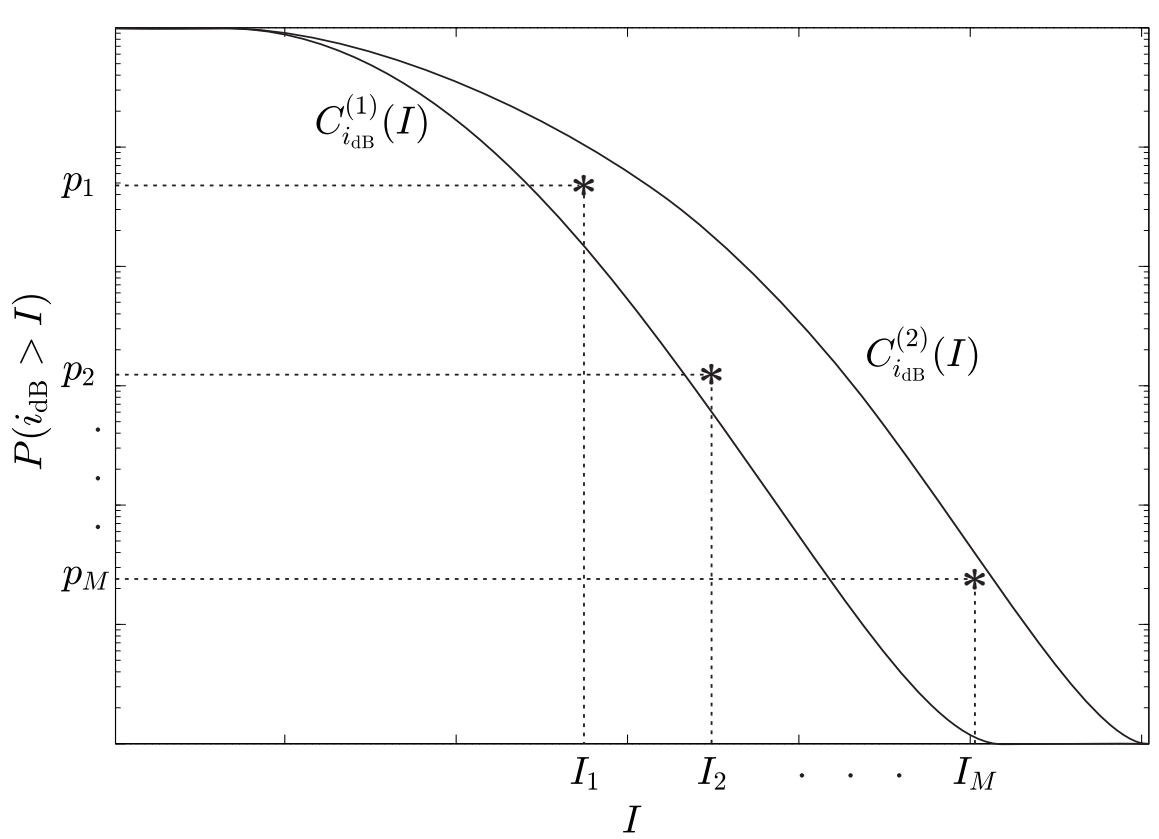

Figura 3.2: Funções Distribuição de Probabilidade Complementar da variável $i_{\mathrm{dB}}$ e critérios de proteção contra a interferência a serem satisfeitos. 
Na Figura 3.2, são ilustrados dois exemplos de CDF para a variável aleatória $i_{\mathrm{dB}}$. Além disso, estão indicados na figura os pontos (asteriscos) correspondentes ao conjunto de restrições em (3-13). Note que a CDF denotada por $C_{i_{\mathrm{dB}}}^{(1)}(I)$ satisfaz ao critério de proteção em (3-13), o que não acontece com $C_{i_{\mathrm{dB}}}^{(2)}(I)$.

Um critério de proteção equivalente a (3-13) e (3-15) pode ser obtido considerando-se os níveis de densidade de potência $I_{p_{j}}$ excedidos com probabilidade $p_{j}$, obtidos resolvendo-se a equação

$$
C_{i_{\mathrm{dB}}}\left(I_{p_{j}}\right)=p_{j} \quad ; \quad j=1,2, \ldots, M
$$

ou seja,

$$
I_{p_{j}}=C_{i_{\mathrm{dB}}}^{-1}\left(p_{j}\right) \quad ; j=1,2, \ldots M .
$$

É possível verificar (ver Figura 3.3) que, se a variável aleatória $i_{\mathrm{dB}}$ é contínua, a condição $C_{i_{\mathrm{dB}}}\left(I_{j}\right) \leq p_{j}$ ocorre se, e somente se, $I_{p_{j}} \leq I_{j}$, indicando que as condições em (3-13) e (3-15) são equivalentes à condição

$$
I_{p_{j}} \leq I_{j} \quad ; \quad j=1,2, \ldots M
$$

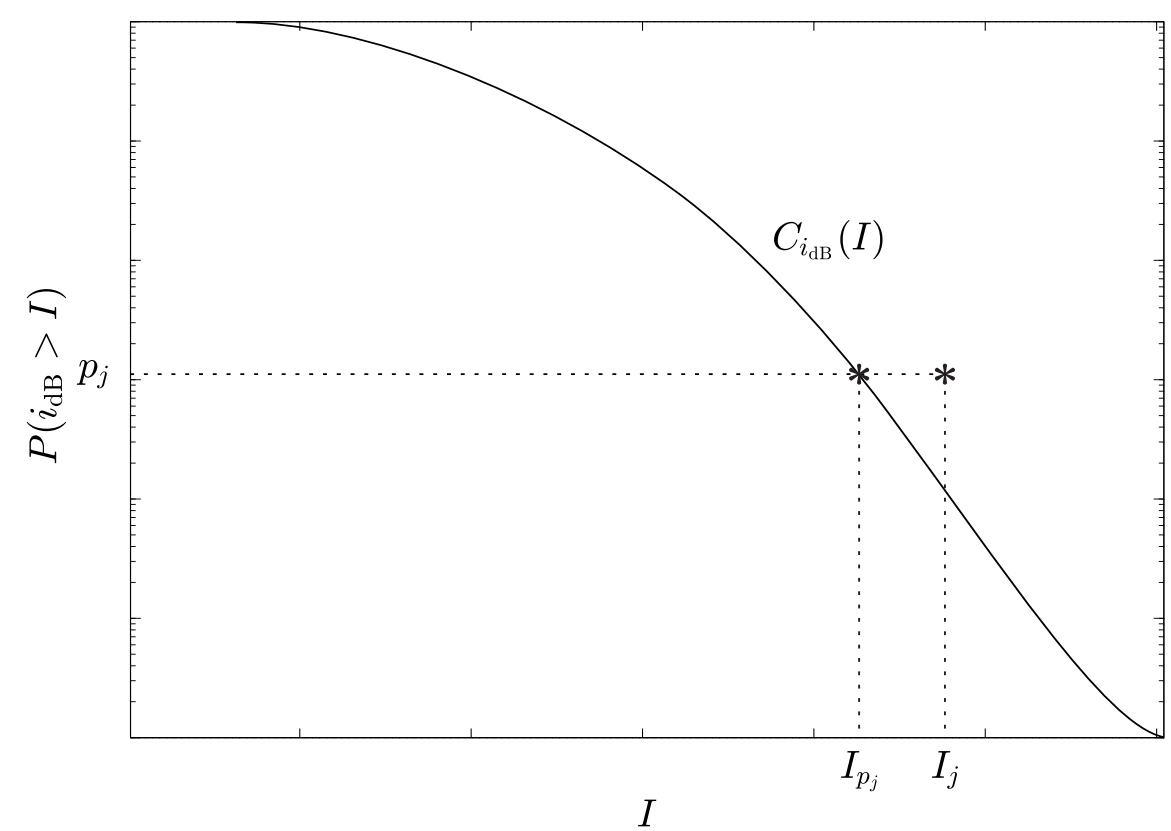

Figura 3.3: Ilustração do critério de proteção contra a interferência em (3-18), $C_{i_{\mathrm{dB}}}(I)$ corresponde a Função Distribuição de Probabilidade Complementar da variável $i_{\mathrm{dB}}$ gerada na entrada de um receptor do FS. 


\section{3}

\section{Determinação da Área de Coordenação}

Nesta seção é apresentado o conceito de Área de Coordenação, que define a região geográfica em torno da estação terrena interferente (FSS) na qual os receptores do FS (vítimas) precisam coordenar com o sistema interferente de modo a garantir sua operação livre de interferências inaceitáveis produzidas pela estação terrena do FSS. Receptores do FS localizados fora desta área podem operar sem a necessidade de coordenação.

$\mathrm{Na}$ determinação da Área de Coordenação são considerados a topografia do terreno, a densidade de potência de transmissão das estações terrenas interferentes e a sua mobilidade na área de serviço $\Omega_{\mathbf{r}}$. A metodologia utilizada tem como base a garantia de que, fora da Área de Coordenação, o critério de interferência em (3-13), ou equivalentemente em (3-15) ou (3-18), é satisfeito.

Inicialmente, introduz-se o conceito de distância de coordenação, $D_{\mathbf{r}}^{j}(\alpha)$, associada a uma ESIM na posição $\mathbf{r} \in \Omega_{\mathbf{r}}$, numa direção de azimute $\alpha \in(0,2 \pi]$, correspondente à $j$-ésima condição do critério de proteção em (3-13). O esquema ilustrativo da distância de coordenação para uma ESIM na posição $\mathbf{r}=\mathbf{R}$ numa direção de azimute $\alpha=\mathrm{A}$ é apresentado na Figura 3.4.

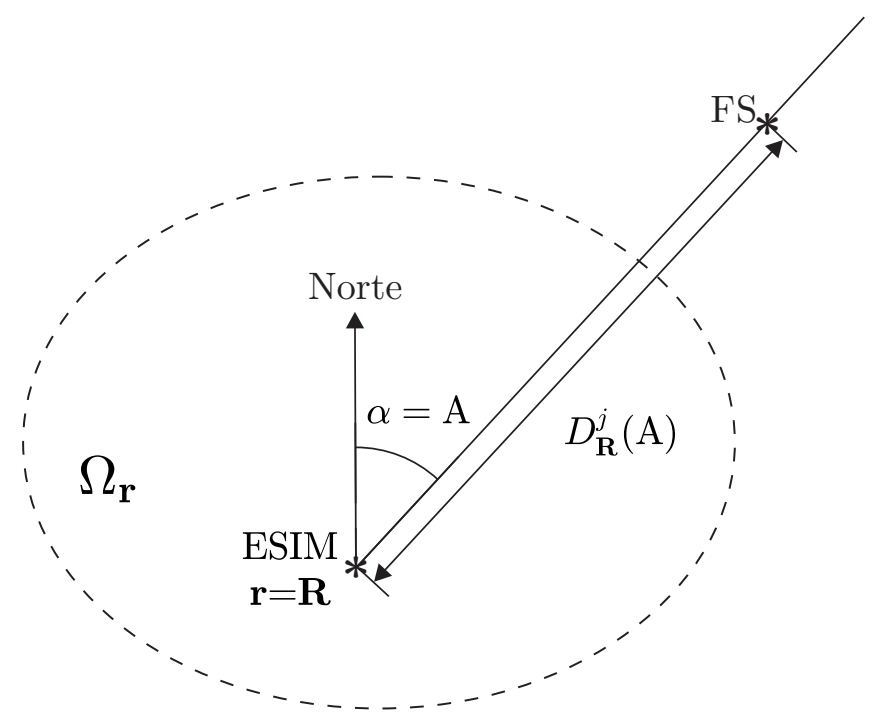

Figura 3.4: Esquema ilustrativo da distância de coordenação $D_{\mathbf{r}}^{j}(\alpha)$, numa posição $\mathbf{r}=\mathbf{R}$ no azimute $\alpha=\mathrm{A}$

A Figura 3.5 ilustra o comportamento de Funções Distribuição de Probabilidade Complementar Condicional

$$
C_{i_{\mathrm{dB}} \mid \mathbf{r}=\mathbf{R}, \alpha=\mathrm{A}}(I)=P\left(i_{\mathrm{dB}}>I \mid \mathbf{r}=\mathbf{R}, \alpha=\mathrm{A}\right)
$$

das densidades de potência interferente $i_{\mathrm{dB}}$, associadas a receptores FS locali- 
zados a diferentes distâncias da ESIM. Na figura, é indicada ainda a $j$-ésima condição do critério de interferência em (3-13) (asterisco). Note que, à medida que a distância $d$ entre a ESIM e o receptor FS aumenta, a probabilidade da densidade de potência interferente $i_{\mathrm{dB}}$ ser maior que $I_{j}$ diminui. Conforme ilustrado na Figura 3.5, a distância de coordenação $D_{\mathbf{R}}^{j}(\mathrm{~A})$ corresponde à distância $d$ tal que $C_{i_{\mathrm{dB}} \mid \mathbf{r}=\mathbf{R}, \alpha=\mathrm{A}}\left(I_{j}\right)=p_{j}$. Assim,

$$
\begin{array}{llll}
\text { caso } & d<D_{\mathbf{R}}^{j}(\mathrm{~A}) & \text { tem-se } & C_{i_{\mathrm{dB}} \mid \mathbf{r}=\mathbf{R}, \alpha=\mathrm{A}}\left(I_{j}\right)>p_{j} \\
\text { caso } & d=D_{\mathbf{R}}^{j}(\mathrm{~A}) & \text { tem-se } & C_{i_{\mathrm{dB}} \mid \mathbf{r}=\mathbf{R}, \alpha=\mathrm{A}}\left(I_{j}\right)=p_{j} \\
\text { caso } & d>D_{\mathbf{R}}^{j}(\mathrm{~A}) & \text { tem-se } & C_{i_{\mathrm{dB}} \mid \mathbf{r}=\mathbf{R}, \alpha=\mathrm{A}}\left(I_{j}\right)<p_{j} .
\end{array}
$$

Em resumo, a distância de coordenação $D_{\mathbf{R}}^{j}(\mathrm{~A})$ pode ser definida como a menor distância $d$ tal que a $j$-ésima condição do critério de proteção é satisfeita $\forall d>D_{\mathbf{R}}^{j}(\mathrm{~A})$. Assim, a determinação da distância de coordenação $D_{\mathbf{R}}^{j}(\mathrm{~A})$, associada à $j$-ésima condição do critério de interferência, pode requer o cálculo de $C_{i_{\mathrm{dB}} \mid \mathbf{r}=\mathbf{R}, \alpha=\mathrm{A}}\left(I_{j}\right)$ para diferentes valores de $d$ na vizinhança de $D_{\mathbf{R}}^{j}(\mathrm{~A})$.

Observe que, a partir de (3-11) e (3-14), tem-se

$$
C_{i_{\mathrm{dB}} \mid \mathbf{r}=\mathbf{R}, \alpha=\mathrm{A}}\left(I_{j}\right)=F_{\ell_{\mathrm{dB}} \mid \mathbf{r}=\mathbf{R}, \alpha=\mathrm{A}}\left(p_{t_{\mathrm{dB}}}+g_{t_{\mathrm{dB}}}\left(\theta_{\mathbf{R}}\right)+g_{r_{\mathrm{dB}}}(0)-I_{j}\right)
$$

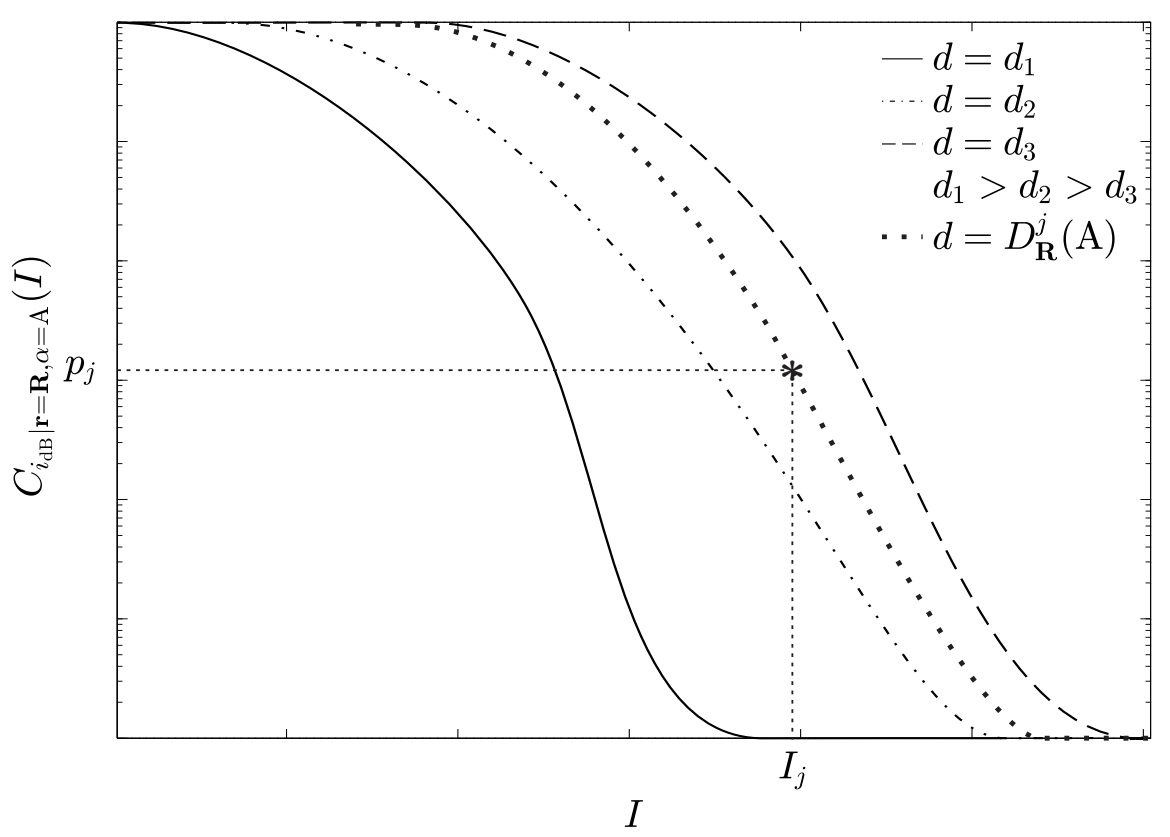

Figura 3.5: Influencia da variação da distancia entre o receptor FS e a estação interferente ESIM no formato da $C_{i_{\mathrm{dB}} \mid \mathbf{r}=\mathbf{R}, \alpha=\mathrm{A}}(I)$ para o $j$ critério de proteção sendo analisado.

Finalmente, a distância de coordenação que atende às $M$ condições do critérios de proteção em (3-13) é definida como,

$$
D_{\mathbf{R}}(\mathrm{A})=\max _{j}\left(D_{\mathbf{R}}^{j}(\mathrm{~A})\right) ; j=1,2, \ldots, M
$$


Na Figura 3.6 ilustra-se um exemplo das distâncias de coordenação obtidas num cenário real, empregando como condições os critérios de proteção das recomendações ITU-R F.758-6 [13] (longo prazo) e ITU-R SM.1448 [12] (curto prazo), respectivamente dados por

$$
P\left(i_{\mathrm{dB}}>-146\right) \leq 0,2
$$

$\mathrm{e}$

$$
P\left(i_{\mathrm{dB}}>-111\right) \leq 5 \times 10^{-5}
$$

Neste caso $M=2$, sendo que $j=1$ representa o longo prazo e $j=2$ o curto prazo. Considerou-se a ESIM na posição $\mathbf{r}=\mathbf{R}$ definida pela latitude $\theta=40,82^{\circ} \mathrm{N}$ e longitude $\phi=97,60^{\circ} \mathrm{O}$, as distâncias foram determinadas na direção do azimute $\mathrm{A}=90^{\circ}$. A densidade de potência de transmissão da ESIM foi fixada a $1 \mathrm{~dB}(\mathrm{~W} / \mathrm{MHz})$. O ganho da antena transmissora na direção do FS foi determinada a partir da recomendação ITU-R S.465-6 [15], o ganho da antena receptora (FS) na direção da ESIM foi determinada para o pior caso sendo a mesma para um diâmetro da antena de $0,5 \mathrm{~m}$ e frequência de transmissão de $29 \mathrm{GHz}, g_{r_{\mathrm{dB}}}(0)=41 \mathrm{dBi}$.

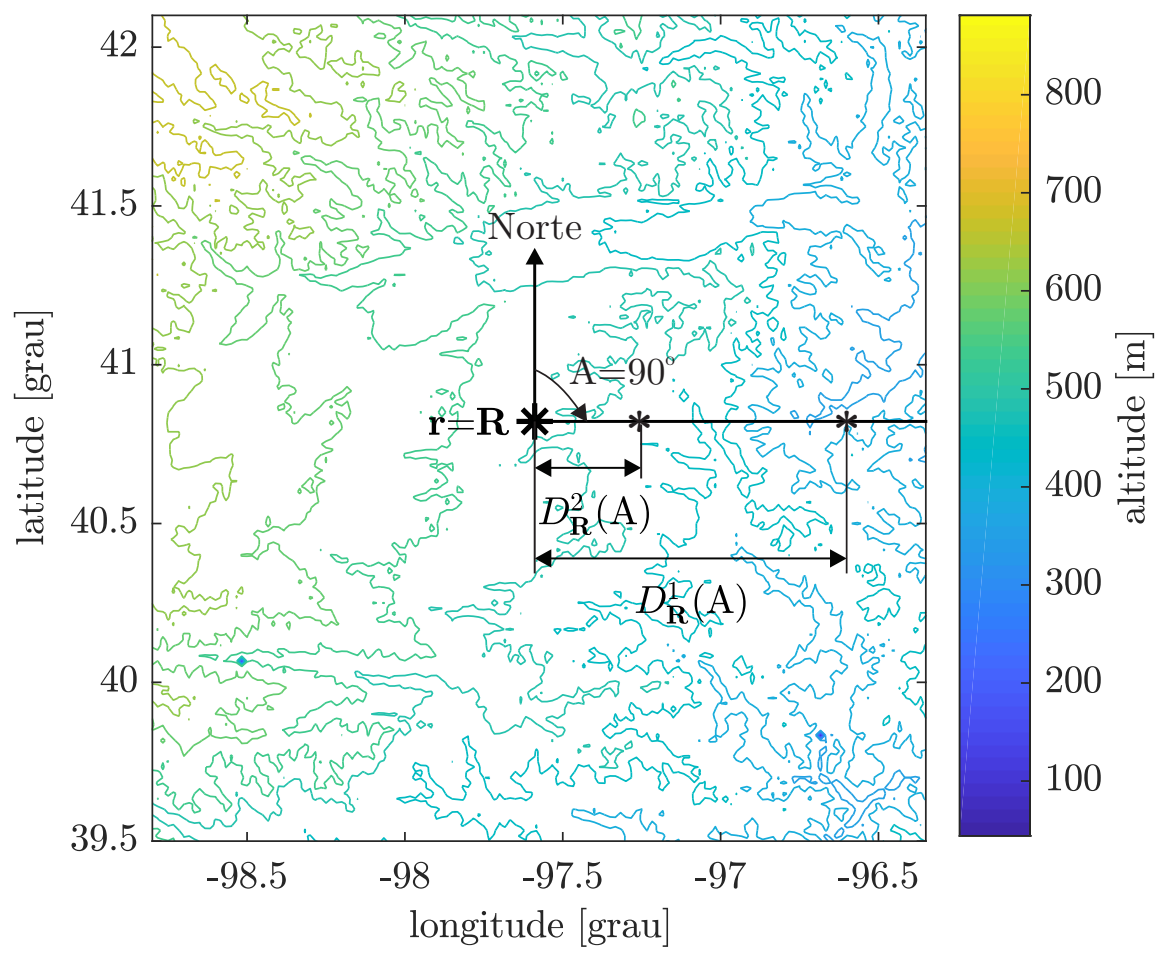

Figura 3.6: Exemplo das distâncias $D_{\mathbf{R}}^{1}(\mathrm{~A})$ - longo prazo e $D_{\mathbf{R}}^{2}(\mathrm{~A})$ - curto prazo prazos respectivamente num cenário real para uma ESIM numa posição $\mathbf{r}$ com latitude $\theta=40,82^{\circ} \mathrm{N}$, longitude $\phi=97,60^{\circ} \mathrm{O}$ e azimute $\mathrm{A}=90^{\circ}$. 
$\mathrm{O}$ contorno de coordenação $\mathcal{C}_{\mathbf{r}}^{j}$, correspondente à $j$-ésima condição do critério de proteção, demarca o limite geográfico ao redor de uma ESIM na posição $\mathbf{r} \in \Omega_{\mathbf{r}}$ onde os receptores do FS precisam coordenar com o sistema interferente, fora da região limitada pelo $\mathcal{C}_{\mathbf{r}}^{j}$ os receptores do FS não precisam coordenar. Este contorno de coordenação é definido pelas distâncias de coordenação obtidas para todos os azimutes em torno da posição $\mathbf{r}$ da ESIM, ou seja,

$$
\mathcal{C}_{\mathbf{r}}^{j}=D_{\mathbf{r}}^{j}(\alpha) \quad ; \quad 0<\alpha<2 \pi,
$$

O esquema ilustrativo do contorno de coordenação para uma ESIM na posição $\mathbf{r}=\mathbf{R}$ é apresentado na Figura 3.7.

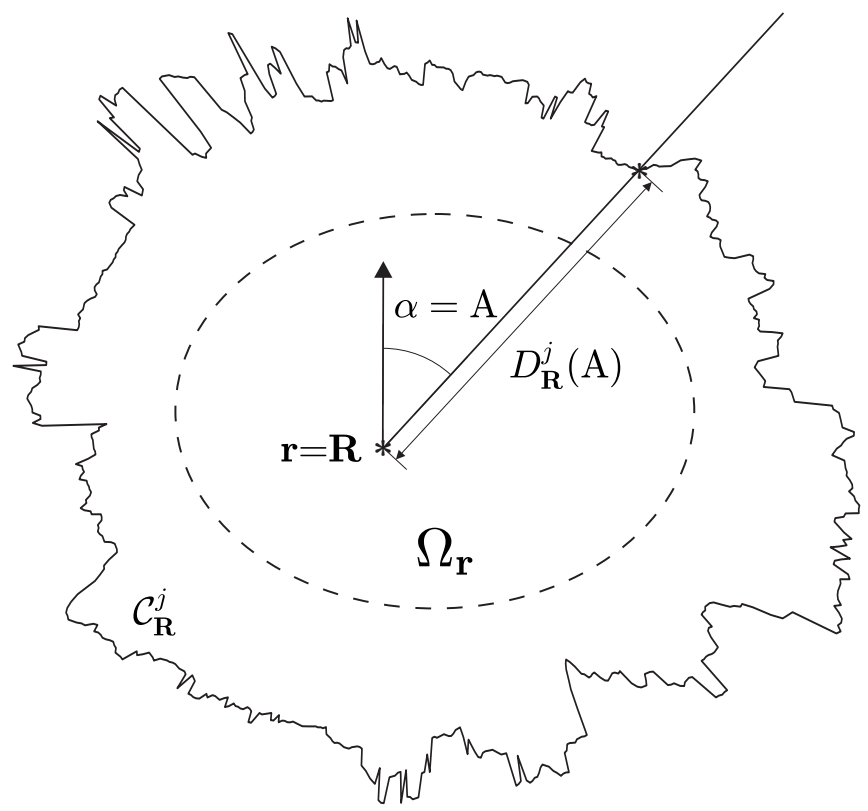

Figura 3.7: Esquema ilustrativo do Contorno de Coordenação ao redor de uma estação terrena em movimento (ESIM) na posição $\mathbf{r}=\mathbf{R}$.

Finalmente, o contorno de coordenação para uma estação terrena transmissora numa posição $\mathbf{r} \in \Omega_{\mathbf{r}}$, que atende às $M$ restrições do critério de proteção em (3-13) é definido como,

$$
\mathcal{C}_{\mathbf{r}}=D_{\mathbf{r}}(\alpha) \quad ; \quad 0<\alpha<2 \pi
$$

com $D_{\mathbf{r}}(\alpha)$ definido por (3-22), ou seja,

$$
D_{\mathbf{r}}(\alpha)=\max _{j}\left(D_{\mathbf{r}}^{j}(\alpha)\right) \quad ; j=1,2, \ldots, M
$$

Na Figura 3.8 estão ilustrados exemplos de contornos de coordenação obtidos num cenário real. Novamente, as condições do critério de proteção empregadas foram extraídas das recomendações ITU-R F.758-6 [13] e ITU-R SM.1448 [12]. Considerou-se a ESIM na posição $\mathbf{r}=\mathbf{R}$ definida pela latitude 
$\theta=40,82^{\circ} \mathrm{N}$ e longitude $\phi=97,60^{\circ} \mathrm{O}$. A densidade de potência de transmissão da ESIM foi fixada a $1 \mathrm{~dB}(\mathrm{~W} / \mathrm{MHz})$. O ganho da antena transmissora na direção do FS foi determinada a partir da recomendação ITU-R S.465-6 [15], o ganho da antena receptora (FS) na direção da ESIM foi determinada para o pior caso sendo a mesma para um diâmetro da antena de $0,5 \mathrm{~m}$ e frequência de transmissão de $29 \mathrm{GHz}, g_{r_{\mathrm{dB}}}(0)=41 \mathrm{dBi}$

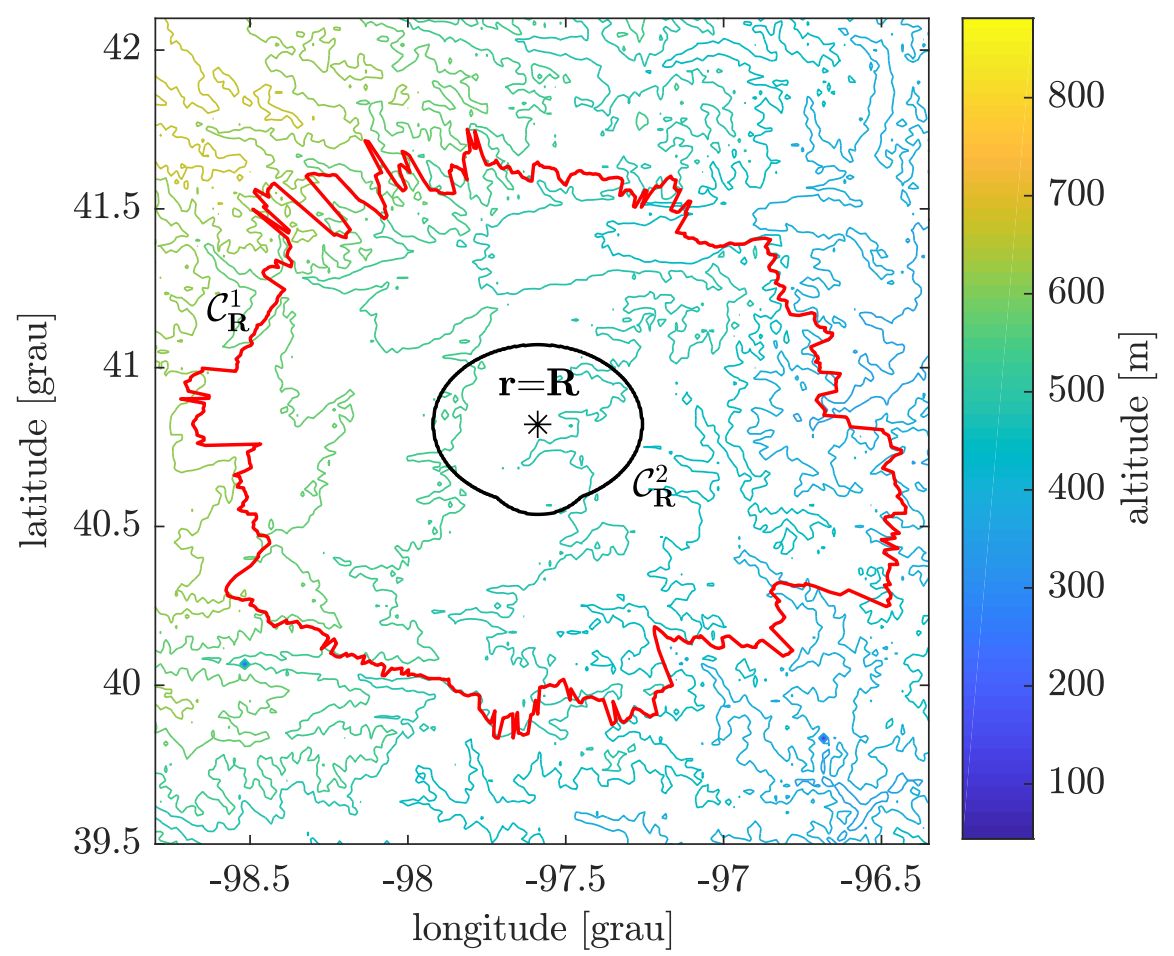

Figura 3.8: Exemplo da obtenção do $\mathcal{C}_{\mathbf{R}}^{1}$ - longo prazo e $\mathcal{C}_{\mathbf{R}}^{2}$ - curto prazo numa situação real para uma ESIM numa posição $\mathbf{R}$ com latitude $\theta=40,82^{\circ} \mathrm{N}$ e longitude $\phi=97,60^{\circ} \mathrm{O}$

Para uma estação localizada em $\mathbf{r} \in \Omega_{\mathbf{r}}$, o contorno de coordenação $\mathcal{C}_{\mathbf{r}}^{j}$ associado à $j$-ésima condição do critério de interferência em (3-13), ou equivalentemente em (3-15) ou (3-18), delimita uma Região de Coordenação $\mathcal{R}_{\mathbf{r}}^{j}$. Para a definição desta região, se faz necessária a introdução de um operador $\operatorname{azim}(\cdot)$ que indica o azimute de um vetor, ou seja, o azimute de um vetor $\mathbf{x}$ é dado por $\operatorname{azim}(\mathbf{x})$.

Assim, a Região de Coordenação $\mathcal{R}_{\mathbf{r}}^{j}$ para uma estação localizada em $\mathbf{r} \in \Omega_{\mathbf{r}}$, é definida como

$$
\mathcal{R}_{\mathbf{r}}^{j}=\left\{\mathbf{y} \in \mathbb{R}^{2}:|\mathbf{y}-\mathbf{r}| \leq D_{\mathbf{r}}^{j}(\operatorname{azim}(\mathbf{y}-\mathbf{r}))\right\}
$$


O fato da estação terrena interferente estar se movimentando na área de serviço $\Omega_{\mathbf{r}}$ motiva a definição de uma Área de Coordenação associada a toda a área de serviço. Assim, define-se Área de Coordenação associada à área de serviço $\Omega_{\mathbf{r}}$, e correspondente à $j$-ésima condição do critério de proteção, como sendo a região fora da qual os receptores do FS podem operar sem a necessidade de coordenação com a estação terrena interferente, independentemente de sua localização. Esta área de coordenação é definida por

$$
\mathcal{A}_{\Omega_{\mathbf{r}}}^{j}=\bigcup_{\mathbf{r} \in \Omega_{\mathbf{r}}} \mathcal{R}_{\mathbf{r}}^{j}
$$

e encontra-se ilustrada na Figura 3.9.

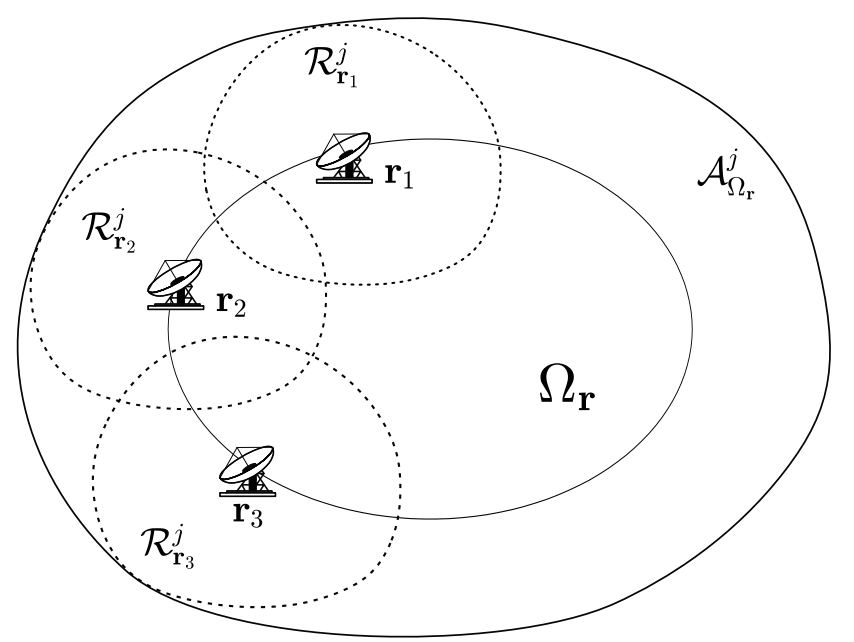

Figura 3.9: Exemplo da Área de Coordenação para uma rede de ESIMs operando na região $\Omega_{\mathbf{r}}$ partindo da união das Regiões de Coordenação.

Na Figura 3.10 estão ilustrados exemplos de áreas de coordenação obtidos num cenário real. Novamente, as condições do critério de proteção empregadas foram extraídas das recomendações ITU-R F.758-6 [13] e ITU-R SM.1448 [12] denotando como $\mathcal{A}_{\Omega_{\mathrm{r}}}^{1}$ - longo prazo (traço vermelho) e $\mathcal{A}_{\Omega_{\mathrm{r}}}^{2}$ - curto prazo (traço preto). Considerou-se a ESIM operando em uma região circular com raio de $30 \mathrm{~km}$ e centro definido pela latitude $\theta=20^{\circ} \mathrm{S}$ e longitude $\phi=44^{\circ} \mathrm{O}$. A densidade de potência de transmissão da ESIM foi fixada a $1 \mathrm{~dB}(\mathrm{~W} / 1 \mathrm{MHz})$. O ganho da antena transmissora na direção do FS foi determinada a partir da recomendação ITU-R S.465-6 [15], o ganho da antena receptora (FS) na direção da ESIM foi determinada para o pior caso sendo a mesma para um diâmetro da antena de $0,5 \mathrm{~m}$ e frequência de transmissão de $29 \mathrm{GHz}, g_{r_{\mathrm{dB}}}(0)=41 \mathrm{dBi}$. 


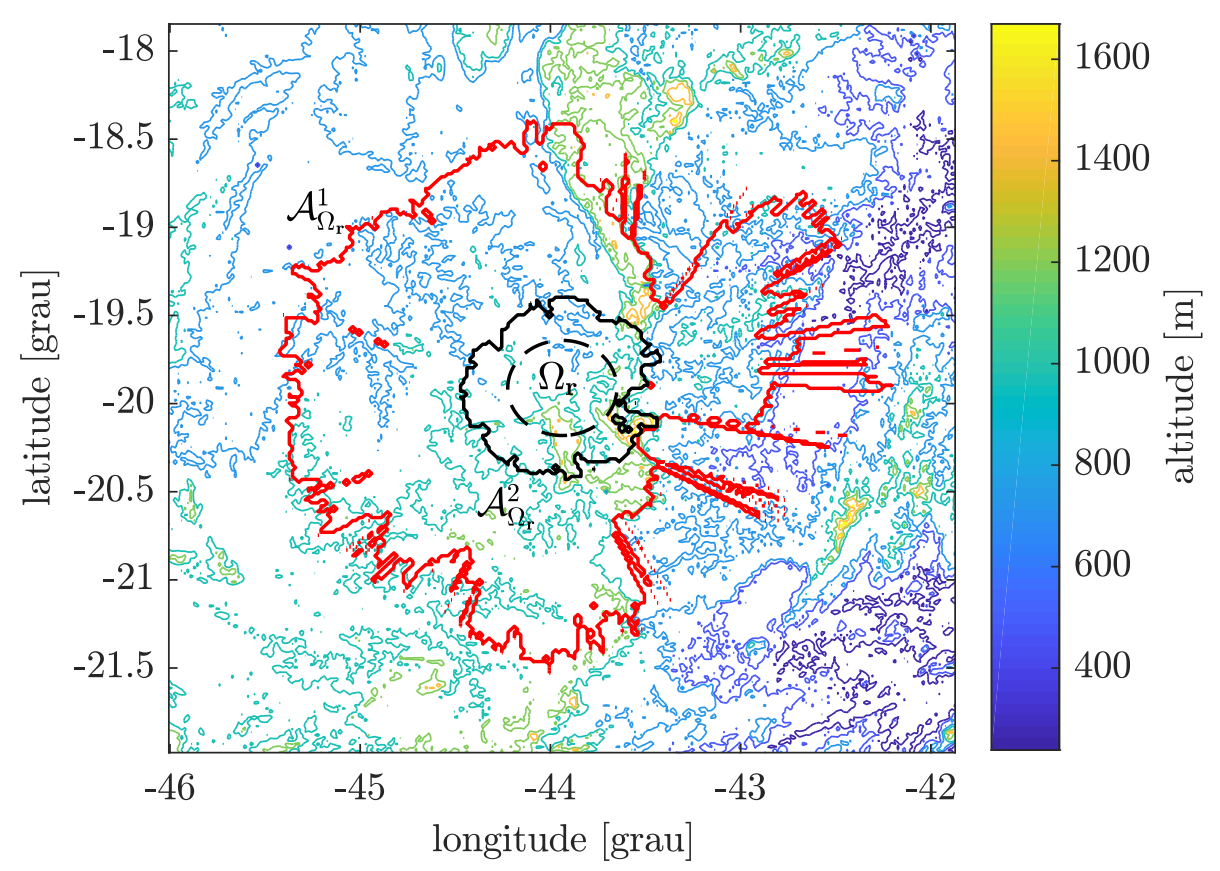

Figura 3.10: Exemplo da obtenção de $\mathcal{A}_{\Omega_{\mathbf{r}}}^{1}$ - longo prazo e $\mathcal{A}_{\Omega_{\mathbf{r}}}^{2}$ - curto prazo numa situação real para ESIM operando numa região circular de raio $30 \mathrm{~km}$ e centro na posição geográfica definida pela latitude $\theta=20^{\circ} \mathrm{S}$ e longitude $\phi=44^{\circ} \mathrm{O}$.

A Área de Coordenação $\mathcal{A}_{\Omega_{\mathbf{r}}}$, associada à área de serviço $\Omega_{\mathbf{r}}$, que atende a todas as $M$ restrições do critério de proteção em (3-13) é então definida como

$$
\mathcal{A}_{\Omega_{\mathbf{r}}}=\bigcup_{j=1}^{M} \mathcal{A}_{\Omega_{\mathbf{r}}}^{j}
$$

\section{4}

\section{Área de Coordenação Pré Especificada}

Dada a dificuldade em se utilizar regiões de coordenação como a da Figura 3.10 em um texto de regulamentação, existe a possibilidade de, com base na região de coordenação obtida, se especificar uma distância fixa $D$, medida a partir da borda da área de serviço $\Omega_{\mathbf{r}}$, a partir da qual receptores do FS podem operar sem a necessidade de coordenação. Isto facilitaria, a aplicação do regulamento. Entretanto, a escolha de $D$ deve ser feita criteriosamente. Para isso, seja $\mathcal{R}_{\mathbf{r}}(D)$ a Região de Coordenação definida pela distância pré estabelecida $D$ e associada a uma ESIM localizada na posição $\mathbf{r} \in \Omega_{\mathbf{r}}$, ou seja,

$$
\mathcal{R}_{\mathbf{r}}(D)=\left\{\mathbf{x} \in \mathbb{R}^{2}:|\mathbf{x}-\mathbf{r}| \leq D\right\}
$$




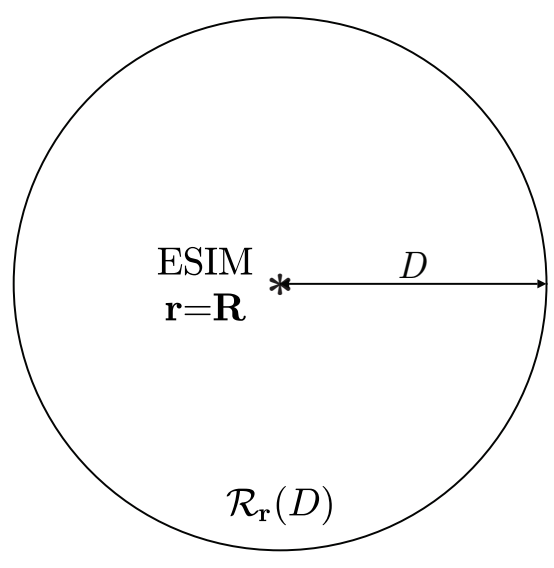

(a)

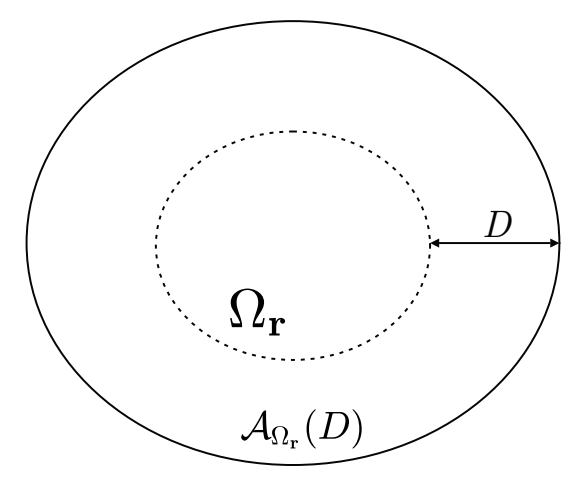

(b)

Figura 3.11: Áreas de Coordenação Pré-estabelecidas: (a) Região de Coordenação definida pela distância pré-estabelecida $D$ e associada à uma ESIM localizada em $\mathbf{r} \in \Omega_{\mathbf{r}}$; (b) Área de Coordenação definida pela distância préestabelecida $D$, associada a toda a área de serviço $\Omega_{\mathbf{r}}$.

A Área de Coordenação definida pela distância pré-estabelecida $D$, e associada a toda a área de serviço $\Omega_{\mathbf{r}}$, é então definida por

$$
\mathcal{A}_{\Omega_{\mathbf{r}}}(D)=\bigcup_{\mathbf{r} \in \Omega_{\mathbf{r}}} \mathcal{R}_{\mathbf{r}}(D)
$$

Note que tanto $\mathcal{R}_{\mathbf{r}}(D)$ quanto $\mathcal{A}_{\Omega_{\mathbf{r}}}(D)$ não dependem diretamente do critério de proteção em (3-13). Exemplos de $\mathcal{R}_{\mathbf{r}}(D)$ quanto $\mathcal{A}_{\Omega_{\mathbf{r}}}(D)$ estão ilustrados na Figura 3.11.

Note que, conforme ilustrado na Figura 3.12, a utilização de uma área de coordenação associada a uma distância $D$ pré-estabelecida (Área de Coordenação Pré-estabelecida) gera algumas distorções quando $\mathcal{A}_{\Omega_{\mathbf{r}}}(D)$ é comparada à área de coordenação real obtida pela metodologia apresentada na Seção 3.3. Com efeito, existem localidades onde, de acordo com a Área de Coordenação Pré-estabelecida $\mathcal{A}_{\Omega_{\mathrm{r}}}(D)$, receptores do FS devem coordenar com a ESIM, mas que na verdade, de acordo com a área de coordenação real, não precisariam coordenar. Este fato reflete a ideia usual de falso alarme. Assim é possível se associar a probabilidade de se ter uma localização onde Área de Coordenação Pré-estabelecida $\mathcal{A}_{\Omega_{\mathbf{r}}}(D)$ indique a necessidade de coordenação quando, na realidade, a coordenação não é necessária, a uma probabilidade de falso alarme. Esta probabilidade de falso alarme pode ser estimada pela razão

$$
P_{f a}(D)=\frac{\operatorname{area}\left(\mathcal{A}_{\Omega_{\mathbf{r}}}(D) \cap \overline{\mathcal{A}}_{\Omega_{\mathbf{r}}}^{j}\right)}{\operatorname{area}\left(\overline{\mathcal{A}}_{\Omega_{\mathbf{r}}}^{j}\right)} .
$$

onde $\overline{\mathcal{A}}_{\Omega_{\mathrm{r}}}^{j}=\left\{\mathbf{x} \in \Omega_{\mathbf{s}}: \mathbf{x} \notin \mathcal{A}_{\Omega_{\mathbf{r}}}^{j}\right\}$, com $\mathcal{A}_{\Omega_{\mathbf{r}}}^{j}$ dado por (3-29) e $\Omega_{\mathbf{s}}$ representando 
a região geográfica onde os serviços vitima (FS) e interferente (FSS/ESIM) compartilham a mesma faixa de frequências. Estas regiões encontram-se ilustradas na Figura 3.12. Note que uma variação na área de $\Omega_{\mathrm{s}}$ influi diretamente na probabilidade de falso alarme obtida a partir de (3-33).

Além disso, existem localidades onde, de acordo com a Área de Coordenação Pré-estabelecida $\mathcal{A}_{\Omega_{\mathrm{r}}}(D)$, receptores do FS devem coordenar com a ESIM, quando a área de coordenação real indica que eles realmente precisariam coordenar. Este fato reflete a ideia usual de detecção. Assim é possível se associar a probabilidade de se ter uma localização onde a Área de Coordenação Pré-estabelecida $\mathcal{A}_{\Omega_{\mathbf{r}}}(D)$ indique a necessidade de coordenação quando ela é realmente necessária a uma probabilidade de detecção. Esta probabilidade de detecção pode ser estimada pela razão

$$
P_{d}(D)=\frac{\operatorname{area}\left(\mathcal{A}_{\Omega_{\mathbf{r}}}(D) \cap \mathcal{A}_{\Omega_{\mathbf{r}}}^{j}\right)}{\operatorname{area}\left(\mathcal{A}_{\Omega_{\mathbf{r}}}^{j}\right)}
$$

onde a Área de Coordenação real $\mathcal{A}_{\Omega_{\mathbf{r}}}^{j}$ e a Área de Coordenação PréEstabelecida $\mathcal{A}_{\Omega_{\mathbf{r}}}(D)$ correspondem às regiões indicadas na Figura 3.12. A probabilidade de perda $P_{p}(D)$, ou seja, a probabilidade se ter uma localidade onde a Área de Coordenação Pré-estabelecida $\mathcal{A}_{\Omega_{\mathrm{r}}}(D)$ indique não ser necessária a coordenação quando ela é realmente necessária é dada por

$$
P_{p}(D)=1-P_{d}(D)
$$

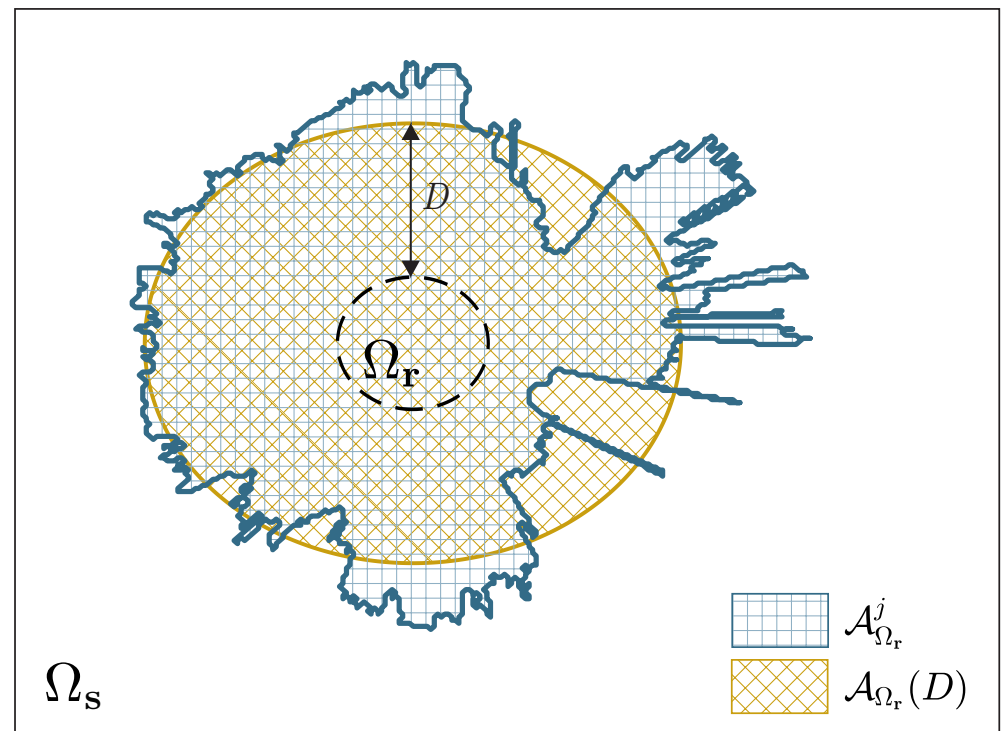

Figura 3.12: Ilustração da Área de Coordenação Pré Estabelecida $\mathcal{A}_{\Omega_{\mathrm{r}}}(D)$ e da Área de Coordenação Real $\mathcal{A}_{\Omega_{\mathrm{r}}}^{j}$, associada a $j$-ésima condição do critério de proteção, obtida a partir da metodologia descrita na Seção 3.3. 
Note que o ideal seria se ter uma probabilidade de detecção igual a 1 (e consequentemente $P_{p}(D)=0$ ) e uma probabilidade de falso alarme igual a zero. O compromisso na escolha desses dois parâmetros é usualmente analisado a partir de curvas de $P_{d}(D) \times P_{f a}(D)$. Na teoria de detecção, estas curvas são denominadas Curvas ROC (Receiver Operating Characteristics). Um exemplo destas curvas é apresentado na Figura 3.13. Nesta figura, valores do par $\left(P_{f a}(D), P_{d}(D)\right)$ são mostrados para distâncias $D$ que variam de 0 a infinito.

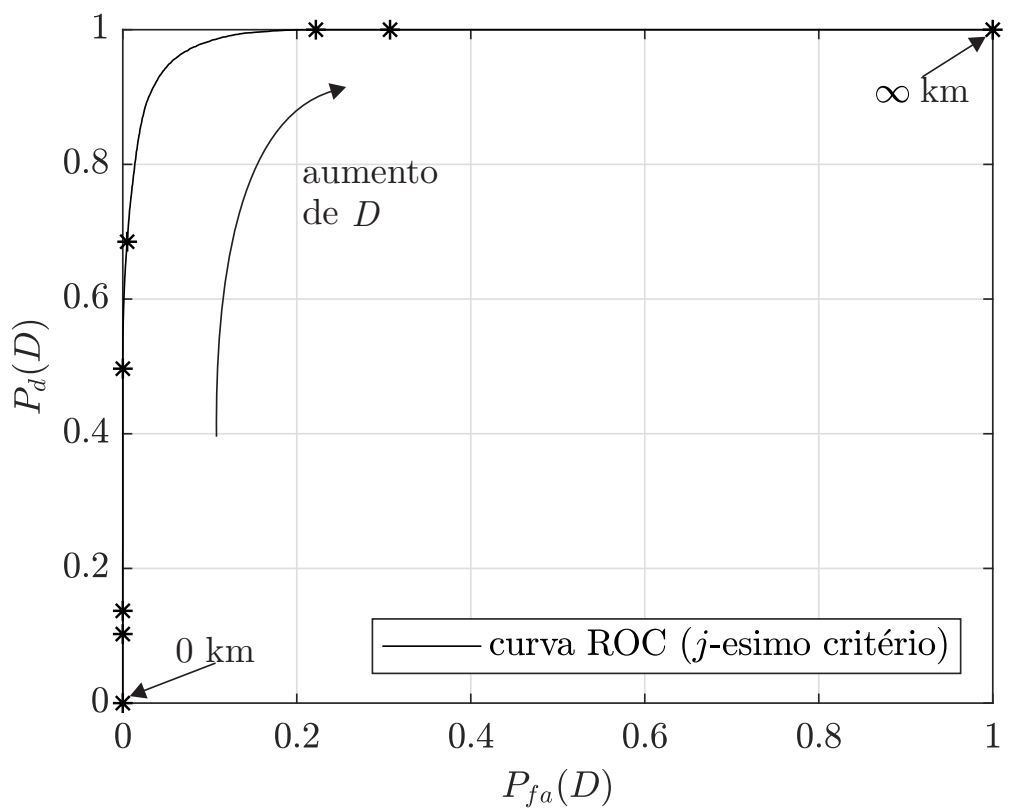

Figura 3.13: Exemplo de ROC obtida a partir de variar $D$ no intervalo de $[0, \infty)$ no eixo das abcissas - $P_{f a}$ e no eixo das ordenadas $P_{d}$.

É interessante observar que quanto maior a probabilidade de falso alarme, maior o número de coordenações desnecessárias, o que implica num aumento da quantidade de trabalho inútil. Por outro lado, conforme ilustrado na Figura 3.13 o comportamento típico de uma Curva ROC indica ser difícil se obter probabilidades de deteç̧ão altas quando a probabilidade de falso alarme é muito pequena. Estes fatos mostram a importância das Curvas ROC na escolha da distância $D$. Note que uma vez escolhida a distância $D$ que será utilizada para definir a necessidade de coordenação, ficam determinados os valores associados de probabilidade de detecção e probabilidade de falso alarme.

Neste ponto, vale lembrar que todos os cálculos para determinar as áreas de coordenação consideraram que, independentemente de sua localização, a ESIM opera com uma densidade de potência de transmissão fixa (e.g. 1 $\mathrm{dB}(\mathrm{W} / \mathrm{MHz}))$. Uma maneira de diminuir a probabilidade de perda $P_{p}(D)$, e consequentemente aumentar $P_{d}(D)$, é considerar que, dependendo de sua 
localização, a ESIM pode ser obrigada a operar com densidades de potência de transmissão reduzidas (e.g. menores que $1 \mathrm{~dB}(\mathrm{~W} / \mathrm{MHz})$ ).

Assim, considerando-se a Área de Coordenação Pré-estabelecida $\mathcal{A}_{\Omega_{\mathrm{r}}}(D)$ e a $j$-ésima restrição do critério de proteção, é possível determinar, para cada localização $\mathbf{r} \in \Omega_{\mathbf{r}}$, a densidade de potência máxima de transmissão $p_{\mathbf{r}}^{j}$ da ESIM que garanta que receptores do FS localizados fora de $\mathcal{A}_{\Omega_{\mathbf{r}}}(D)$ satisfaçam a $j$-ésima restrição do critério de proteção e, consequentemente, não necessitem coordenar com a ESIM.

Para determinar $p_{\mathbf{r}}^{j}$, considere inicialmente que $p_{\mathbf{r s}}^{j}$ seja a maior densidade de potência com a qual uma ESIM localizada em $\mathbf{r} \in \Omega_{\mathbf{r}}$ pode operar, garantindo que um receptor do FS localizado em $\mathbf{s} \in \overline{\mathcal{A}}_{\Omega_{\mathrm{r}}}(D)$ esteja protegido de acordo com a j-ésima restrição do critério de proteção. Observe que, conforme ilustrado na Figura 3.14, um aumento no valor de $p_{\mathbf{r s}}^{j}$ implica num deslocamento para a direita da Função Distribuição de Probabilidade Complementar da densidade de potência interferente afetando o receptor FS localizado em $\mathbf{s} \in \overline{\mathcal{A}}_{\Omega_{\mathbf{r}}}(D)$.

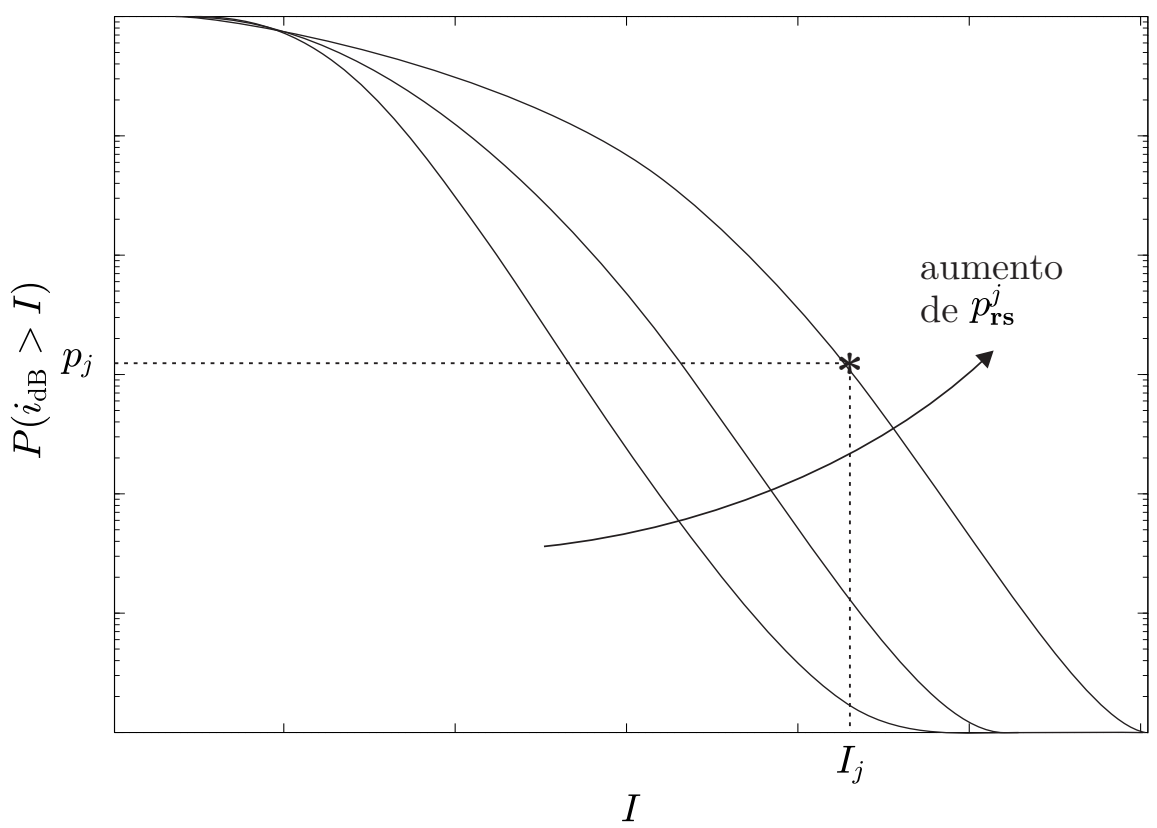

Figura 3.14: Esquema do comportamento da Função Distribuição de Probabilidade Complementar da densidade de potência de densidade interferente no receptor FS.

Uma vez determinado $p_{\mathbf{r s}}^{j}$, a densidade de potência máxima de transmissão $p_{\mathbf{r}}^{j}$ da ESIM que garante que receptores do FS localizados fora de $\mathcal{A}_{\Omega_{\mathbf{r}}}(D)$ satisfaçam a $j$-ésima restrição do critério de proteção é dada por

$$
p_{\mathbf{r}}^{j}=\min _{\mathbf{s} \in \overline{\mathcal{A}}_{\Omega_{\mathbf{r}}}(D)} p_{\mathbf{r s}}^{j}
$$


Exemplos de $p_{\mathbf{r}}^{j}$, para $\mathbf{r} \in \Omega_{\mathbf{r}}$, estão ilustrados nas figuras 3.15 e 3.16 para $\Omega_{\mathbf{r}}$ associado, respectivamente, a uma rodovia e para $\Omega_{\mathbf{r}}$ associado a uma área de serviço.

Finalmente a densidade de potência máxima de transmissão $p_{\mathbf{r}}$ da ESIM que garante que receptores do FS localizados fora de $\mathcal{A}_{\Omega_{\mathbf{r}}}(D)$ satisfaçam as $M$ restrição do critério de proteção é dada por

$$
p_{\mathbf{r}}=\min _{j} p_{\mathbf{r}}^{j}
$$




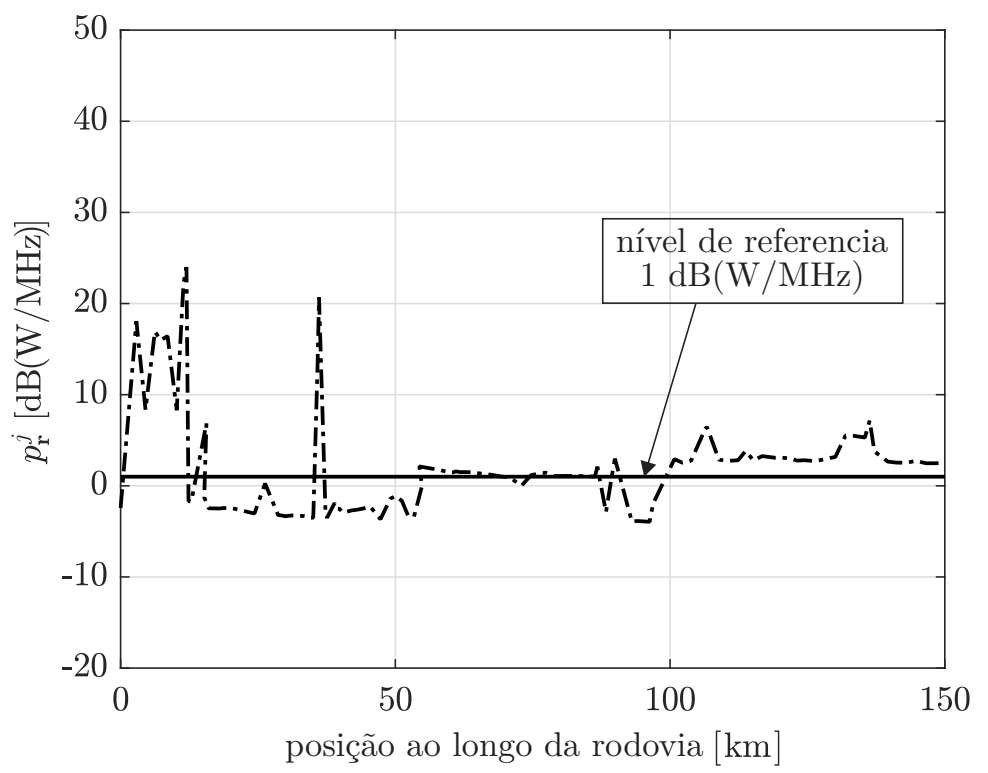

Figura 3.15: Exemplo do comportamento da densidade espectral de potência da ESIM em $\mathbf{r} \in \Omega_{\mathbf{r}}$ - rodovia, para o $j$-ésimo critério de proteção, que garante a proteção de receptores do FS em $\overline{\mathcal{A}}_{\Omega_{\mathbf{r}}}(D)$.

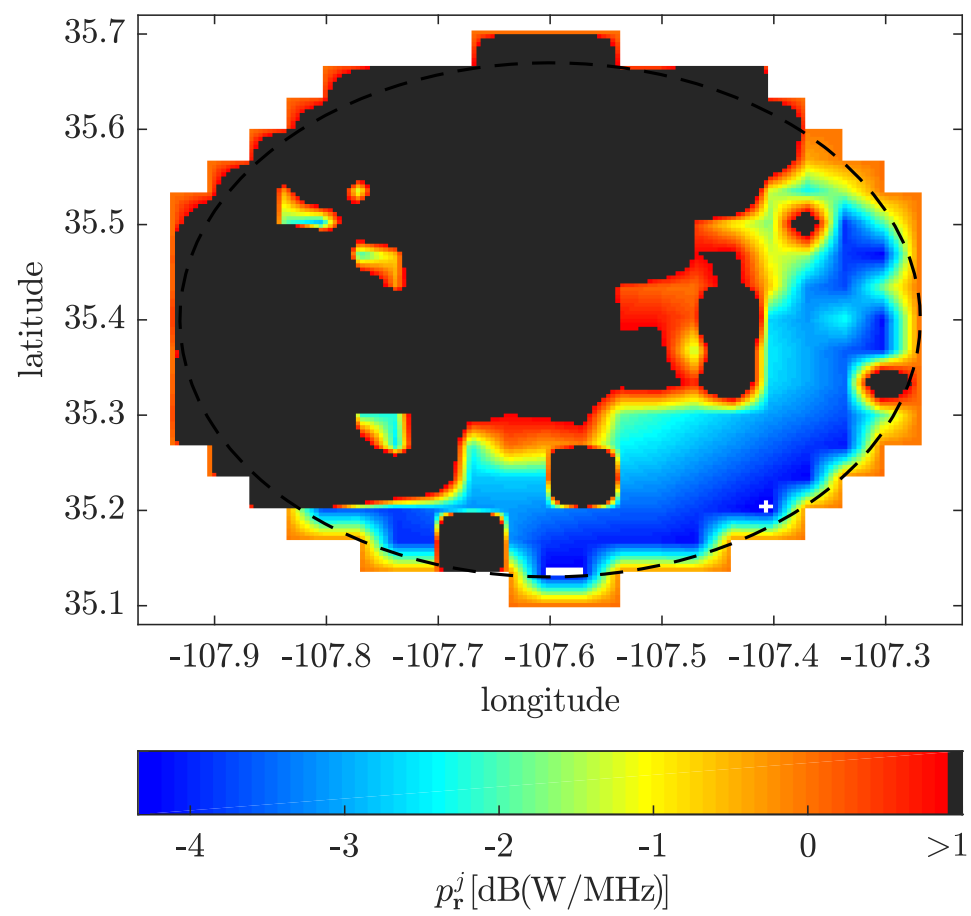

Figura 3.16: Exemplo do comportamento da densidade espectral de potência da ESIM em $\mathbf{r} \in \Omega_{\mathbf{r}}$ - região de serviço circular, para o $j$-ésimo critério de proteção, que garante a proteção de receptores do $\mathrm{FS}$ em $\overline{\mathcal{A}}_{\Omega_{\mathbf{r}}}(D)$. 


\section{4}

\section{Resultados Numéricos}

Neste capítulo, a metodologia apresentada na Seção 3.3 é utilizada para determinar a Área de Coordenação onde os receptores do FS precisam coordenar com o sistema interferente, neste caso estações terrenas em movimento (ESIM - Earth Station in Motion), que utilizam um satélite geoestacionário e operam na faixa de 27,5 - 29,5 GHz. A metodologia proposta foi avaliada considerando-se cenários envolvendo regiões com diferentes tipos de relêvo (e.g. montanhoso, aproximadamente plano), e diferentes áreas de serviço $\Omega_{\mathbf{r}}$ para as ESIM como, por exemplo, rodovias ou linha ferroviárias e áreas de cobertura associadas a feixes de recepção do satélite.

Num segundo tipo de análise, a metodologia apresentada na Seção 3.4, que considera uma área de coordenação alternativa associada a uma distância pré-estabelecida, foi utilizada na avaliação do valor máximo de densidade de potência de transmissão das ESIM que garante que receptores do FS localizados fora desta área de coordenação estão protegidos da interferência produzida pela ESIM. Este valor máximo de densidade de potência foi determinado para todas as possíveis posições geográficas da ESIM em $\Omega_{\mathbf{r}}$. Curvas do tipo ROC (receiver operating characteristics), usualmente empregadas em problemas binários de detecção, foram utilizadas na determinação de valores adequados da distância pré-estabelecida que determinou a área de coordenação alternativa nos exemplos abordados.

Os resultados obtidos podem certamente contribuir para a definição dos procedimentos regulamentares que nortearão o compartilhamento de frequências entre ESIMs do FSS e receptores do FS, tópico incluído como um dos pontos a serem avaliados pela Conferência Mundial de Comunicações de 2019 (Item 1.5 da agenda da WRC-19).

Resultados relativos a cenários, envolvendo diferentes tipos de relêvo (montanhoso e aproximadamente plano), são apresentados nas seções $4.1 \mathrm{e}$ 4.2, respectivamente. Para cada cenário, duas classes de áreas de serviço (rodovias e áreas de cobertura associadas a feixes de recepção do satélite) são consideradas na determinação das áreas de coordenação $\left\{\mathcal{A}_{\Omega_{\mathbf{r}}}^{j}, j=1, \ldots, M\right\}$ correspondentes às $M$ condições do critério de proteção. O fato deste tipo de área de coordenação ser bastante irregular, faz sua utilização em textos 
regulamentares muito complexa. Assim, conforme descrito na Seção 3.4, foi definida uma área de coordenação alternativa, baseada numa distância $D$ pré especificada. O valor de $D$ foi determinado de forma criteriosa (alta probabilidade de detecção e baixa probabilidade de falso alarme) utilizando-se curvas do tipo ROC.

Atualmente, não existe uma recomendação especifica da ITU que defina critérios de proteção, contra interferências variantes no tempo, para estações do FS operando na faixa 27,5-29,5 GHZ (e.g, especificação de níveis de interferência associados a percentagens de tempo durante as quais eles não podem ser excedidos). Assim, neste trabalho, são considerados os critérios formulados em duas recomendações do ITU-R: Recomendação ITU-R F.758-6 [13] (critério de longo prazo - $p_{j}=0,2$ ) e Recomendação ITU-R SM.1448 [12] (curto prazo $-p_{j}=5 \times 10^{-5}$ ).

O diagrama de radiação utilizado para a antena transmissora das ESIM é baseado nas recomendações ITU-R F.1245-2 [14] e ITU-R S.465-6 [15]. Estas recomendações abordam diagramas de radiação que devem ser utilizados em estudos de coordenação e avaliação de interferência aplicáveis a sistemas FSS (Fixed Sattelite Service) e FS. O diagrama de radiação utilizado é dado por

$$
g_{t_{\mathrm{dB}}}(\theta)=\left\{\begin{array}{cl}
G_{\max }-2.5 \times 10^{-3}\left(\frac{\mathcal{D}}{\lambda} \theta\right)^{2} & ; 0^{\circ}<\theta<\theta_{1} \\
G_{1} & ; \theta_{1} \leq \theta \leq \theta_{2} \\
32-25 \cdot \log \theta & ; \theta_{2}<\theta<48^{\circ} \\
-10 & ; \quad 48^{\circ} \leq \theta \leq 180^{\circ}
\end{array}\right.
$$

onde $G_{\text {max }}$ é o ganho máximo da antena em $(\mathrm{dBi}), \mathcal{D}$ é o diâmetro da antena (metros), $\lambda$ é o comprimento de onda (metros) e $G_{1}$ é o ganho do primeiro lóbulo lateral $(\mathrm{dBi})$, dado por $2+15 \cdot \log (\mathcal{D} / \lambda)$. Ainda em $(4-1), \theta_{1}$ e $\theta_{2}$ são dados por,

$$
\theta_{1}=\frac{20 \lambda}{\mathcal{D}} \sqrt{G_{\max }-G_{1}}
$$

e

$$
\theta_{2}=10^{\frac{32-G_{1}}{25}}
$$

O ganho máximo em (4-1) foi obtido a partir de,

$$
G_{\text {max }}=10 \log \left[0.55\left(\frac{\pi \mathcal{D}}{\lambda}\right)^{2}\right] .
$$

O valor de $\mathcal{D}$ foi escolhido levando-se em consideração as características típicas para uma rede ESIM operando em 29 GHz. Utilizou-se uma antena de diâmetro $\mathcal{D}=0.5 \mathrm{~m}$ que, na faixa de frequências considerada, corresponde a um ganho máximo $G_{\max }=41 \mathrm{dBi}$.

Para o receptor FS vitima, utilizou-se o diagrama de radiação da recomendação ITU-R F.1245-2 [14] embora, como indicado na Seção 3.1, tenha 
sido considerada a situação de pior caso na o qual a antena receptora do FS aponta, a todo momento, para a estação ESIM interferente. Foi utilizado $g_{r_{\mathrm{dB}}}(0)=41 \mathrm{dBi}$ (antena de diâmetro 0,5 m).

As perdas de propagação sofridas pelo sinal interferente foram modeladas a partir da Recomendação ITU-R P.452-16 [17], que aborda duas metodologias. A primeira diz respeito à predição da interferência em céu claro (clear sky) e engloba cinco modelos de propagação: difração, reflexão e refração nas camadas atmosféricas, espalhamento troposférico e perdas devidas ao ambiente em torno das estações (edificações, florestas, etc.). Esta metodologia pode ser aplicada tanto a enlaces em visibilidade quanto a enlaces trans-horizonte. A segunda metodologia refere-se às perdas devidas a espalhamento por hidrometeoros e conduz à função densidade de probabilidade da perda experimentada pelo sinal interferente. No presente trabalho, considerou-se a propagação em céu claro e portanto apenas a primeira metodologia foi utilizada na determinação da função distribuição de probabilidade da perda $\ell$ de propagação. Para este cálculo foi necessária a obtenção de expressões matemáticas que fornecem parâmetros específicos da geometria utilizada a partir das posições geográficas da ESIM e do receptor FS. Uma descrição resumida do procedimento utilizado é apresentada no Apêndice A.

Em todos os cenários analisados, considerou-se que, dado o diagrama de radiação da antena transmissora, a ESIM transmite a maior densidade de potência tal que os níveis de e.i.r.p. (equivalent isotropically radiated power) transmitidos fora do eixo satisfaçam aos limites contidos na Recomendação ITU-R S.524-9 [16]. O procedimento para a determinação desta máxima densidade de potência de transmissão é apresentado no Apêndice B. No caso de antenas com diâmetros de 0,5 e 1,0 metros, o procedimento do Apêndice $\mathrm{B}$ conduziu, em ambos os casos, a uma densidade de potência máxima aproximadamente igual a $1 \mathrm{~dB}(\mathrm{~W} / \mathrm{MHz})$. Além disso, foram utilizados, em todos os cenários, os parâmetros técnicos apresentados na Tabela 4.1. 
Tabela 4.1: Parâmetros utilizados nos exemplos apresentados nas seções 4.1 e 4.2 .

\begin{tabular}{|l|c|}
\hline \hline Parâmetro & Valor \\
\hline \hline porcentagem do tempo $P_{1}$ (longo prazo) $[\%]$ & 20 \\
\hline nível de interferência excedido $P_{1} \%$ do tempo $[\mathrm{dB}(\mathrm{W} / \mathrm{MHz})]$ & -146 \\
\hline porcentagem do tempo $P_{2}($ curto prazo $[\%]$ & 0,005 \\
\hline nível de interferência excedido $P_{2} \%$ do tempo $[\mathrm{dB}(\mathrm{W} / \mathrm{MHz})]$ & -111 \\
\hline frequência $[\mathrm{GHz}]$ & 29 \\
\hline diâmetro antena do receptor FS [m] & 0.5 \\
\hline altitude satélite $[\mathrm{km}]$ & 35.786 \\
\hline altura sobre o solo ESIM $[\mathrm{m}]$ & 2 \\
\hline diâmetro da antena ESIM $[\mathrm{m}]$ & 0,5 \\
\hline altura sobre o solo receptor FS [m] & 100 \\
\hline \hline
\end{tabular}

\section{1}

\section{Região Montanhosa}

A região montanhosa considerada nesta seção refere-se a uma região geográfica em torno da longitude $107^{\circ} \mathrm{O}$ e latitude $35^{\circ} \mathrm{N}$, localizada no estado de New Mexico, no Estados Unidos, onde o nível do terreno varia de 1.500 a 4.000 metros aproximadamente. O relêvo desta região pode ser apreciado na Figura 4.1 onde, como referência, está indicada a localização da cidade de Albuquerque. Na região foram avaliados dois cenários. No primeiro, as estações interferentes (ESIM) se movem ao longo do trecho de uma rodovia e, no segundo, dentro da área de cobertura do feixe de recepção do satélite considerado. Em ambos os cenários, considerou-se o satélite do FSS servindo as ESIM na posição orbital $107,5^{\circ} \mathrm{O}$. Cada um dos cenários é avaliado nas subseções seguintes.

\subsection{1}

Zona de serviço do tipo rodovia ou linha ferroviária numa região montanhosa.

Neste cenário, considerou-se que as ESIM se movem ao longo de um trecho de aproximadamente $215 \mathrm{~km}$ da rodovia interestadual I-40, localizado entre as cidades de Gallup e Albuquerque, conforme ilustrado na Figura 4.2. Para a implementação dos procedimentos descritos nas seções 3.3 e 3.4, as possíveis posições da ESIM ao longo da rodovia foram discretizadas em pontos espaçados de aproximadamente $1 \mathrm{~km}$.

Os resultados obtidos pela aplicação do procedimento descrito na Seção 3.3 são apresentados na Figura 4.3. A Área de Coordenação $\mathcal{A}_{\Omega_{\mathrm{r}}}^{1}$, correspondente à restrição de longo prazo do critério de proteção $\left(p_{1}=0,2\right)$, é mostrada 


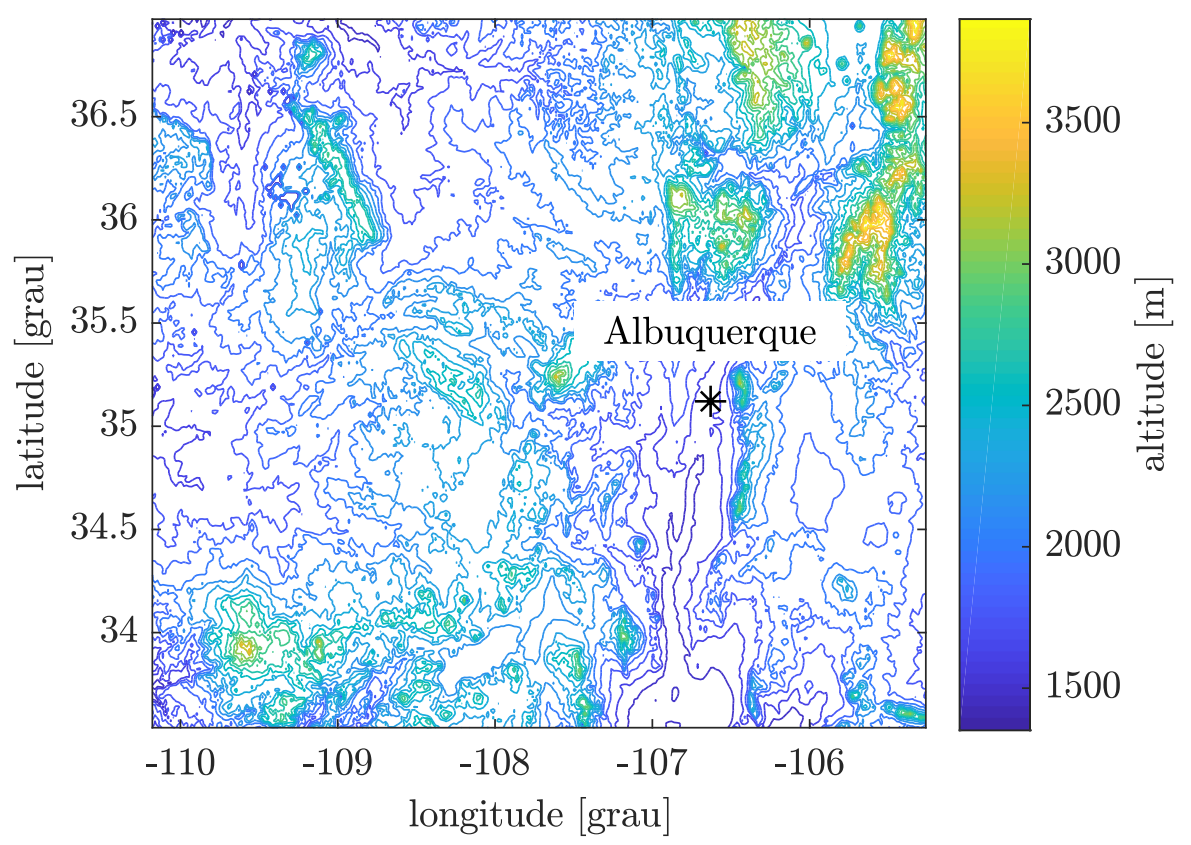

Figura 4.1: Relêvo da região montanhosa localizada no estado de New Mexico, no Estados Unidos.

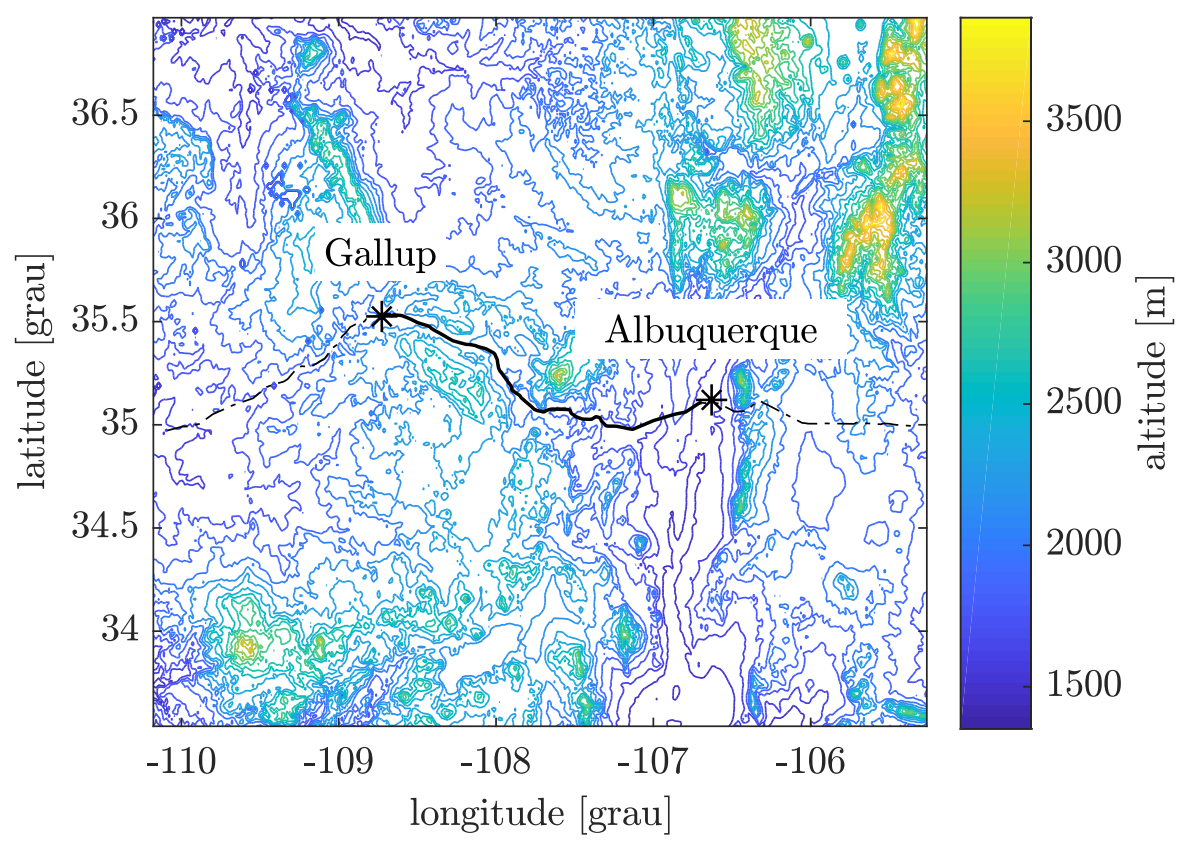

Figura 4.2: Parte da rodovia interestadual I-40 que cobre o percurso entre as cidades de Gallup e Albuquerque no estado de New Mexico no Estados Unidos.

em vermelho. A Área de Coordenação $\mathcal{A}_{\Omega_{\mathbf{r}}}^{2}$, correspondente à restrição de curto prazo do critério de proteção $\left(p_{2}=5 \times 10^{-5}\right)$, é mostrada em preto. Note que a área de coordenação correspondente à restrição de longo prazo é mais restri- 
tiva do que a área de coordenação correspondente à restrição de curto prazo. Neste exemplo específico, observe ainda que, nos primeiros $100 \mathrm{~km}$ de rodovia a partir da cidade de Gallup, os limites das duas áreas de coordenação (longo prazo e curto prazo) são bastante parecidos. Isto se deve ao relêvo desta parte da rodovia, que é margeada, em ambos os lados, por altas elevações.

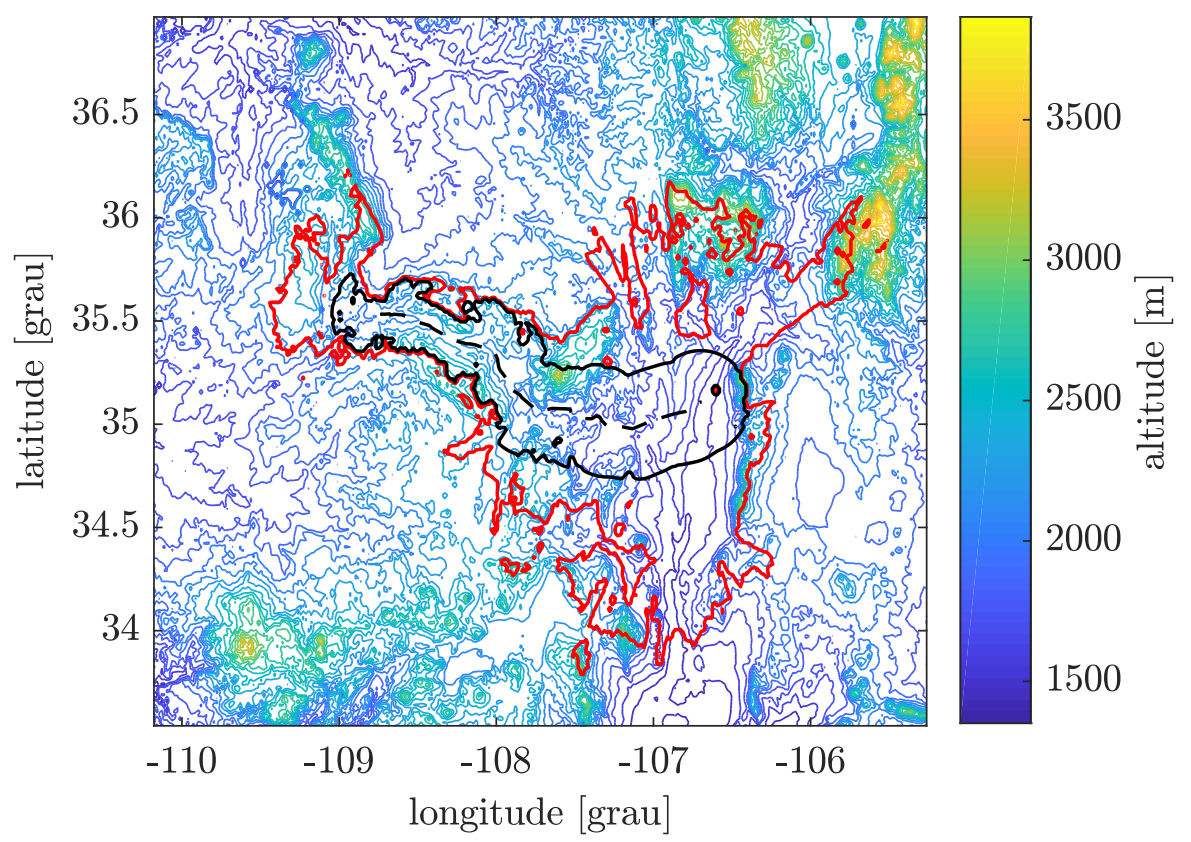

Figura 4.3: Áreas de Coordenação obtidas com o procedimento da Seção 3.3, para ESIMs operando em um trecho da rodovia I-40, numa região com topografia predominantemente montanhosa. A linha vermelha corresponde ao critério de proteção de longo prazo $\left(p_{1}=0,2\right)$ e a linha preta ao critério de curto prazo $\left(p_{2}=5 \times 10^{-5}\right)$.

A aplicação do procedimento descrito na Seção 3.4 a este cenário conduziu às curvas ROC apresentadas nas figuras 4.4 e 4.5 para as restrições de longo e curto prazo do critério de proteção, respectivamente. Nas figuras 4.4 e 4.5 estão destacados os pontos da curva ROC associados a algumas distâncias D. Mais especificamente, são mostrados os pontos correspondentes a distâncias $D$ iguais a $0,10,27,8,70,90,148,6$ e $160 \mathrm{~km}$, além do ponto correspondente à distância $D$ infinita. Os valores de probabilidade de detecção e probabilidade de falso alarme associados a estas distâncias são apresentados na Tabela 4.2, para os dois critérios (longo e curto prazos).

Observe que, se o critério de curto prazo é considerado (Figura 4.5), a distância $D=27,8 \mathrm{~km}$ é, claramente, a mais adequada. Entretanto, se olharmos para a Figura 4.4 (critério de longo prazo), verificamos que esta distância, embora associada a uma baixa probabilidade de falso alarme, 


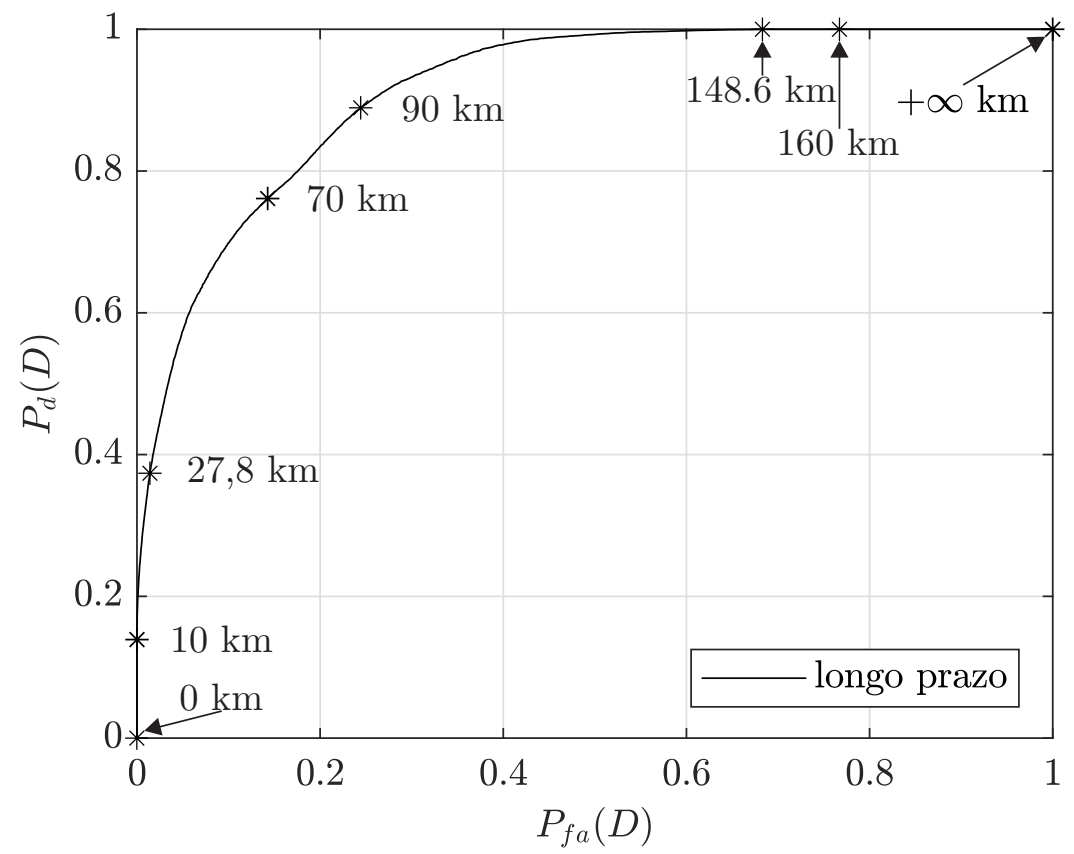

Figura 4.4: Curva ROC associada ao critério de longo prazo (região montanhosa e área de serviço caracterizada por trecho de rodovia).

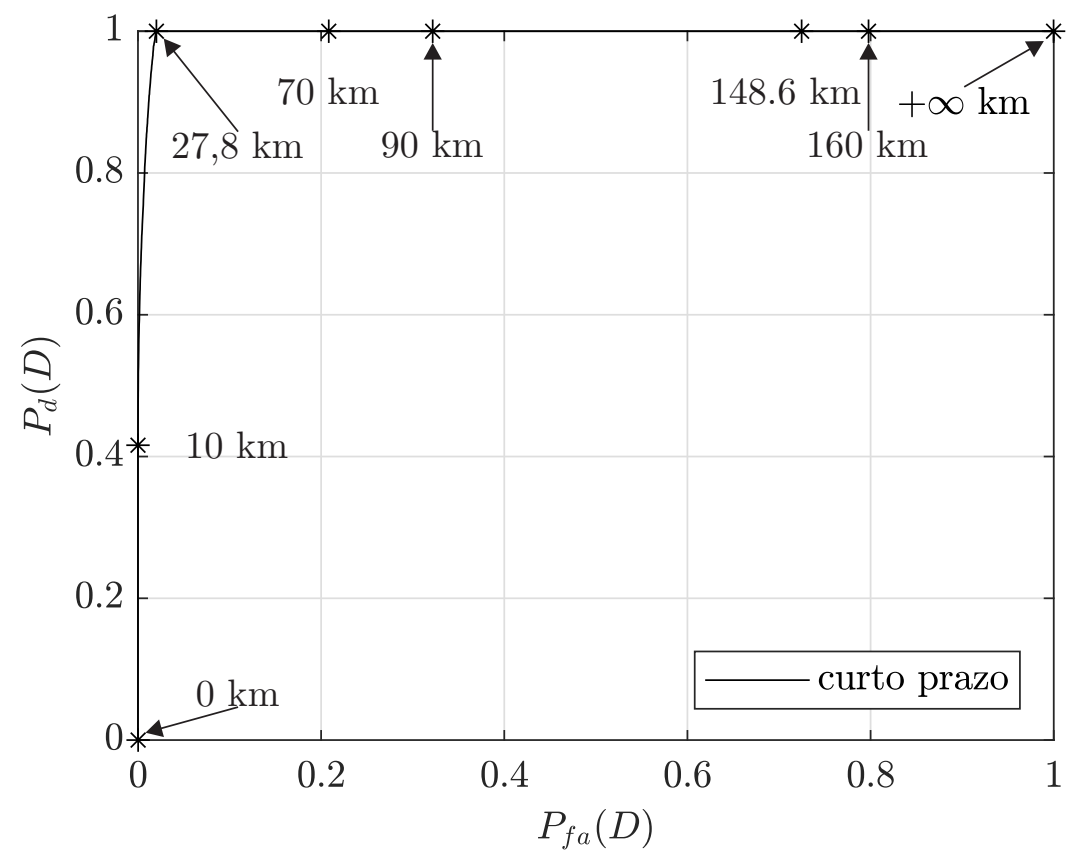

Figura 4.5: Curva ROC associada ao critério de curto prazo (região montanhosa e área de serviço caracterizada por trecho de rodovia).

corresponde a uma probabilidade de detecção muito baixa $\left(P_{d}=0,3737\right)$. Neste caso, a distância $D$ deve ser escolhida com base no critério de longo prazo. A curva ROC da Figura 4.4 indica as distâncias $D=70 \mathrm{~km}$ e $D=90$ 
$\mathrm{km}$ parecem ser as candidatas mais apropriadas, os contornos associados as áreas de coordenação alternativas $\left(\mathcal{A}_{\Omega_{\mathbf{r}}}(70)\right.$ e $\left.\mathcal{A}_{\Omega_{\mathbf{r}}}(90)\right)$, para estas distâncias estão ilustrados na Figura 4.6.

Tabela 4.2: Probabilidades de falso alarme e probabilidades de detecção para as distâncias $D$ destacadas nas figuras 4.4 e 4.5 .

\begin{tabular}{||c|cc|cc||}
\hline \hline \multirow{2}{*}{ distância $D[\mathrm{~km}]$} & \multicolumn{2}{|c|}{ critério longo prazo } & \multicolumn{2}{c||}{ critério curto prazo } \\
\cline { 2 - 5 } & $P_{f a}$ & $P_{d}$ & $P_{f a}$ & $P_{d}$ \\
\hline \hline 0 & 0 & 0 & 0 & 0 \\
10 & 0,0001 & 0,1391 & 0,0002 & 0,4001 \\
27,8 & 0,0124 & 0,3777 & 0,0171 & 1 \\
70 & 0,1421 & 0,7534 & 0,2066 & 1 \\
90 & 0,2425 & 0,8837 & 0,3203 & 1 \\
148,6 & 0,6329 & 1 & 0,6822 & 1 \\
160 & 0,7619 & 1 & 0,7939 & 1 \\
$\infty$ & 1 & 1 & 1 & 1 \\
\hline \hline
\end{tabular}

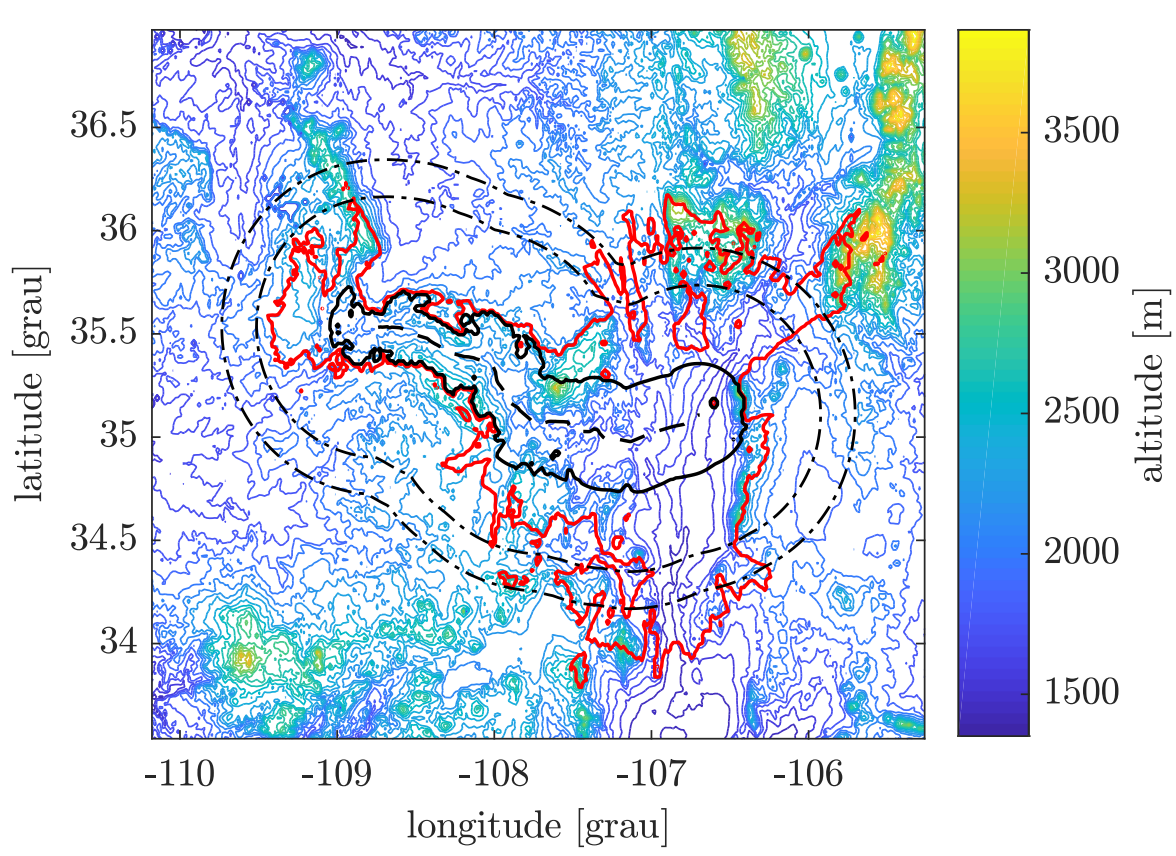

Figura 4.6: Áreas Pré-Especificada para distâncias $D=70 \mathrm{~km}$ e $D=90 \mathrm{~km}$ ao redor de uma rodovia numa região predominantemente montanhosa.

As figuras 4.7 e 4.8 apresentam os valores $p_{\mathbf{r}}^{j}$ da máxima densidade de potência que garante que a $j$-ésima condição do critério de proteção seja atendida, definida em (3-36), em função da posição $\mathbf{r} \in \Omega_{\mathbf{r}}$ da ESIM, para distâncias $D$ iguais a 70 e $90 \mathrm{~km}$, respectivamente. Nestas figuras, a posição $\mathbf{r} \in \Omega_{\mathbf{r}}$ é caracterizada pela distância ao longo da rodovia, medida a partir da 
cidade de Gallup. A título de referência, está também indicado, em ambas as figuras, o nível de densidade de potência utilizado na determinação das áreas de coordenação $\left\{\mathcal{A}_{\Omega_{\mathrm{r}}}^{j} ; j=1,2\right\}$. Este nível de densidade de potência (nível máximo que garante o atendimento aos limites de emissão fora do eixo da Recomendação ITU-R S.524 [16]), obtido através do procedimento descrito no Apêndice B, é igual a $1 \mathrm{~dB}(\mathrm{~W} / \mathrm{MHz})$ tanto para $j=1$ quanto para $j=2$.

Observe que, para sistemas que operam com a máxima densidade de potência permitida pela Recomendação ITU-R S.524 (1 dB(W/MHz)), tanto para $D=70 \mathrm{~km}$ quanto para $D=90 \mathrm{~km}$, as restrições à densidade de potência de transmissão são impostas pelo critério de longo prazo. Estas restrições aparecem principalmente para pontos da rodovia cujas distância a Gallup são maiores do que $129 \mathrm{~km}$, podendo chegar a reduções de $14 \mathrm{~dB}$ e $11 \mathrm{~dB}$ no caso de $D=70 \mathrm{~km}$ e $D=90 \mathrm{~km}$, respectivamente. Obviamente, um sistema que opere com uma densidade de potência igual a $-10 \mathrm{~dB}(\mathrm{~W} / \mathrm{MHz})$, ou seja, 0,1 $\mathrm{W} / \mathrm{MHz}$, não teria restrições quanto à potência de transmissão ao longo de todo o percurso se a distância $D=90 \mathrm{~km}$ for considerada. Se considerarmos $D=70 \mathrm{~km}$, as restrições impostas seriam da ordem de $3 \mathrm{~dB}$ e ocorreriam no final do percurso.

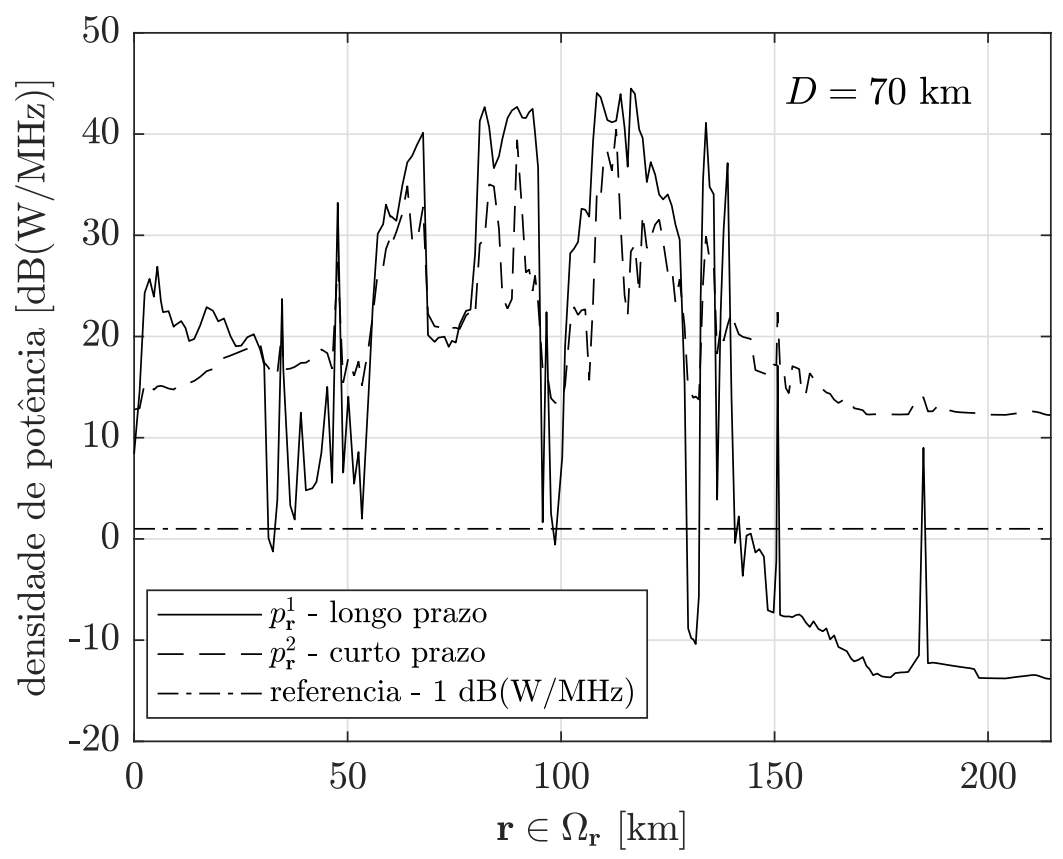

Figura 4.7: Máxima densidade de potência de transmissão das ESIM ao longo do trecho da rodovia I-40 considerado. A posição $\mathbf{r} \in \Omega_{\mathbf{r}}$ é caracterizada pela distância ao longo da rodovia, medida a partir da cidade de Gallup. 


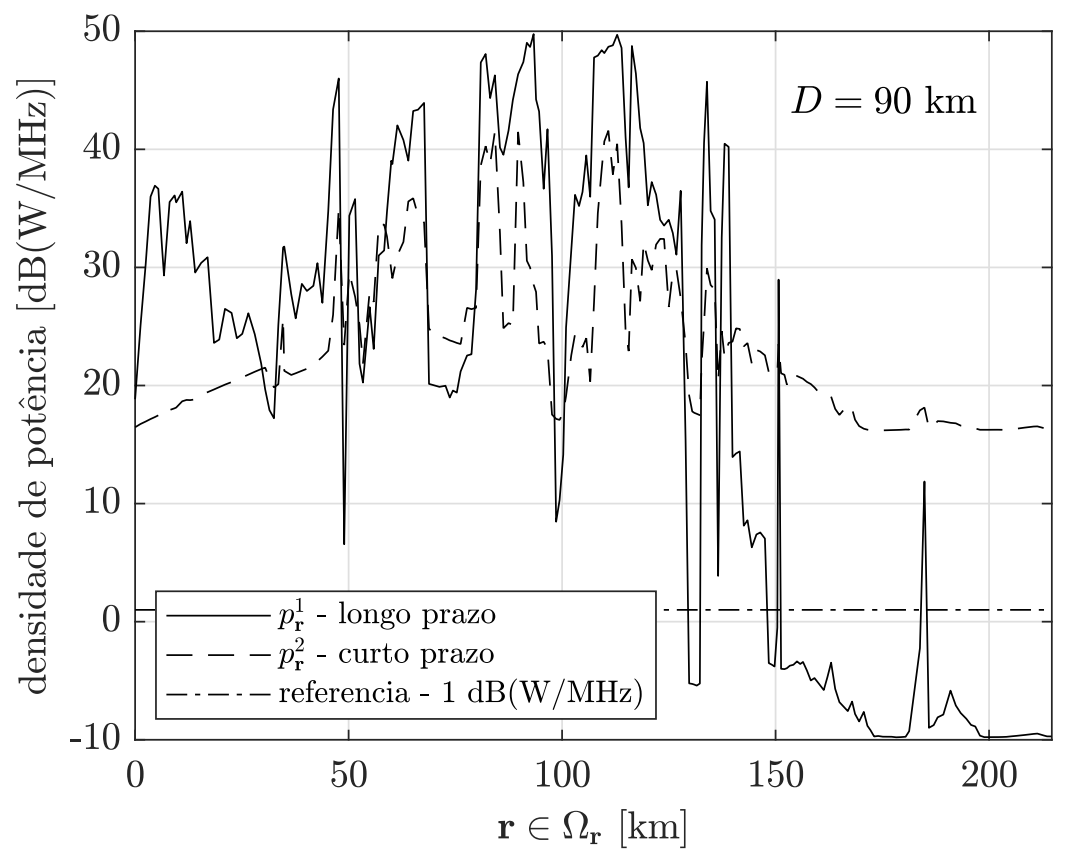

Figura 4.8: Máxima densidade de potência de transmissão das ESIM ao longo do trecho da rodovia I-40 considerado. A posição $\mathbf{r} \in \Omega_{\mathbf{r}}$ é caracterizada pela distância ao longo da rodovia, medida a partir da cidade de Gallup.

\subsection{2}

Zona de serviço definida pelo feixe de recepção de um satélite geostacionário numa região montanhosa.

Neste cenário, considerou-se que as ESIM se movem dentro da área de cobertura do feixe de recepção de um satélite geostacionário, com centro na posição geográfica definida pela latitude $35,4^{\circ} \mathrm{N}$ e longitude $107,6^{\circ} \mathrm{O}$. Neste exemplo, considerou-se um feixe com seção reta circular e contorno de $-3 \mathrm{~dB}$ na superfície da Terra com raio igual a $30 \mathrm{~km}$, cobrindo assim um área geográfica de aproximadamente $1414 \mathrm{~km}^{2}$. Conforme ilustrado na Figura 4.9, neste caso, a área de serviço $\Omega_{\mathbf{r}}$ encontra-se ao oeste da cidade de Albuquerque. Para a implementação dos procedimentos descritos nas seções 3.3 e 3.4, as possíveis posições da ESIM na região de serviço foram discretizadas numa grade de pontos espaçados de aproximadamente 1,8532 km em latitude e 1,5116 km em longitude.

Os resultados obtidos pela aplicação do procedimento descrito na Seção 3.3 são apresentados na Figura 4.10. A Área de Coordenação $\mathcal{A}_{\Omega_{\mathrm{r}}}^{1}$, correspondente à restrição de longo prazo do critério de proteção $\left(p_{1}=0,2\right)$, é mostrada em vermelho. A Área de Coordenação $\mathcal{A}_{\Omega_{\mathbf{r}}}^{2}$, correspondente à restrição de curto prazo do critério de proteção $\left(p_{2}=5 \times 10^{-5}\right)$, é mostrada em preto. Note que a área de coordenação correspondente à restrição de longo prazo é novamente mais restritiva do que a área de coordenação correspondente à restrição de 


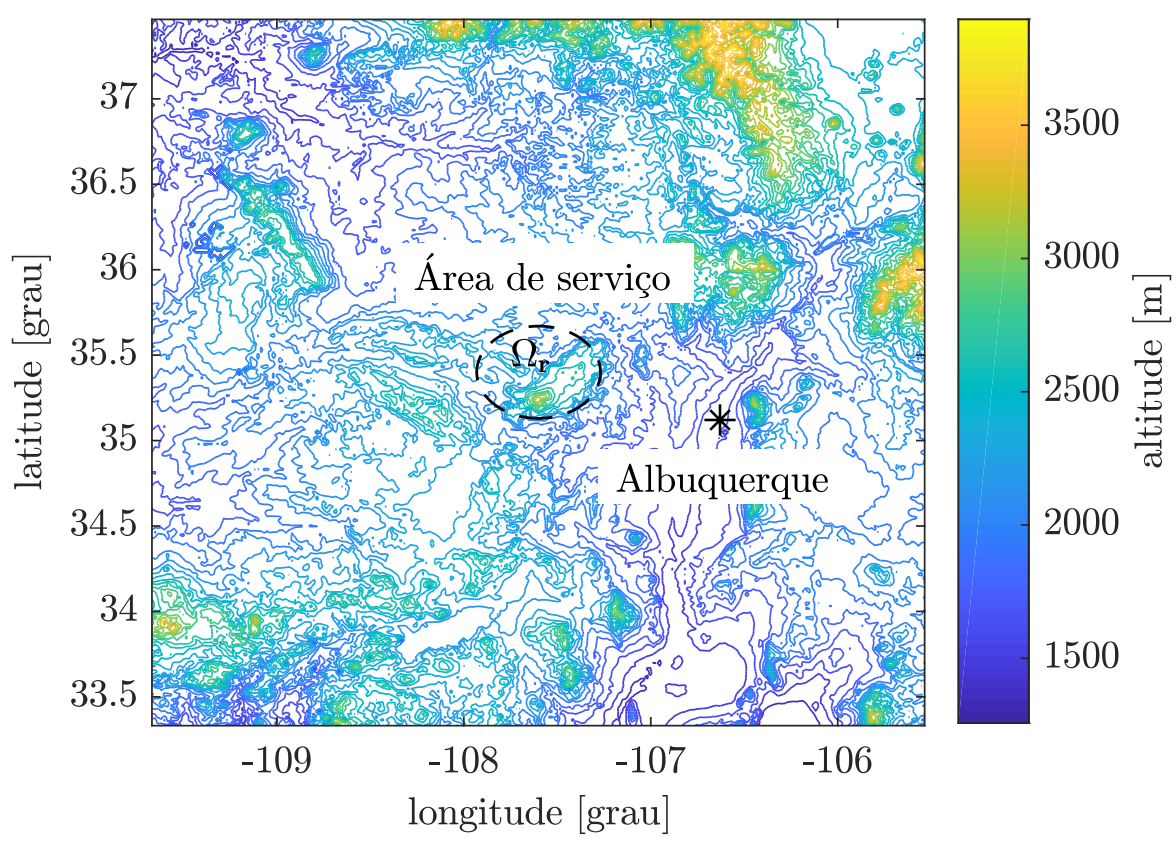

Figura 4.9: Área de serviço do feixe de recepção do satélite geostacionário com centro definido pela latitude $35,4^{\circ} \mathrm{N}$ e longitude $107,6^{\circ} \mathrm{O}$ no estado de New Mexico no Estados Unidos.

curto prazo. Observe na Figura 4.10 a forte influência do relêvo da região no formato da Área de Coordenação associada ao critério de longo prazo - $\mathcal{A}_{\Omega_{\mathrm{r}}}^{1}$, que se mostra bem irregular e definida, em grande parte, pelas elevações presentes na região.

A aplicação do procedimento descrito na Seção 3.4 a este cenário conduziu às curvas ROC apresentadas nas figuras 4.11 e 4.12 para as restrições de longo e curto prazo do critério de proteção, respectivamente. Nas figuras 4.11 e 4.12 estão destacados os pontos da curva ROC associados a algumas distâncias $D$. Mais especificamente, são mostrados os pontos correspondentes a distâncias $D$ iguais a $0,10,27,7,115,130,156,6$ e $160 \mathrm{~km}$, além do ponto correspondente à distância $D$ infinita. Os valores de probabilidade de detecção e probabilidade de falso alarme associados a estas distâncias são apresentados na Tabela 4.3, para os dois critérios (longo e curto prazos). Observe que, se o critério de curto prazo é considerado (Figura 4.12), a distância $D=27,7 \mathrm{~km}$ é, claramente, a mais adequada. Entretanto, novamente, se olharmos para a Figura 4.11 (critério de longo prazo), verificamos que esta distância, embora associada a uma baixa probabilidade de falso alarme, corresponde a uma probabilidade de detecção muito baixa $\left(P_{d}=0,1783\right)$. Neste caso, como no cenário anterior, a distância $D$ deve ser escolhida com base no critério de longo prazo. A curva ROC da Figura 4.11 indica as distâncias $D=115 \mathrm{~km}$ e $D=130 \mathrm{~km}$ 


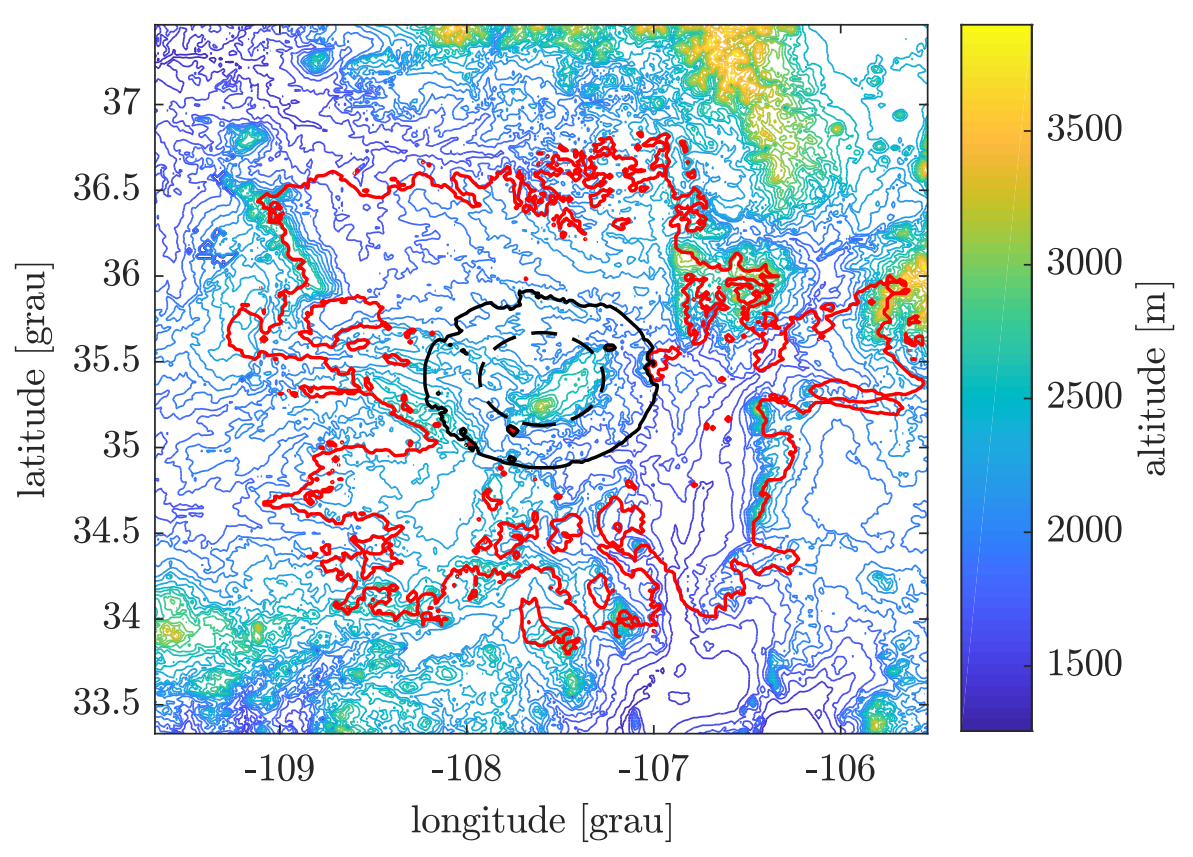

Figura 4.10: Áreas de Coordenação obtidas com o procedimento da Seção 3.3, para ESIMs operando numa região circular, com topografia predominantemente montanhosa. A linha vermelha corresponde ao critério de proteção de longo prazo $\left(p_{1}=0,2\right)$ e a linha preta ao critério de curto prazo $\left(p_{2}=5 \times 10^{-5}\right)$.

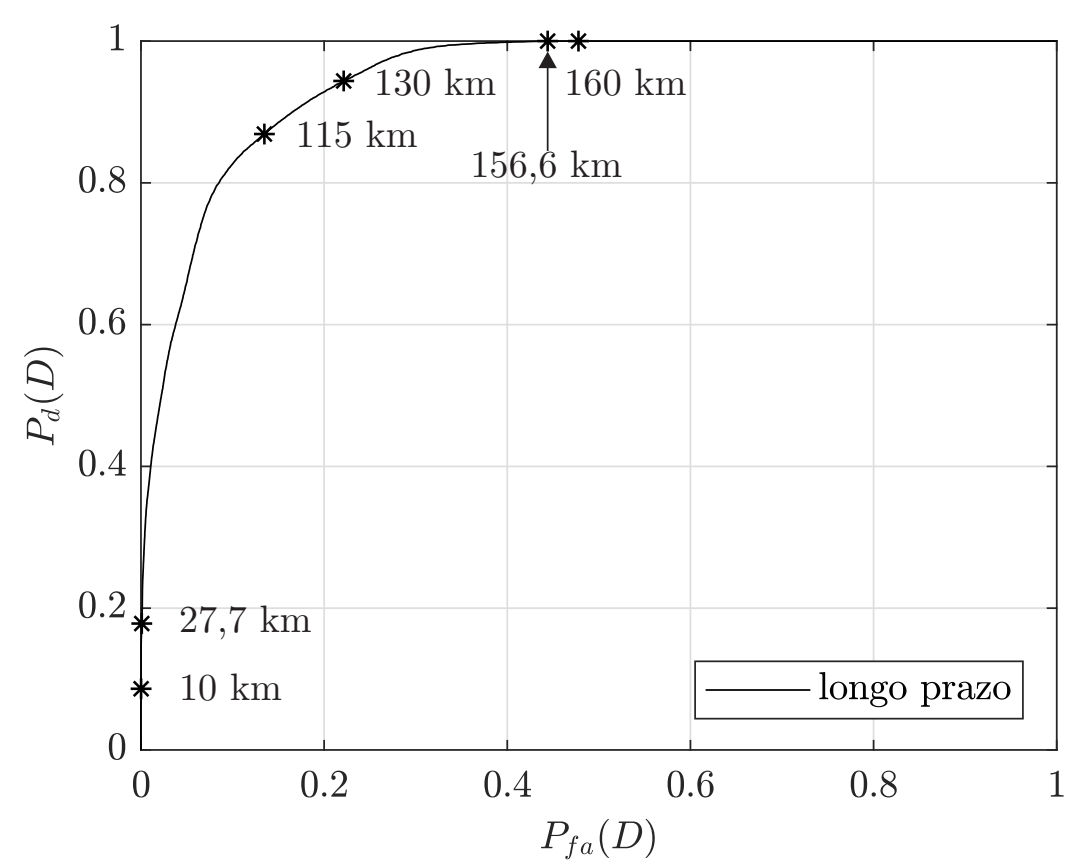

Figura 4.11: Curva ROC associada ao critério de longo prazo (região montanhosa e área de serviço caracterizada pelo feixe de recepção do satélite geostacionário). 


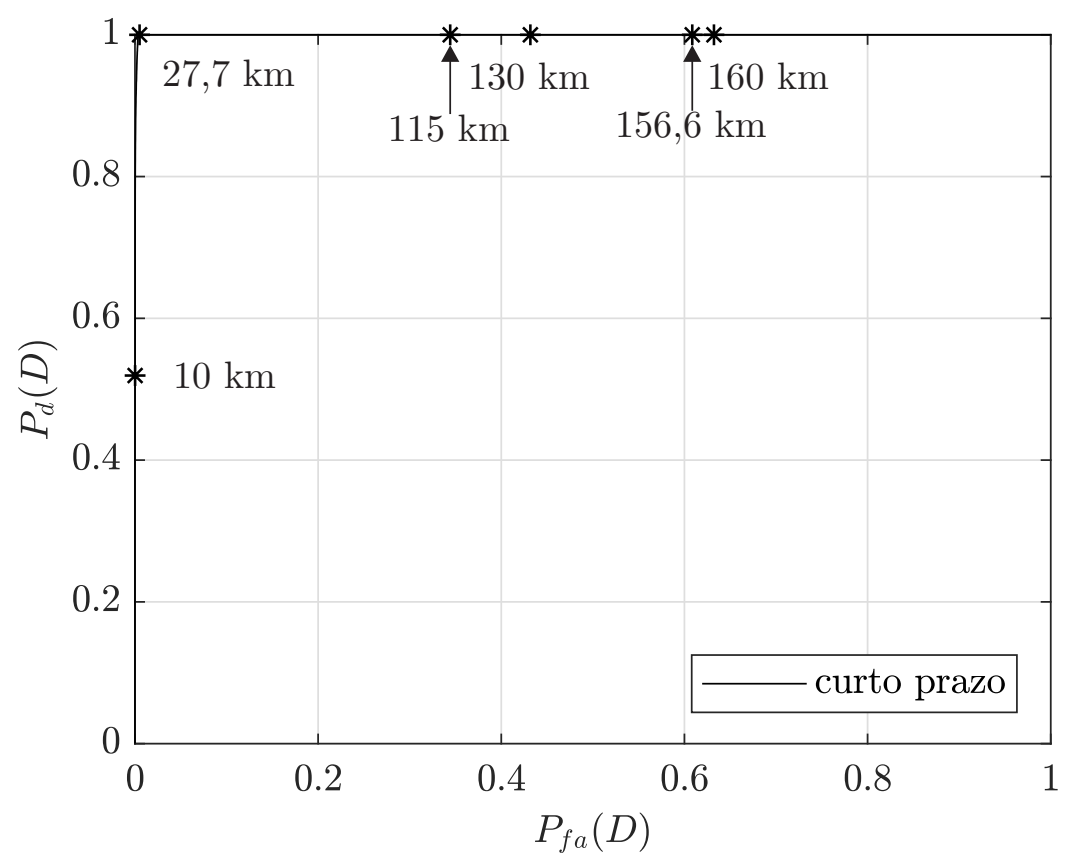

Figura 4.12: Curva ROC associada ao critério de curto prazo (região montanhosa e área de serviço caracterizada pelo feixe de recepção do satélite geostacionário).

parecem ser as candidatas mais apropriadas, os contornos associados as áreas de coordenação alternativas $\left(\mathcal{A}_{\Omega_{\mathbf{r}}}(115)\right.$ e $\left.\mathcal{A}_{\Omega_{\mathrm{r}}}(130)\right)$, para estas distâncias estão ilustrados na Figura 4.13.

Tabela 4.3: Probabilidades de falso alarme e probabilidades de detecção para as distâncias $D$ destacadas nas figuras 4.11 e 4.12 .

\begin{tabular}{||c|cc|cc||}
\hline \hline \multirow{2}{*}{ distância $D[\mathrm{~km}]$} & \multicolumn{2}{|c|}{ critério longo prazo } & \multicolumn{2}{c||}{ critério curto prazo } \\
\cline { 2 - 5 } & $P_{f a}$ & $P_{d}$ & $P_{f a}$ & $P_{d}$ \\
\hline \hline 0 & 0 & 0 & 0 & 0 \\
10 & 0,0001 & 0,0863 & 0,0002 & 0,5193 \\
27,7 & 0,0009 & 0,1783 & 0,0050 & 1 \\
115 & 0,1348 & 0,8689 & 0,3442 & 1 \\
130 & 0,2214 & 0,9438 & 0,4318 & 1 \\
156,6 & 0,4441 & 1 & 0,6086 & 1 \\
160 & 0,4777 & 1 & 0,6322 & 1 \\
$\infty$ & 1 & 1 & 1 & 1 \\
\hline \hline
\end{tabular}

As figuras 4.14 e 4.15 apresentam os valores da máxima densidade de potência $p_{\mathbf{r}}$ transmitida pela ESIM, definida em (3-37) e (3-36), em função da posição $\mathbf{r} \in \Omega_{\mathbf{r}}$ da ESIM, para distâncias $D$ iguais a 115 e $130 \mathrm{~km}$, respectivamente. Nestas figuras, a posição $\mathbf{r} \in \Omega_{\mathbf{r}}$ é caracterizada por sua 


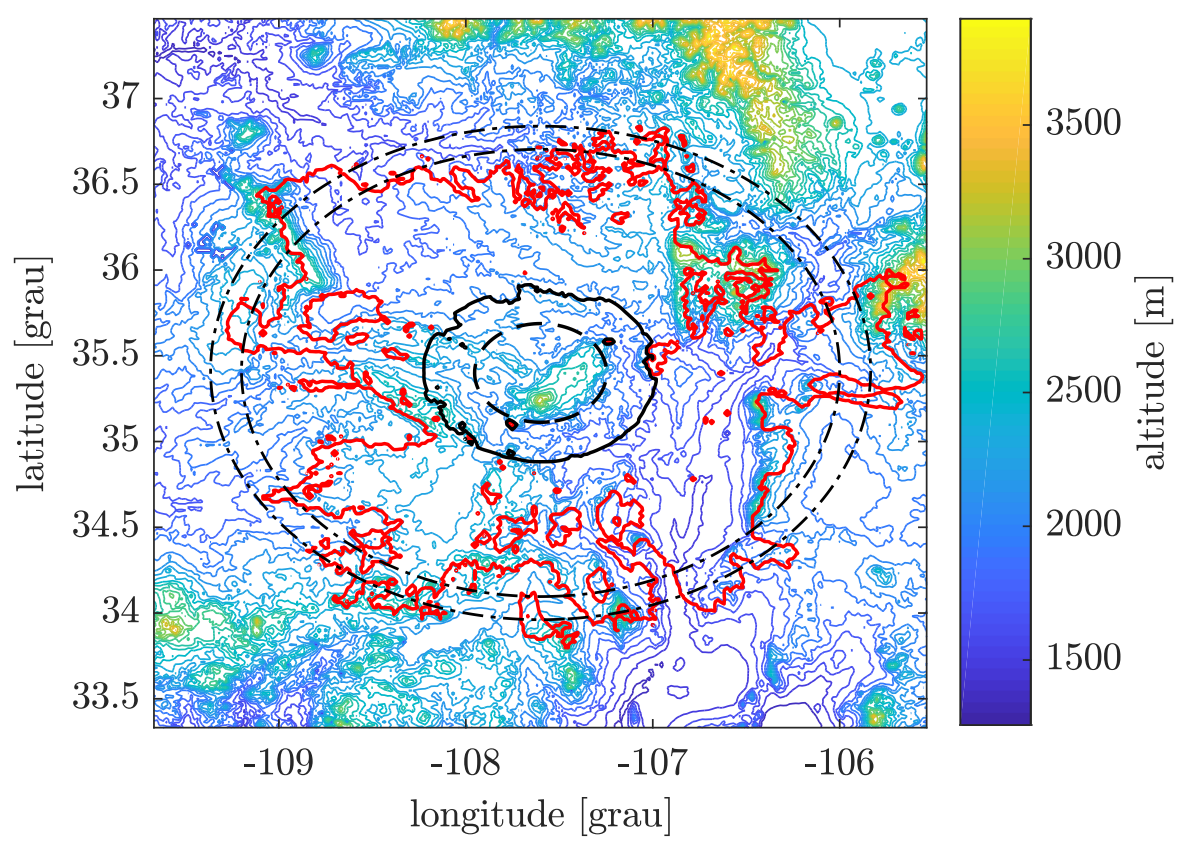

Figura 4.13: Áreas Pré-Especificada para distâncias $D=115 \mathrm{~km}$ e $D=130$ $\mathrm{km}$ ao redor de uma região de serviço circular.

latitude $\Theta_{\mathbf{r}}$ e sua longitude $\Phi_{\mathbf{r}}$. A título de referência, em ambas as figuras, está indicada pela cor preta, a região onde a máxima densidade de potência transmitida pela ESIM pode ser maior do que nível de referencia. Este nível de densidade de potência, obtido através do procedimento descrito no Apêndice $\mathrm{B}$, é igual a $1 \mathrm{~dB}(\mathrm{~W} / \mathrm{MHz})$ tanto para $j=1$ quanto para $j=2$.

Observe que, para sistemas que operam com a máxima densidade de potência permitida pela Recomendação ITU-R S.524 (1 dB(W/MHz)), tanto para $D=115 \mathrm{~km}$ quanto para $D=130 \mathrm{~km}$, existem regiões onde a densidade de potência de transmissão tem que ser reduzida (menor a $1 \mathrm{~dB}(\mathrm{~W} / \mathrm{MHz})$ ). Estas restrições aparacem principalmente na borda da região de operação (zonas de altas elevações), podendo chegar a reduções de 6 dB e 4 dB no caso de $D=115 \mathrm{~km}$ e $D=130 \mathrm{~km}$, respectivamente. Supondo un sistema que opere com uma densidade de potência igual a $-5 \mathrm{~dB}(\mathrm{~W} / \mathrm{MHz})$, ou seja, $0,32 \mathrm{~W} / \mathrm{MHz}$, não teria restrições quanto à potência toda a região de serviço se a distância $D=130 \mathrm{~km}$ for considerada. Se considerarmos $D=115 \mathrm{~km}$, as restrições impostas seriam da ordem de 0,3463 dB, o que significaria em uma diminuição possivelmente insignificante de densidade de potência. 


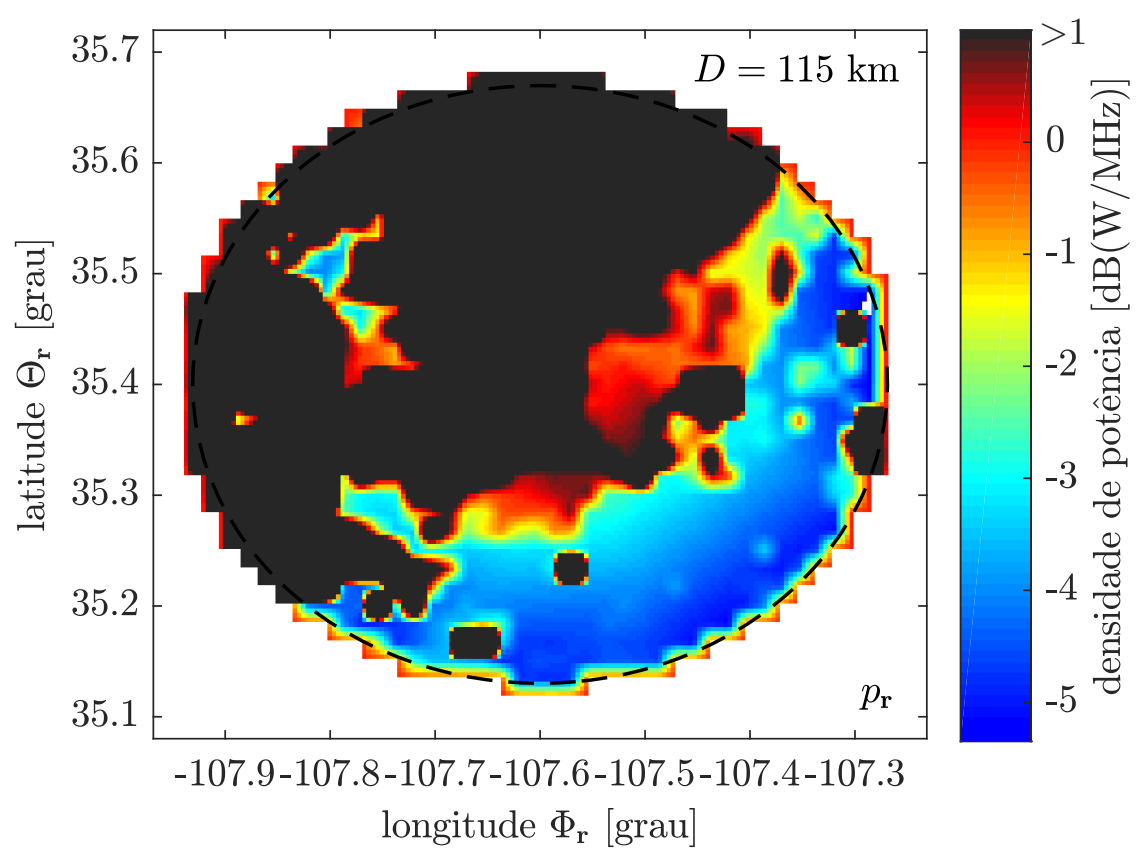

Figura 4.14: Máxima densidade de potência de transmissão das ESIM ( $D=115$ $\mathrm{km}$ ) na área de serviço (feixe recepção satélite GEO). A posição $\mathbf{r} \in \Omega_{\mathbf{r}}$ é caracterizada pela posição geográfica.

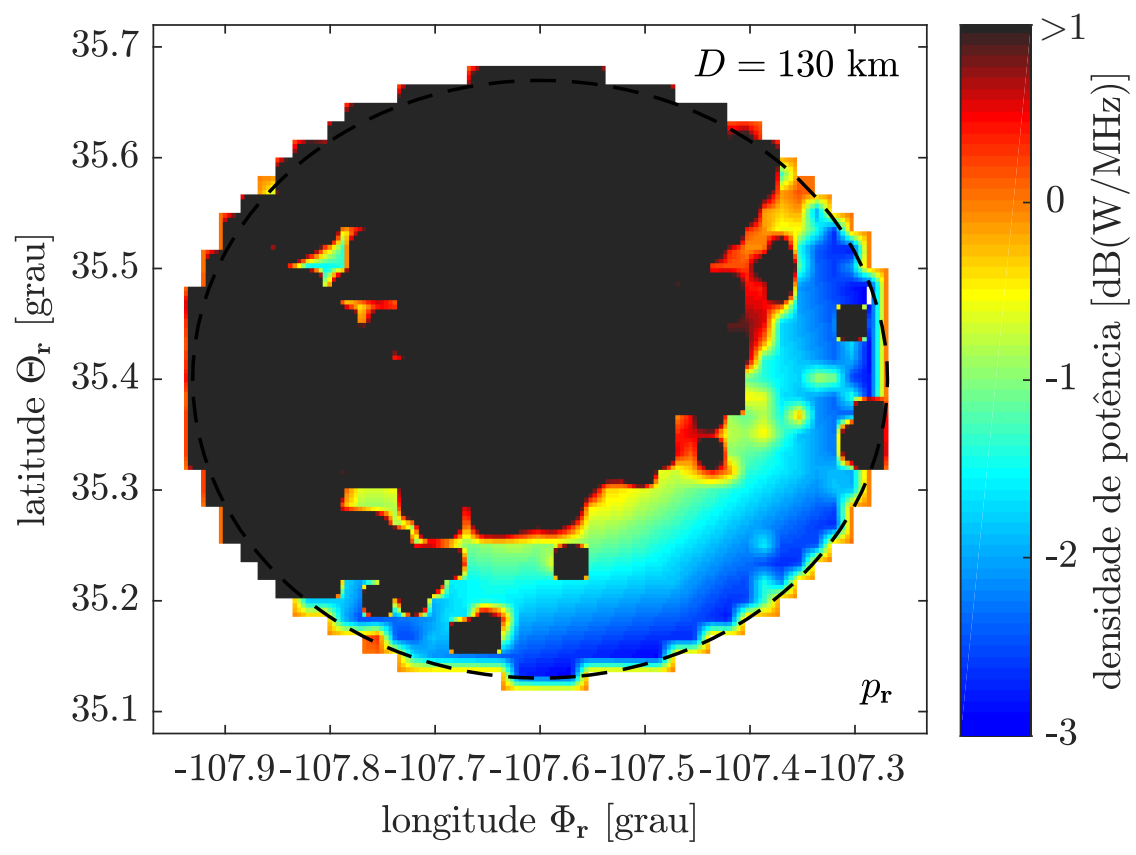

Figura 4.15: Máxima densidade de potência de transmissão das ESIM ( $D=130$ $\mathrm{km}$ ) na área de serviço (feixe recepção satélite GEO). A posição $\mathbf{r} \in \Omega_{\mathbf{r}}$ é caracterizada pela posição geográfica. 


\section{2}

\section{Região Plana}

A região plana considerada nesta seção refere-se a uma região geográfica em torno da longitude $98^{\circ} \mathrm{O}$ e latitude $41^{\circ} \mathrm{N}$, localizada no estado de Nebraska, no Estados Unidos, onde o nível do terreno varia de 300 a 900 metros aproximadamente. O relêvo desta região pode ser apreciado na Figura 4.16 onde, como referência, está indicada a localização da cidade de Lincoln. Na região foram avaliados dois cenários. Como no caso da região montanhosa, no primeiro cenário as estações interferentes (ESIM) se movem ao longo do trecho de uma rodovia e, no segundo, dentro da área de cobertura do feixe de recepção do satélite considerado. Em ambos os cenários, considerou-se o satélite do FSS servindo as ESIM na posição orbital $97^{\circ} \mathrm{O}$. Cada um dos cenários é avaliado nas subseções seguintes.

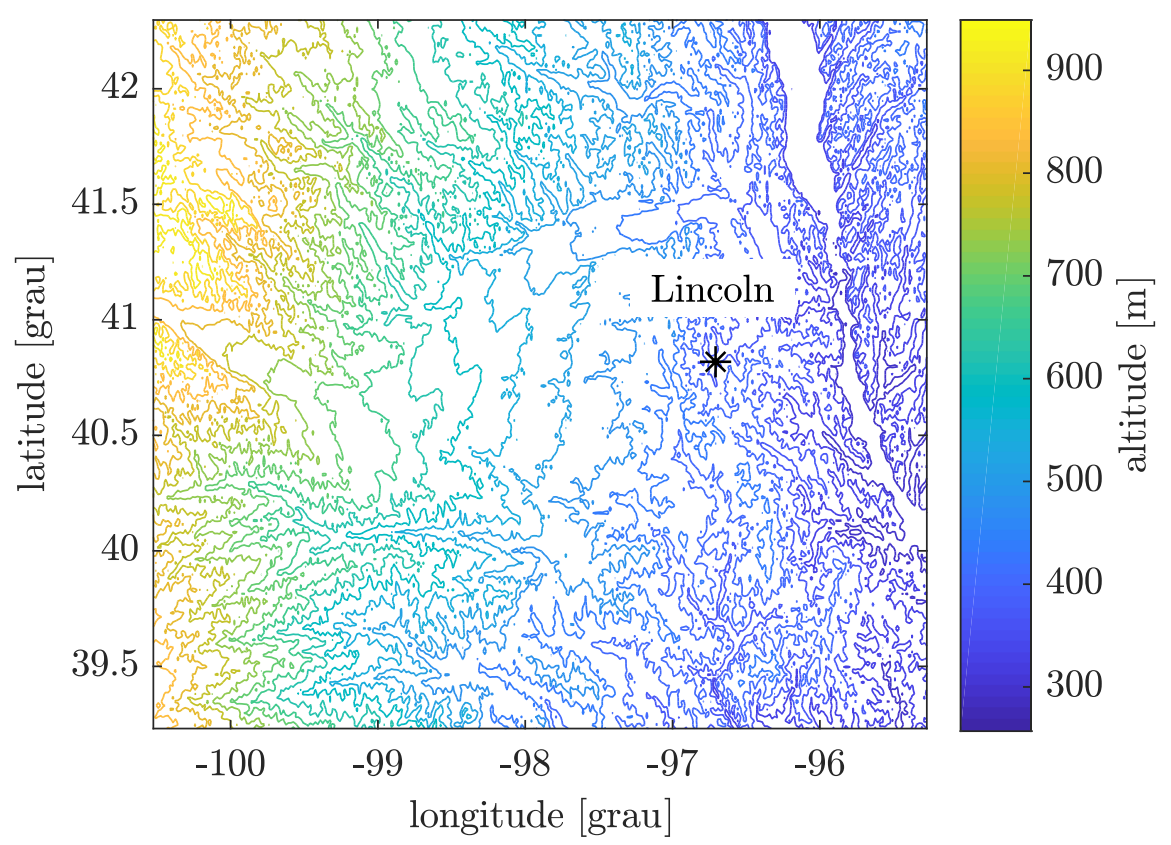

Figura 4.16: Relêvo da região plana localizada no estado de Nebraska, no Estados Unidos.

\subsection{1}

Zona de serviço do tipo rodovia ou linha ferroviária numa região predominantemente plana.

Neste cenário, considerou-se que as ESIM se movem ao longo de um trecho de aproximadamente $215 \mathrm{~km}$ da rodovia interestadual I-80, localizado entre as cidades de Kearney e Lincoln, conforme ilustrado na Figura 4.17. Para a implementação dos procedimentos descritos nas seções 3.3 e 3.4, as possíveis 
posições da ESIM ao longo da rodovia foram discretizadas em pontos espaçados de aproximadamente $1 \mathrm{~km}$ da mesma maneira que foi feito na implementação do exemplo amostrado na subseção 4.1.1 (região montanhosa).

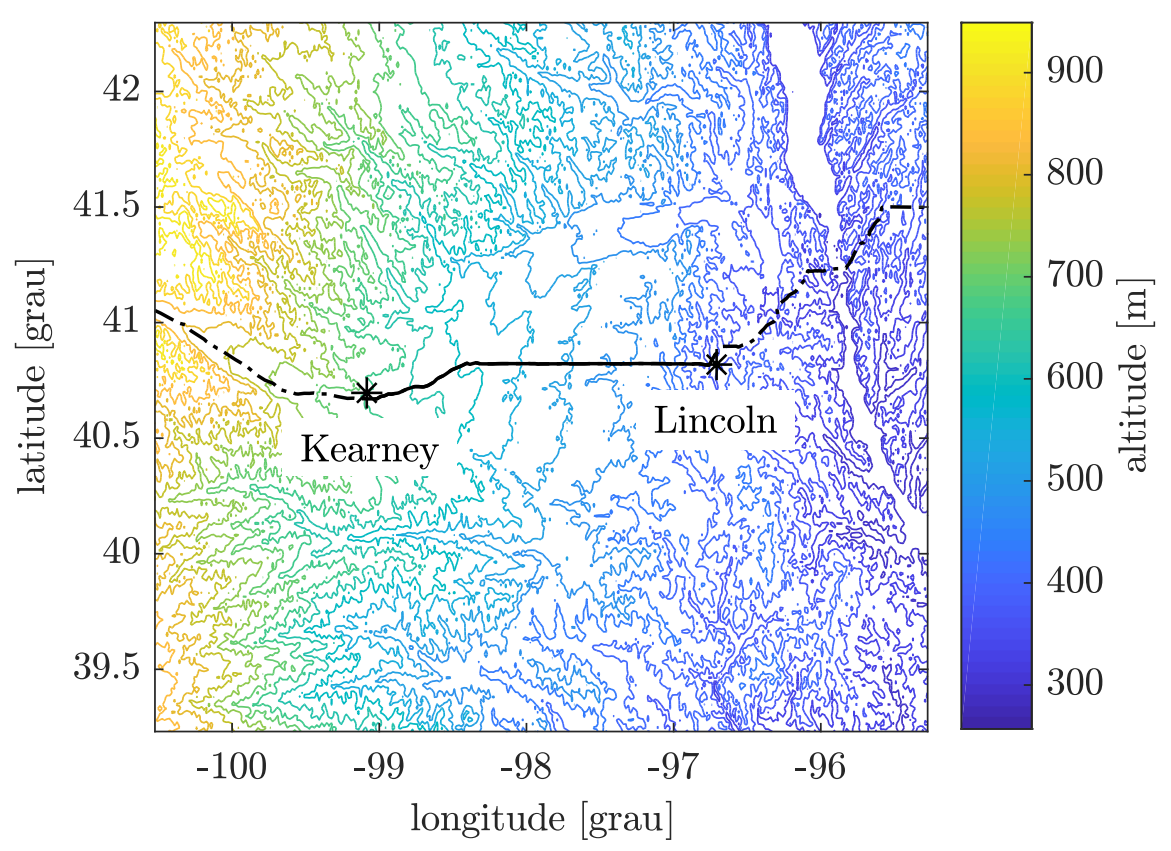

Figura 4.17: Parte da rodovia interestadual I-80 que cobre o percurso entre as cidades de Kearney e Lincoln no estado de Nebraska no Estados Unidos.

Os resultados obtidos pela aplicação do procedimento descrito na Seção 3.3 são apresentados na Figura 4.18. A Área de Coordenação $\mathcal{A}_{\Omega_{\mathrm{r}}}^{1}$, correspondente à restrição de longo prazo do critério de proteção $\left(p_{1}=0,2\right)$, é mostrada em vermelho. A Área de Coordenação $\mathcal{A}_{\Omega_{\mathrm{r}}}^{2}$, correspondente à restrição de curto prazo do critério de proteção $\left(p_{2}=5 \times 10^{-5}\right)$, é mostrada em preto. Note que a área de coordenação correspondente à restrição de longo prazo é novamente mais restritiva do que a área de coordenação correspondente à restrição de curto prazo. Neste exemplo pode-se notar que as áreas de coordenação correspondentes a ambos critérios (longo e curto prazo) são bastante distintas, diferentemente do que ocorreu no caso de região montanhosa (ver Figura 4.3), onde nos primeiros quilômetros as duas áreas eram aproximadamente coincidentes.

A aplicação do procedimento descrito na Seção 3.4 a este cenário conduziu às curvas ROC apresentadas nas figuras 4.19 e 4.20 para as restrições de longo e curto prazo do critério de proteção, respectivamente. Nas figuras 4.19 e 4.20 estão destacados os pontos da curva ROC associados a algumas distâncias $D$. Mais especificamente, são mostrados os pontos correspondentes a distâncias $D$ iguais a $0,10,31,2,90,100,114,2$ e $160 \mathrm{~km}$, além do ponto 


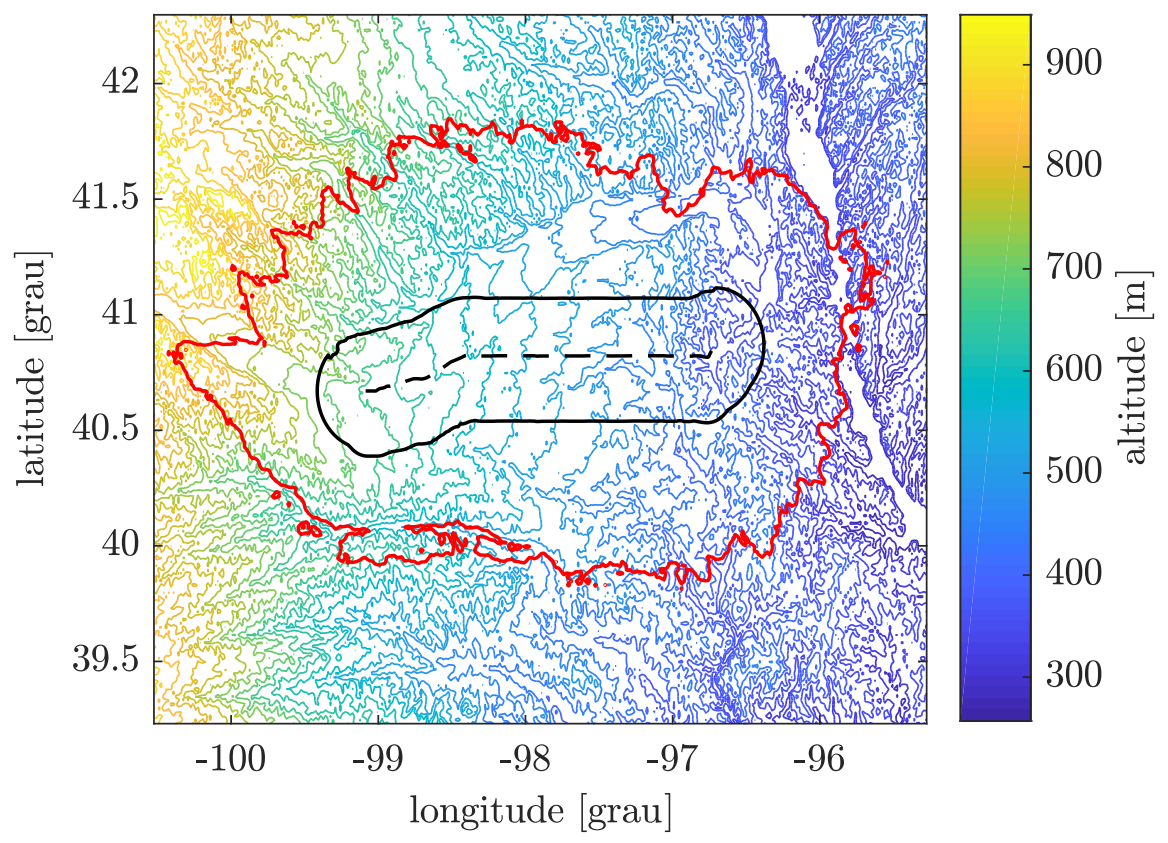

Figura 4.18: Áreas de Coordenação obtidas com o procedimento da Seção 3.3, para ESIMs operando em um trecho da rodovia I-80, numa região com topografia predominantemente plana. A linha vermelha corresponde ao critério de proteção de longo prazo $\left(p_{1}=0,2\right)$ e a linha preta ao critério de curto prazo $\left(p_{2}=5 \times 10^{-5}\right)$.

correspondente à distância $D$ infinita. Os valores de probabilidade de detecção e probabilidade de falso alarme associados a estas distâncias são apresentados na Tabela 4.4, para os dois critérios (longo e curto prazos).

Observe que, se o critério de curto prazo é considerado (Figura 4.20), a distância $D=31,2 \mathrm{~km}$ é, claramente, a mais adequada. Entretanto, novamente, se olharmos para a Figura 4.19 (critério de longo prazo), verificamos que esta distância, embora associada a uma probabilidade de falso alarme seja igual a cero, corresponde a uma probabilidade de detecção muito baixa $\left(P_{d}=0,2620\right)$. Assim, a distância $D$ deve ser escolhida com base no critério de longo prazo. A curva ROC da Figura 4.19 indica as distâncias $D=90 \mathrm{~km}$ e $D=100 \mathrm{~km}$ parecem ser as candidatas mais apropriadas, os contornos associados as áreas de coordenação alternativas $\left(\mathcal{A}_{\Omega_{\mathbf{r}}}(90)\right.$ e $\left.\mathcal{A}_{\Omega_{\mathbf{r}}}(100)\right)$, para estas distâncias estão ilustrados na Figura 4.21.

As figuras 4.22 e 4.23 apresentam os valores $p_{\mathbf{r}}^{j}$ da máxima densidade de potência que garante que a $j$-ésima condição do critério de proteção seja atendida, definida em (3-36), em função da posição $\mathbf{r} \in \Omega_{\mathbf{r}}$ da ESIM, para distâncias $D$ iguais a 90 e $100 \mathrm{~km}$, respectivamente. Nestas figuras, a posição $\mathbf{r} \in \Omega_{\mathbf{r}}$ é caracterizada pela distância ao longo da rodovia, medida a partir da 


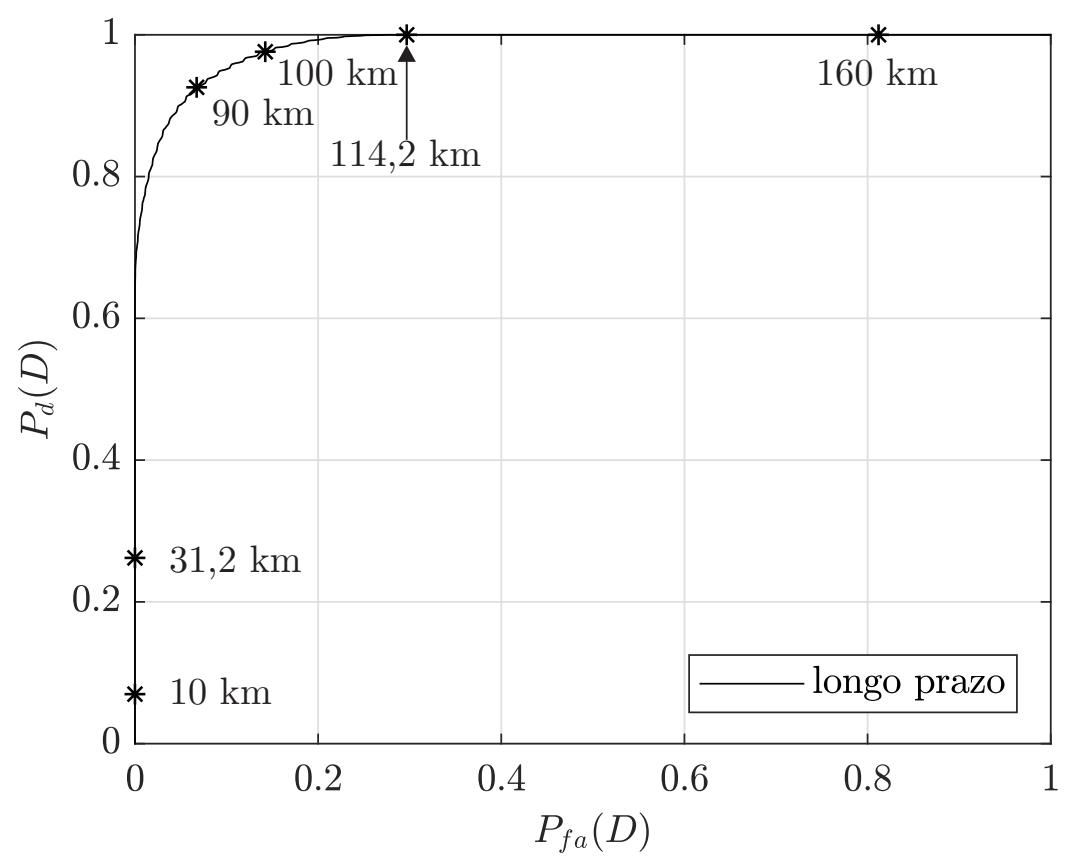

Figura 4.19: Curva ROC associada ao critério de longo prazo (região plana e área de serviço caracterizada por trecho de rodovia).

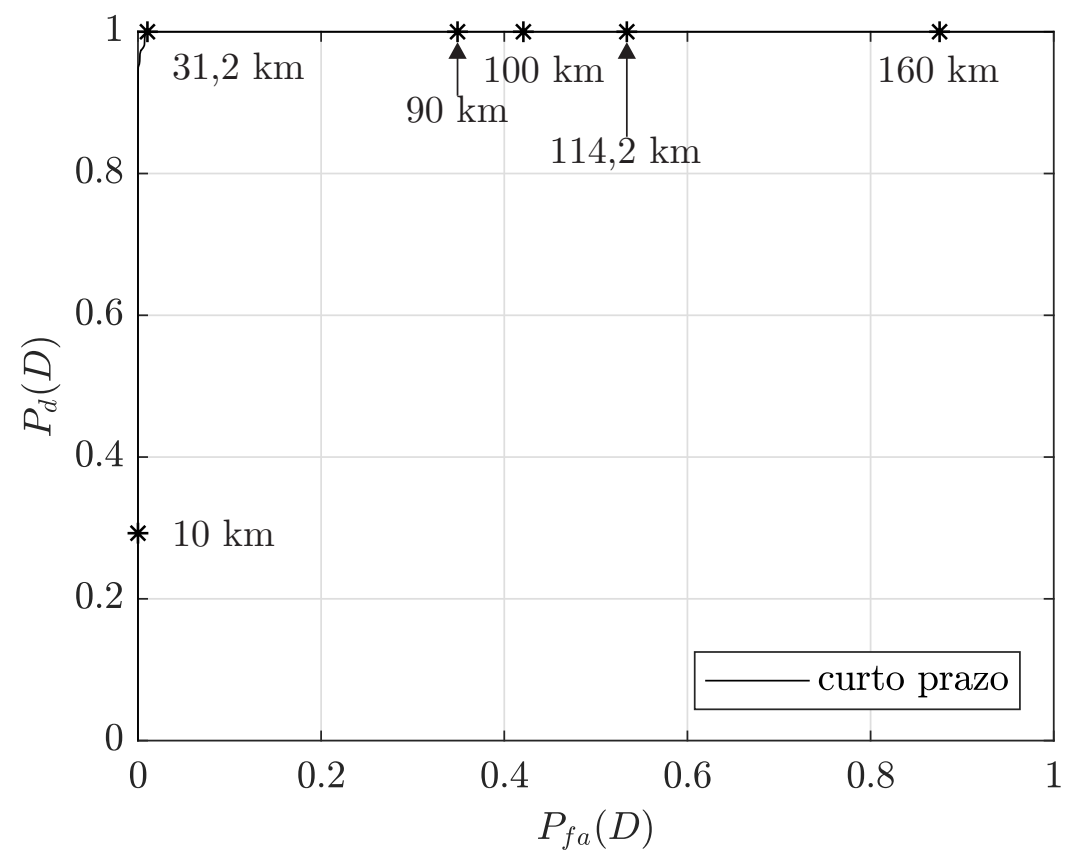

Figura 4.20: Curva ROC associada ao critério de curto prazo (região plana e área de serviço caracterizada por trecho de rodovia).

cidade de Kearney. A título de referência, está também indicado, em ambas as figuras, o nível de densidade de potência utilizado na determinação das áreas de coordenação $\left\{\mathcal{A}_{\Omega_{\mathbf{r}}}^{j} ; j=1,2\right\}$. Este nível de densidade de potência (nível 
Tabela 4.4: Probabilidades de falso alarme e probabilidades de detecção para as distâncias $D$ destacadas nas figuras 4.19 e 4.20 .

\begin{tabular}{||c|cc|cc||}
\hline \hline \multirow{2}{*}{ distância $D[\mathrm{~km}]$} & \multicolumn{2}{|c|}{ critério longo prazo } & \multicolumn{2}{c||}{ critério curto prazo } \\
\cline { 2 - 5 } & $P_{f a}$ & $P_{d}$ & $P_{f a}$ & $P_{d}$ \\
\hline \hline 0 & 0 & 0 & 0 & 0 \\
10 & 0 & 0,0698 & 0 & 0,2926 \\
31,2 & 0 & 0,2620 & 0,0103 & 1 \\
90 & 0,0674 & 0,9259 & 0,3490 & 1 \\
100 & 0,1423 & 0,9761 & 0,4209 & 1 \\
114,2 & 0,2967 & 1 & 0,5338 & 1 \\
160 & 0,8120 & 1 & 0,8754 & 1 \\
$\infty$ & 1 & 1 & 1 & 1 \\
\hline \hline
\end{tabular}

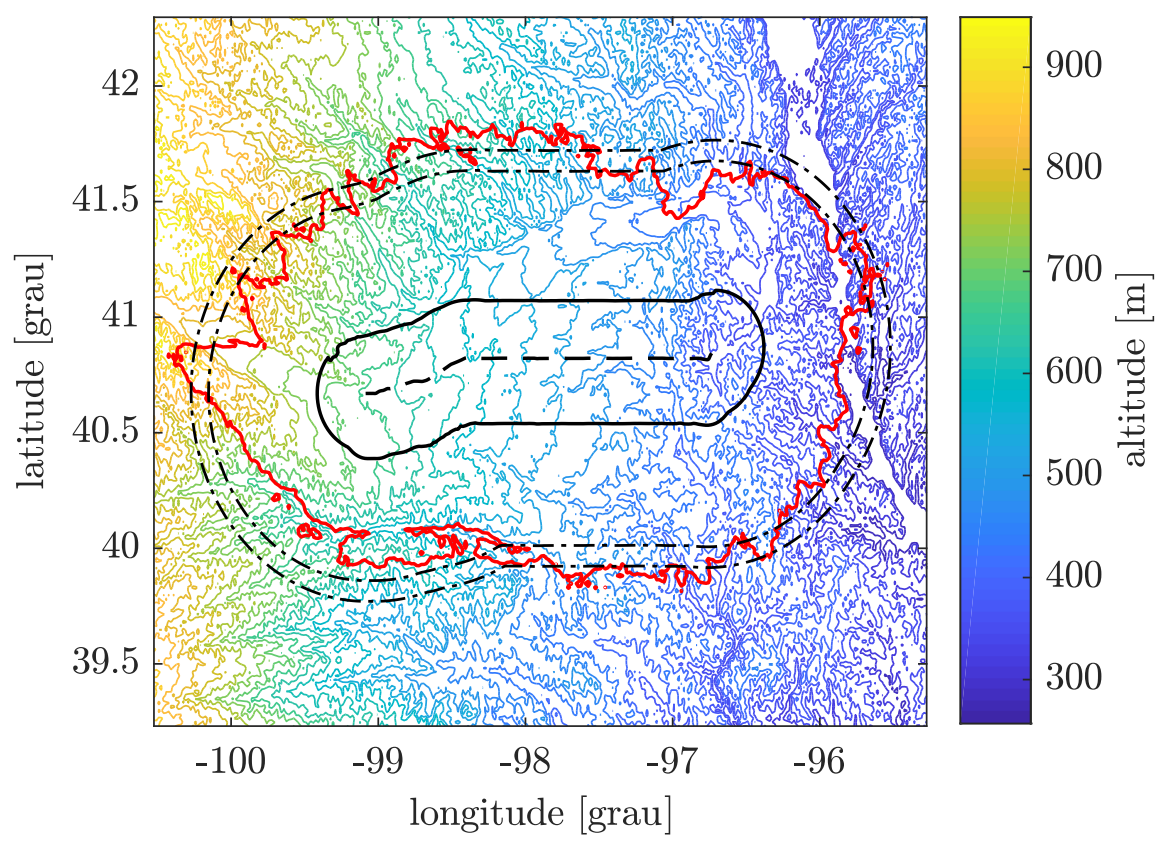

Figura 4.21: Áreas Pré-Especificada para distâncias $D=90 \mathrm{~km}$ e $D=100 \mathrm{~km}$ ao redor de uma rodovia numa região predominantemente plana.

máximo que garante o atendimento aos limites de emissão fora do eixo da Recomendação ITU-R S.524 [16]), obtido através do procedimento descrito no Apêndice $\mathrm{B}$, é igual a $1 \mathrm{~dB}(\mathrm{~W} / \mathrm{MHz})$ tanto para $j=1$ quanto para $j=2$.

Observe que, para sistemas que operam com a máxima densidade de potência permitida pela Recomendação ITU-R S.524 (1 dB(W/MHz)), tanto para $D=90 \mathrm{~km}$ quanto para $D=100 \mathrm{~km}$, as restrições à densidade de potência de transmissão são impostas pelo critério de longo prazo. Estas restrições aparecem, no caso $D=90 \mathrm{~km}$, praticamente na totalidade do trecho em analise. No caso $D=100 \mathrm{~km}$, as restrições à densidade de potência são mais 
reduzidas e afetam principalmente o trecho compreendido entre os quilômetros 40 e 125 partindo da cidade de Kearney. As reduções de densidade de potência podem chegar a $10 \mathrm{~dB}$ e $6 \mathrm{~dB}$ nos casos de $D=90 \mathrm{~km}$ e $D=100 \mathrm{~km}$, respectivamente. Obviamente, um sistema que opere com uma densidade de potência igual a $-5 \mathrm{~dB}(\mathrm{~W} / \mathrm{MHz})$, ou seja, $0,32 \mathrm{~W} / \mathrm{MHz}$, não teria restrições quanto à potência de transmissão ao longo de todo o percurso se a distância $D=100 \mathrm{~km}$ for considerada. Se considerarmos $D=90 \mathrm{~km}$, as restrições impostas seriam da ordem de $4 \mathrm{~dB}$ entre o quilômetro 40 e 70 da rodovia a partir da cidade de Kearney.

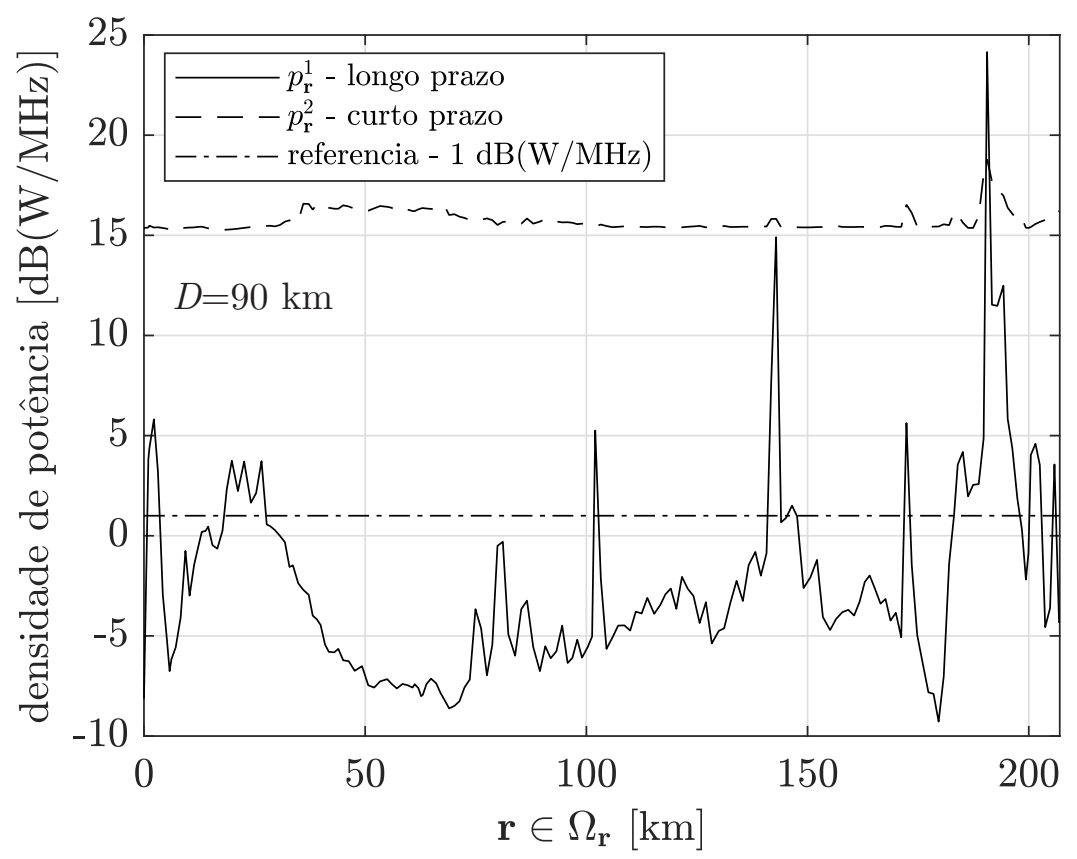

Figura 4.22: Máxima densidade de potência de transmissão das ESIM ao longo do trecho da rodovia I-80 considerado. A posição $\mathbf{r} \in \Omega_{\mathbf{r}}$ é caracterizada pela distância ao longo da rodovia, medida a partir da cidade de Kearney. 


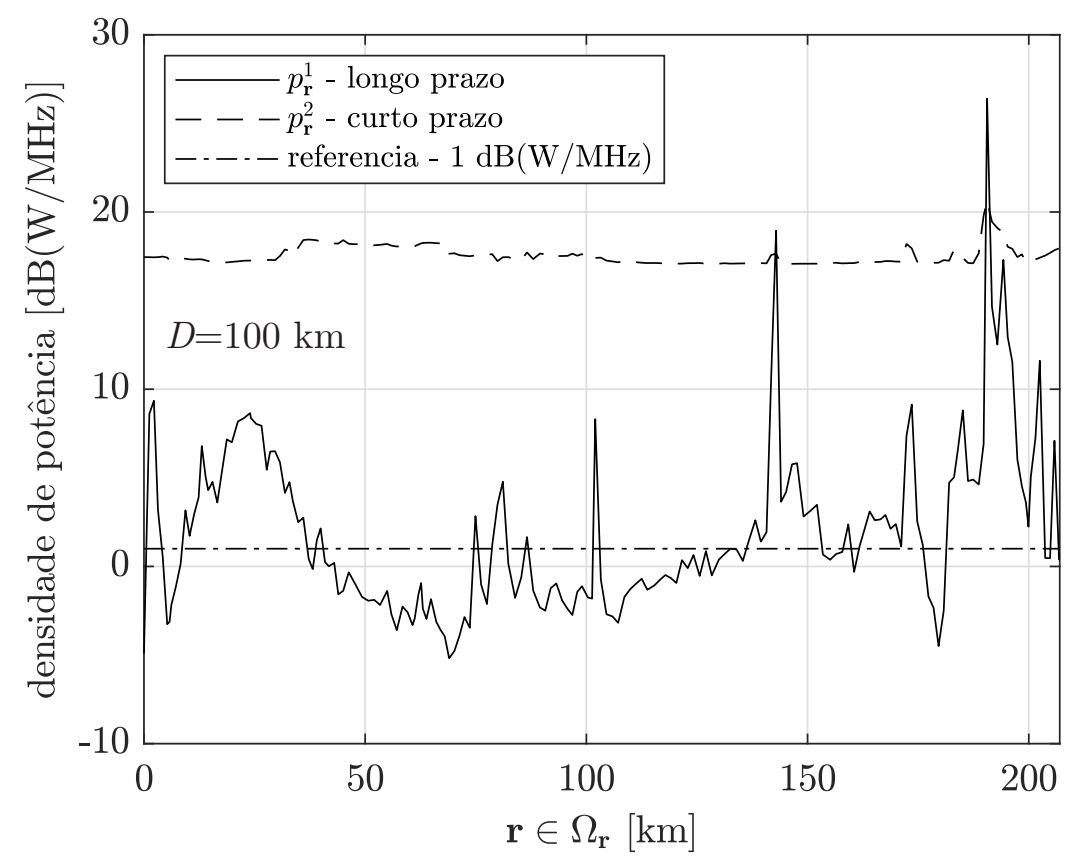

Figura 4.23: Máxima densidade de potência de transmissão das ESIM ao longo do trecho da rodovia I-80 considerado. A posição $\mathbf{r} \in \Omega_{\mathbf{r}}$ é caracterizada pela distância ao longo da rodovia, medida a partir da cidade de Kearney.

\section{2 .2}

Zona de serviço definida pelo feixe de recepção de um satélite geostacionário numa região predominantemente plana.

Neste cenário, considerou-se que as ESIM se movem dentro da área de cobertura do feixe de recepção de um satélite geostacionário, com centro na posição geográfica definida pela latitude $40,8^{\circ} \mathrm{N}$ e longitude $97,5^{\circ} \mathrm{O}$. Neste exemplo novamente, considerou-se um feixe com seção reta circular e contorno de $-3 \mathrm{~dB}$ na superfície da Terra com raio igual a $30 \mathrm{~km}$, cobrindo assim um área geográfica de aproximadamente $1414 \mathrm{~km}^{2}$. Conforme ilustrado na Figura 4.9, neste caso, a área de serviço $\Omega_{\mathbf{r}}$ encontra-se ao oeste da cidade de Albuquerque. Para a implementação dos procedimentos descritos nas seções 3.3 e 3.4, as possíveis posições da ESIM na região de serviço foram discretizadas numa grade de pontos espaçados de aproximadamente 1,8532 km em latitude e 1,5116 km em longitude.

Os resultados obtidos pela aplicação do procedimento descrito na Seção 3.3 são apresentados na Figura 4.25. A Área de Coordenação $\mathcal{A}_{\Omega_{\mathrm{r}}}^{1}$, correspondente à restrição de longo prazo do critério de proteção $\left(p_{1}=0,2\right)$, é mostrada em vermelho. A Área de Coordenação $\mathcal{A}_{\Omega_{\mathbf{r}}}^{2}$, correspondente à restrição de curto prazo do critério de proteção $\left(p_{2}=5 \times 10^{-5}\right)$, é mostrada em preto. Note que a área de coordenação correspondente à restrição de longo prazo é novamente 


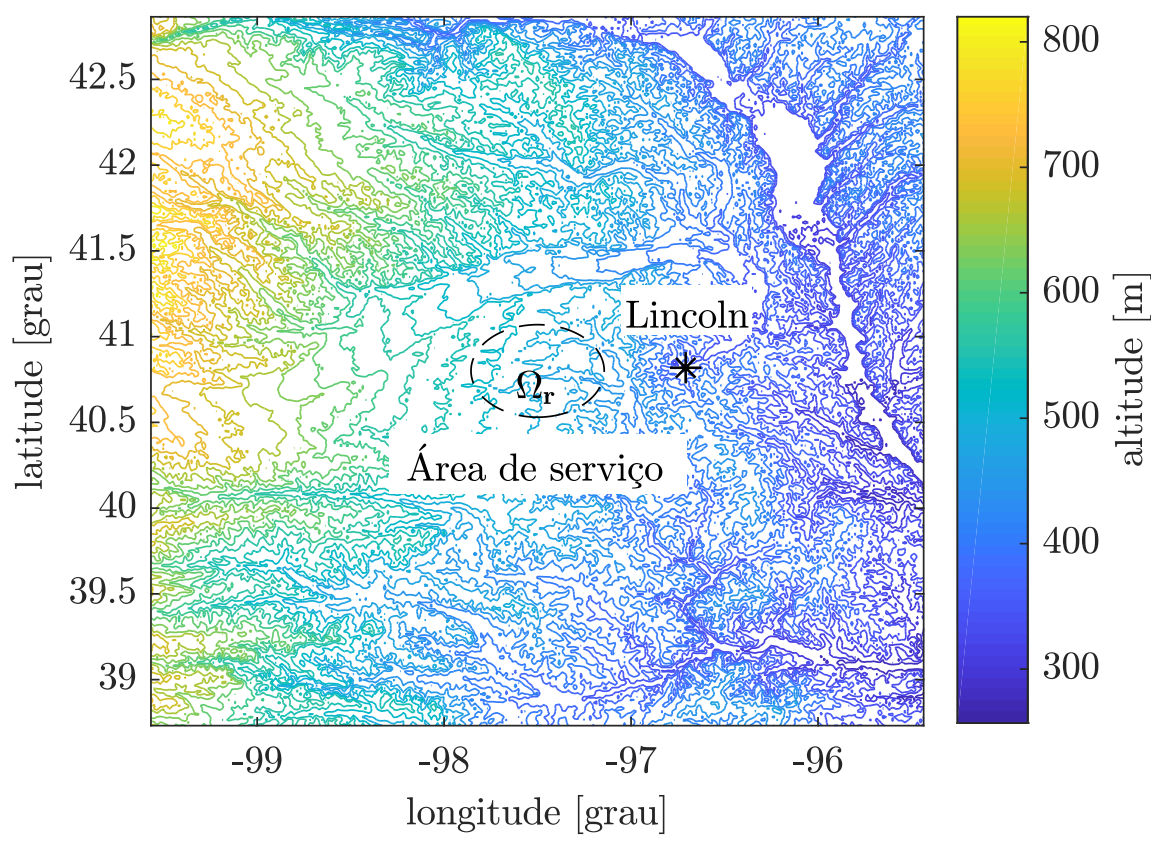

Figura 4.24: Área de serviço do feixe de recepção do satélite geostacionário com centro definido pela latitude $40,8^{\circ} \mathrm{N}$ e longitude $97,5^{\circ} \mathrm{O}$ no estado de Nebraska no Estados Unidos.

mais restritiva do que a área de coordenação correspondente à restrição de curto prazo. Observe na Figura 4.25, a diferença do que aconteceu no mesmo cenário (região montanhosa) ilustrado na Figura 4.10, neste caso não existe influência do relêvo da região no formato da Área de Coordenação para nenhum dos dois critérios (longo e curto prazo). As áreas de coordenação neste caso são definidas pela distância e a curvatura da terra principalmente.

A aplicação do procedimento descrito na Seção 3.4 a este cenário conduziu às curvas ROC apresentadas nas figuras 4.26 e 4.27 para as restrições de longo e curto prazo do critério de proteção, respectivamente. Nas figuras 4.26 e 4.27 estão destacados os pontos da curva ROC associados a algumas distâncias $D$. Mais especificamente, são mostrados os pontos correspondentes a distâncias $D$ iguais a $0,10,30,1,90,100,111,2$ e $160 \mathrm{~km}$, além do ponto correspondente à distância $D$ infinita. Os valores de probabilidade de detecção e probabilidade de falso alarme associados a estas distâncias são apresentados na Tabela 4.5, para os dois critérios (longo e curto prazos).

Observe que, se o critério de curto prazo é considerado (Figura 4.27), a distância $D=30,1 \mathrm{~km}$ é, claramente, a mais adequada. Entretanto, novamente, se olharmos para a Figura 4.26 (critério de longo prazo), verificamos que esta distância, embora associada a uma probabilidade de falso alarme igual a cero, corresponde a uma probabilidade de detecção muito baixa $\left(P_{d}=0,2291\right)$. 


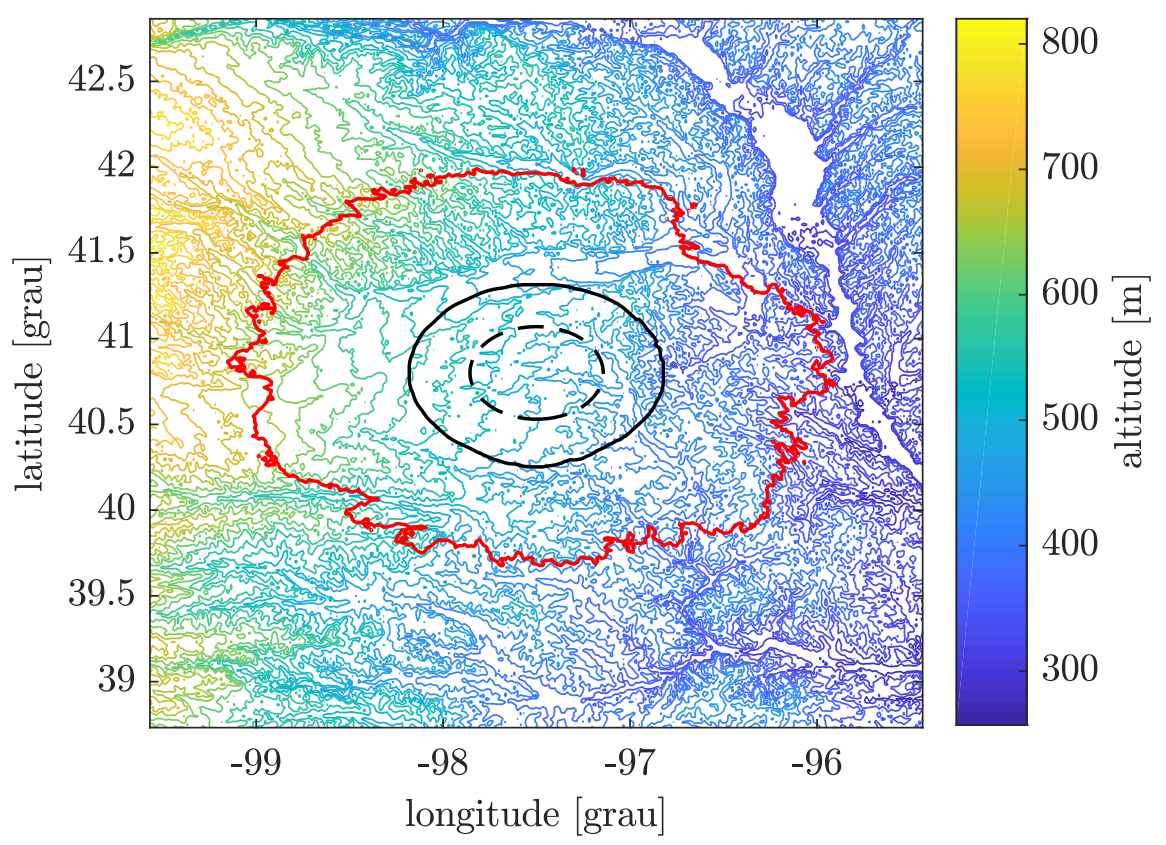

Figura 4.25: Áreas de Coordenação obtidas com o procedimento da Seção 3.3, para ESIMs operando numa região circular, com topografia predominantemente montanhosa. A linha vermelha corresponde ao critério de proteção de longo prazo $\left(p_{1}=0,2\right)$ e a linha preta ao critério de curto prazo $\left(p_{2}=5 \times 10^{-5}\right)$.

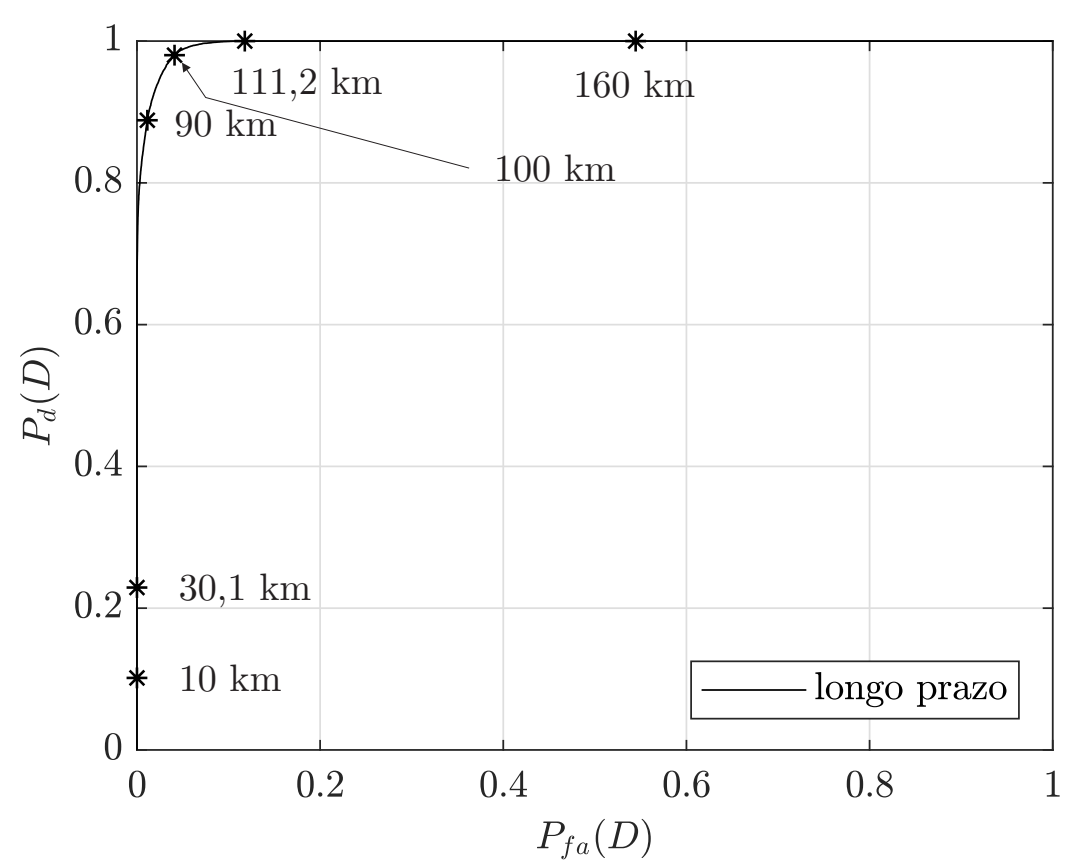

Figura 4.26: Curva ROC associada ao critério de longo prazo (região predominantemente plana e área de serviço caracterizada pelo feixe de recepção do satélite geostacionário). 


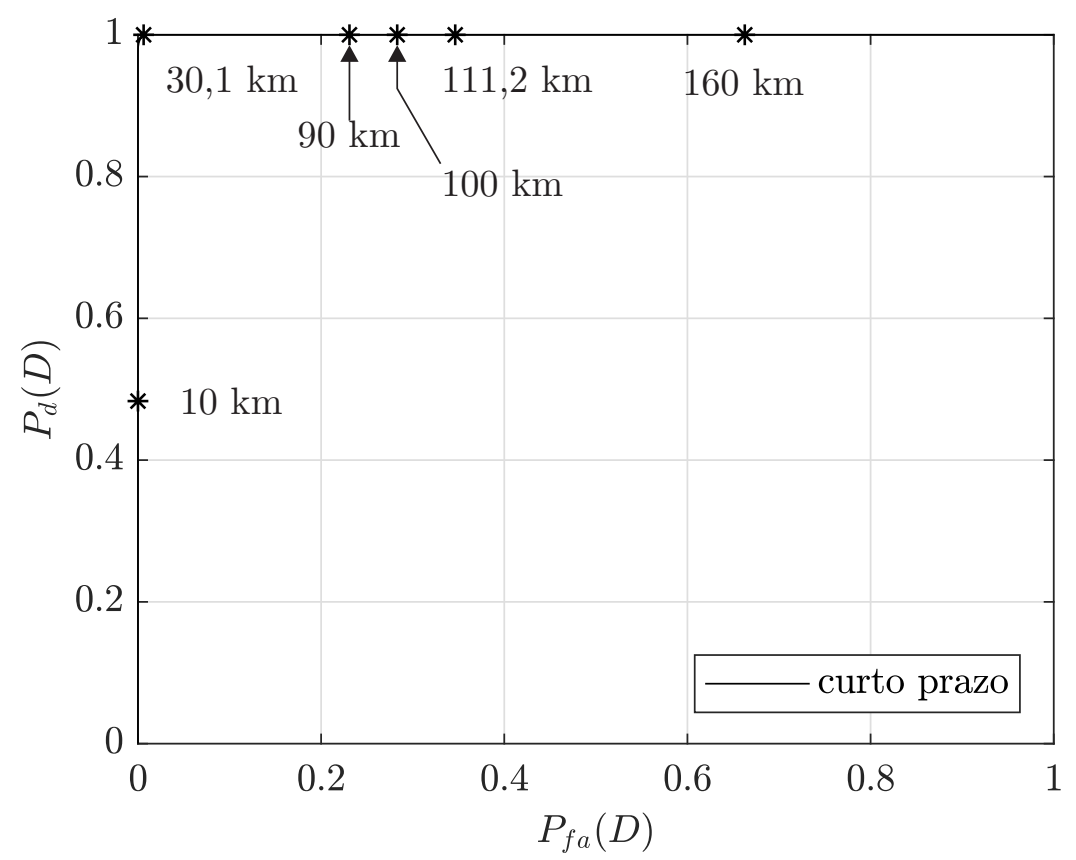

Figura 4.27: Curva ROC associada ao critério de curto prazo (região predominantemente plana e área de serviço caracterizada pelo feixe de recepção do satélite geostacionário).

Neste caso, como em todos os cenários abordados anteriormente, a distância $D$ deve ser escolhida com base no critério de longo prazo. A curva ROC da Figura 4.26 indica a distância $D=100 \mathrm{~km}$ como a mais apropriada. O contorno associado a área de coordenação alternativa $\left(\mathcal{A}_{\Omega_{\mathbf{r}}}(100)\right)$, está ilustrado na Figura 4.28.

Tabela 4.5: Probabilidades de falso alarme e probabilidades de detecção para as distâncias $D$ destacadas nas figuras 4.26 e 4.27 .

\begin{tabular}{||c|cc|cc||}
\hline \multirow{2}{*}{ distância $D[\mathrm{~km}]$} & \multicolumn{2}{|c|}{ critério longo prazo } & \multicolumn{2}{c||}{ critério curto prazo } \\
\cline { 2 - 5 } & $P_{f a}$ & $P_{d}$ & $P_{f a}$ & $P_{d}$ \\
\hline \hline 0 & 0 & 0 & 0 & 0 \\
10 & 0 & 0,1016 & 0 & 0,4833 \\
30,1 & 0 & 0,2291 & 0,0062 & 1 \\
90 & 0,0113 & 0,8883 & 0,2310 & 1 \\
100 & 0,0410 & 0,9801 & 0,2831 & 1 \\
111,2 & 0,1177 & 1 & 0,3464 & 1 \\
160 & 0,5446 & 1 & 0,6626 & 1 \\
$\infty$ & 1 & 1 & 1 & 1 \\
\hline \hline
\end{tabular}

A Figura 4.29 apresenta os valores da máxima densidade de potência $p_{\mathbf{r}}$ transmitida pela ESIM, definida em (3-37) e (3-36), em função da posição 


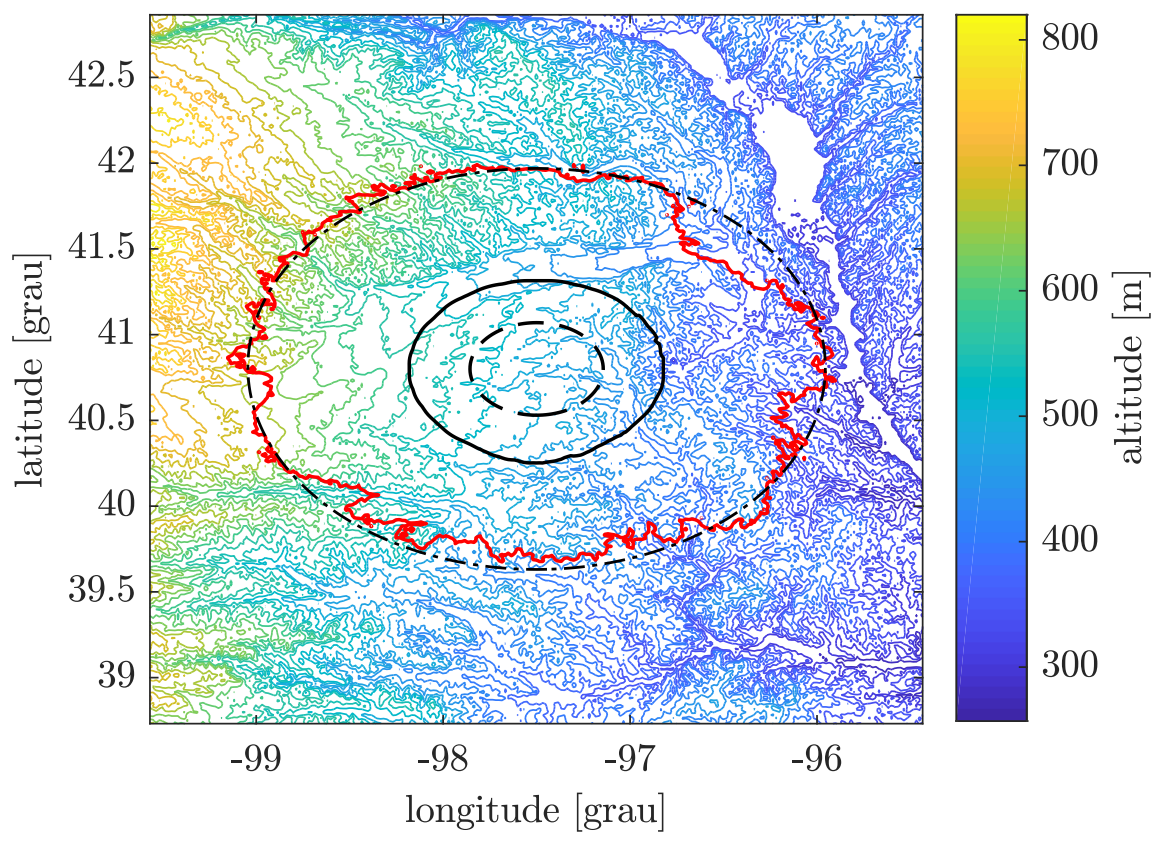

Figura 4.28: Área Pré-Especificada para distância $D=100 \mathrm{~km}$ ao redor de uma região de serviço circular.

$\mathbf{r} \in \Omega_{\mathbf{r}}$ da ESIM, para a distância $D$ igual a $100 \mathrm{~km}$. Na figura, a posição $\mathbf{r} \in \Omega_{\mathbf{r}}$ é caracterizada por sua latitude $\Theta_{\mathbf{r}}$ e sua longitude $\Phi_{\mathbf{r}}$. A título de referência, está indicada pela cor preta, a região onde a máxima densidade de potência transmitida pela ESIM pode ser maior do que nível de referencia. Este nível de densidade de potência, obtido através do procedimento descrito no Apêndice $\mathrm{B}$, é igual a $1 \mathrm{~dB}(\mathrm{~W} / \mathrm{MHz})$ tanto para $j=1$ quanto para $j=2$.

Observe que, para sistemas que operam com a máxima densidade de potência permitida pela Recomendação ITU-R S.524 (1 dB(W/MHz)), para $D=100 \mathrm{~km}$, existe um apequena região onde a densidade de potência de transmissão tem que ser reduzida (menor que $1 \mathrm{~dB}(\mathrm{~W} / \mathrm{MHz})$ ). Estas restrições aparecem principalmente na borda da região de operação, chegando a uma redução máxima $6 \mathrm{~dB}$ apenas na vizinhança da posição geográfica correspondente a $\Phi_{\mathbf{r}}=-97,21$ e $\Theta_{\mathbf{r}}=40,65$. 


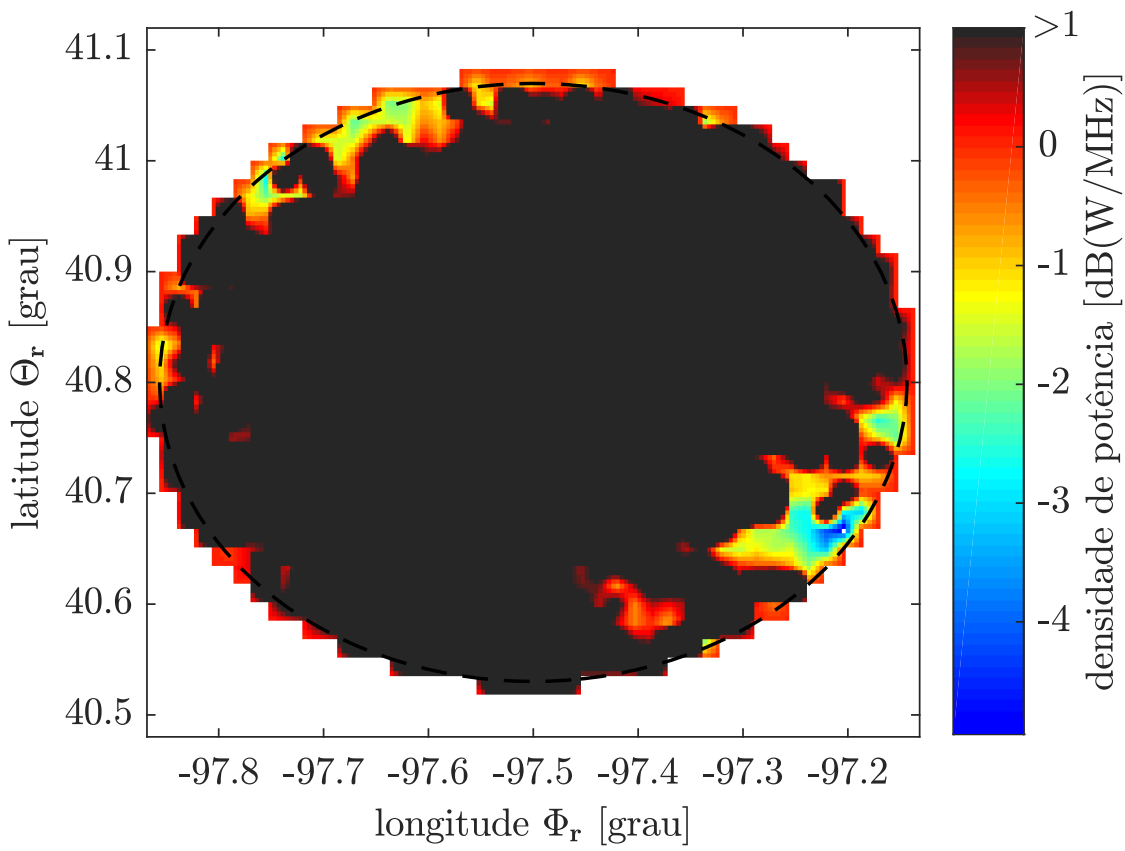

Figura 4.29: Máxima densidade de potência de transmissão das ESIM ( $D=100$ $\mathrm{km}$ ) na área de serviço (feixe recepção satélite GEO). A posição $\mathbf{r} \in \Omega_{\mathbf{r}}$ é caracterizada pela posição geográfica. 


\section{5}

\section{Conclusões}

O problema da proteção dos receptores do serviço fixo terrestre (FS) contra as interferências geradas por estações terrenas em movimento (ESIM), operando no Serviço Fixo por Satélite (FSS) e utilizando um satélite geoestacionário, foi analisado neste trabalho. Em particular considerou-se ESIMs operando na faixa de frequências $27,5-29,5 \mathrm{GHz}$, que é alocada, em caráter primário, a diversos serviços, entre eles FSS e o FS. Assim, é importante que a operação de qualquer um deles não cause interferência prejudicial aos demais. Dentro dessa premissa, a operação de ESIMs no FSS não pode produzir, nos receptores do FS, interferências inaceitáveis, podendo, por este motivo, ser necessária a coordenação entre os dois serviços.

Foram então determinadas Áreas de Coordenação ao redor da área de serviço onde as estações terrenas em movimento (ESIM) atuam. Estas áreas de coordenação foram definidas com base num critério de proteção que garante que receptores do FS localizados fora dela são dispensados do processo de coordenação. Embora tenham sido considerados os critério de proteção das recomendações ITU-R F.758-6 (longo prazo) e ITU-R SM.1448 (curto prazo), a metodologia de análise proposta neste trabalho é aplicável a eventuais novos critérios de proteção que venham a surgir como resultado dos estudos ora em desenvolvimento no âmbito do Grupo de Trabalho 5A da Comissão de Estudos 5 (Serviço Fixo Terrestre) do ITU-R.

Na determinação dessa áreas de coordenação foram utilizados os modelos de propagação da Recomendação ITU-R P.452-16 que abrangem enlaces em visada direta, perdas por difração, espalhamento troposférico e dutos.

No trabalho considerou-se, inicialmente, que as ESIM operam com a mesma densidade de potência em toda a área de serviço (maior densidade de potência que satisfaz os limites de densidade de e.i.r.p. da Recomendação ITU-R S.524-9). Devido ao relevo do terreno as áreas de coordenação obtidas tendem a ter uma forma bastante complexa, sendo assim de difícil aplicação em procedimentos regulamentares. Em consequência disso, foi proposta, neste trabalho, uma Área de Coordenação Alternativa de mais fácil aplicação pratica, baseada em uma distância fixa $D$, previamente estabelecida. Para a determinação da distância $D$ que define a Área de Coordenação Alternativa, 
foi proposta uma metodologia baseada em curvas do tipo ROC para a escolha do valor de $D$ mais adequado.

Ao se utilizar esta área de coordenação alternativa, podem surgir situações não desejáveis onde, de acordo com a área de coordenação alternativa, um receptor do FS esteja dispensado do processo de coordenação quando, na verdade, a área de coordenação real indica a necessidade de coordenação. Este problema pode ser contornado se for imposta uma redução, dependente da localização da ESIM, à sua potência de transmissão. Foi então feita uma análise para determinar o valor da redução de potência em cada ponto da área de serviço das ESIM.

A teoria desenvolvida foi aplicada a cenários envolvendo diferentes tipos de relêvo e diferentes tipos de áreas de serviço. Em termos de áreas de coordenação, verificou-se que, em todos os casos, o critério de proteção de longo prazo mostrou-se mais restritivo, produzindo, em geral, áreas de coordenação maiores do que aquelas produzidas pelo critério de curto prazo. Também no caso da redução de potência, verificou-se que o critério de proteção de longo prazo impunha reduções de potência maiores do que as impostas pelo critério de curto prazo. Os resultados permitiram ainda avaliar o efeito do relêvo, nas áreas de coordenação. 


\section{Referências bibliográficas}

[1] Operation of earth stations in motion (ESIM) communicating with geostationary space stations in the fixed-satellite service allocations at 17.7-19.7 GHz and 27.5-29.5 GHz, 2016. Annex 16 to Working Party 4A Chairman Report.

[2] Provisions relating to earth stations located on board vessels which operate in fixed-satellite service networks in the uplink bands 5925- $6425 \mathrm{MHz}$ and 14-14.5 GHz., 2003. Resolução 902.

[3] Technical and operational requirements for GSO FSS earth stations on mobile platforms in bands from 17.3 to $30.0 \mathrm{GHz}$, 2011. Report ITU-R S.2223.

[4] Technical and operational guidelines for earth stations on mobile platforms communicating with geostationary space stations in the fixed-satellite service in the frequency bands $19.720 .2 \mathrm{GHz}$ and 29.5-30.0 GHz., 2015. Report ITU-R S.2357.

[5] Use of the frequency bands 17.7-19.7 GHz (space-to-Earth) and 27.5-29.5 GHz (Earth-to-space) by earth stations in motion communicating with geostationary space stations in the fixedsatellite service., 2015. Resolução 158.

[6] Technical and Operational Characteristics of Earth stations in motion in the 27.5-29.5 GHz and 17.7-19.7 GHz bands., 2016. Documento 4A/155.

[8] Operation of earth stations in motion (ESIM) in fixed-satellite service allocations at 17.7-19.7 GHz and 27.5-29.5 GHz., 2016. Documento $4 \mathrm{~A} / 27$.

[9] Methodology to estimate the interference from land-based ESIMs when the FS terminal characteristics and location are known, 2016. Annex 11 to Document 4A/63-E.

[10] Methodology to estimate the e.i.r.p. density levels of land-based earth stations in motion (ESIMs) to ensure compliance with 
coordination distance limits and power flux density limits with respect to fixed service stations operating in the $27.5-29.5 \mathrm{GHz}$ frequency band, 2017. Annex 11 to Document 4A/364-E.

[11] Methods for the determination of the coordination area around an earth station in frequency bands between $100 \mathrm{MHz}$ and 105 GHz. Apêndice 7.

[12] Determination of the coordination area around an Earth station in the frequency bands between $100 \mathrm{MHz}$ and $105 \mathrm{GHz}$, May 2000. Recommendation ITU-R SM.1448.

[13] System parameters and considerations in the development of criteria for sharing or compatibility between digital fixed wireless systems in the fixed service and systems in other services and other sources of interference, September 2015. Recommendation ITU-R F.758-6.

[14] Mathematical model of average and related radiation patterns for line-of-sight point-to-point radio-relay system antennas for use in certain coordination studies and interference assessment in the frequency range from $1 \mathrm{GHz}$ to about $70 \mathrm{GHz}$, May 2000 . Recommendation ITU-R F.1245-1.

[15] Reference radiation pattern for earth station antennas in the fixed-satellite service for use in coordination and interference assessment in the frequency range from 2 to $31 \mathrm{GHz}$, January 2010. Recommendation ITU-R S.465-6.

[16] Maximum permissible levels of off-axis e.i.r.p. density from earth stations in geostationary-satellite orbit networks operating in the fixed-satellite service transmitting in the $6 \mathrm{GHz}, 13 \mathrm{GHz}$, $14 \mathrm{GHz}$ and $30 \mathrm{GHz}$ frequency bands, 2006.

[17] Prediction procedure for the evaluation of interference between stations on the surface of the Earth at frequencies above about $0.1 \mathrm{GHz}, 2015$. 
A

\section{Procedimento para determinar o valor $L$ da perda de propa- gação que não é excedido durante $P \%$ do tempo.}

O procedimento empregado neste trabalho para determinar as perdas de propagação não excedida durante o $P \%$ do tempo é abordado na Recomendação ITU-R P.452-16 [17], onde são descritos métodos de predição para avaliar a interferência entre estações situadas na superfície da Terra em frequências desde $0,1 \mathrm{GHz}$ até $50 \mathrm{GHz}$.

Na recomendação, são abordadas duas metodologias para a predição da interferência:

- predição da interferência em céu claro

- predição da interferência por dispersão devida a hidrometeoros.

Os modelos fornecidos na recomendação P.452-16 aplicam-se baixo a hipótese de que o transmissor interferente e o receptor interferido funcionam dentro da capa de superfície da atmosfera. Estes modelos são adequados para calcular as perdas de propagação não excedida durante porcentagens de tempo na gama de $0,001 \leq P \leq 50 \%$, também são apresentados métodos para analisar as características radiometeorológicas e topográficas do percurso o que permite a formulação de uma predição para qualquer tipo de percurso de interferência até uma distancia limite de $10000 \mathrm{~km}$.

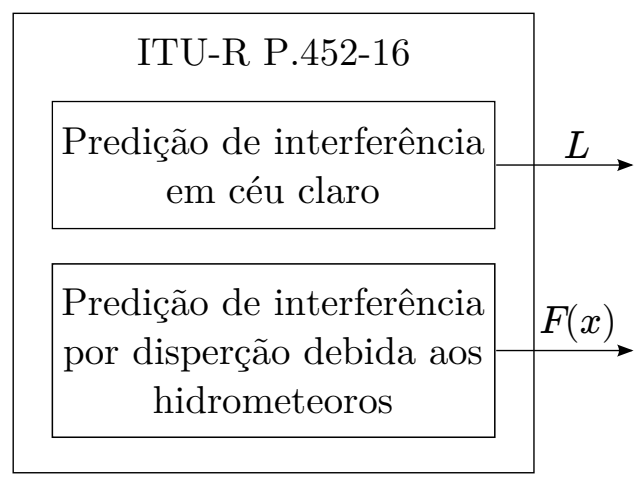

Figura A.1: Metodologias abordadas na recomendação ITU-R P.542-16.

A metodologia empregada neste trabalho para determinar as perdas não excedidas durante $P \%$ do tempo é aquela que supõe condições de céu claro, 
Apêndice A. Procedimento para determinar o valor $L$ da perda de propagação que não é excedido durante $P \%$ do tempo.

o método abrange modelos para as perdas ocasionadas pela difração, reflexão nas camadas e propagação por dutos e dispersão troposférica. Os três modelos são aplicados em cada caso independentemente de que o percurso seja com visibilidade direita ou trans-horizonte. Logo combinam-se os resultados em uma predição global utilizando uma técnica de fusão para obter finalmente um resultado da perda, procedimento no qual se têm em conta os cinco tipos básicos de propagação (visibilidade direita, difração, reflexão e refração nas camadas atmosféricas, espalhamento troposférico, e perdas devidas ao ambiente em torno das estações).

Neste apêndice é apresentado um resumo da metodologia para a predição da interferência em céu claro. Na Figura A.2 é mostrado um diagrama em blocos das seções da metodologia onde fica a formulação toda para determinar as perdas não excedida durante o $p \%$ do tempo, cada uns dos blocos é discutido nas seções seguintes.

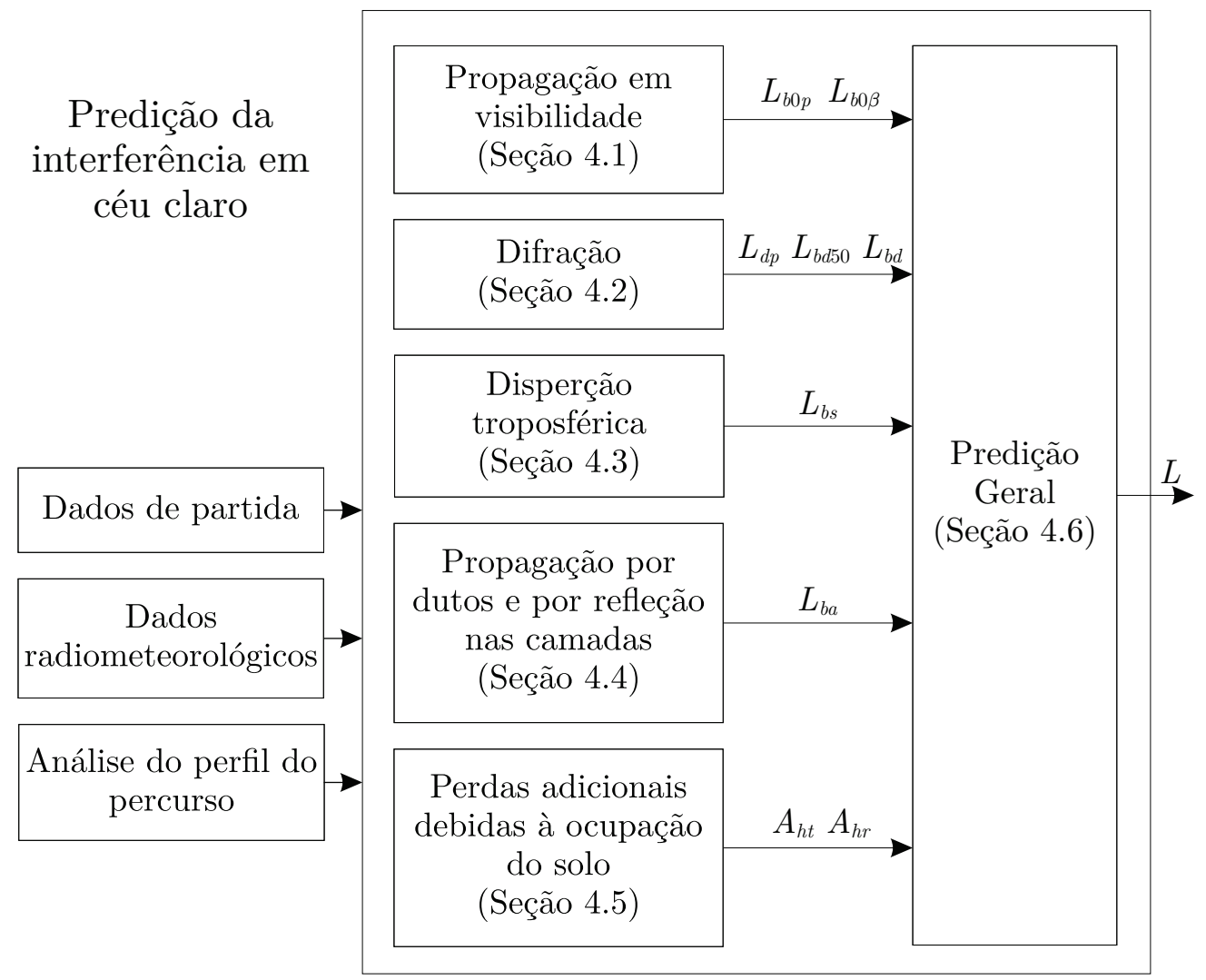

Figura A.2: Procedimento usado para a determinação da perda básica não excedida segum a recomendação UIT P.452-16. 
Apêndice A. Procedimento para determinar o valor $L$ da perda de propagação que não é excedido durante $P \%$ do tempo.

\section{A.1 \\ Dados de partida}

Os dados básicos de partida necessários ao aplicar o procedimento para determinar as perdas não excedidas durante o p\% do tempo em condições de céu claro são as seguintes:

- $f$ : frequência $[\mathrm{GHz}]$

- p: porcentagem de tempo requerido durante o qual não é excedido a perda básica de transmissão [\%]

- $\varphi_{t}$ : latitude da estação interferente [grau]

- $\psi_{t}$ : longitude da estação interferente [grau]

- $\varphi_{r}$ : latitude da estação interferida [grau]

- $\psi_{r}$ : longitude da estação interferida [grau]

- $h_{t g}$ : altura da antena interferente sobre o nível do solo [m]

- $h_{r g}$ : altura da antena interferida sobre o nível do solo [m]

- $G_{t}$ : ganho da antena interferente na direção do horizonte ao longo do percurso ortodrômico $[\mathrm{dBi}]$

- $G_{r}$ : ganho da antena interferida na direção do horizonte ao longo do percurso ortodrômico $[\mathrm{dBi}]$

- Pol: polarização do sinal

\section{A. 2}

\section{Dados radiometeorológicos}

O modelo de predição usa três parâmetros radiometeorológicos para descrever a variabilidade das condições de propagação de fundo e anômala nos diferentes lugares do mundo.

- $\Delta N$ : representa a taxa de variação do índice de refratividade médio com a altura, ao longo de primeiro quilômetro da atmosfera. A Figura A.3 fornece as curvas do valor médio anual de $\Delta N$ no mundo ( $\mathrm{N}$ unidades $/ \mathrm{km}$ )

- $\beta_{0}$ : a porcentagem de tempo no qual pode espera-se, nos primeiros $100 \mathrm{~m}$ de uma atmosfera baixa, sobretaxas da variação da refração superiores a 100 N-unidades/km (\%)

- $N_{0}$ : descreve o valor da refratividade ao nível do mar. A Figura A.4 fornece as curvas deste valor no mundo (N-unidades) 
Apêndice A. Procedimento para determinar o valor $L$ da perda de propagação que não é excedido durante $P \%$ do tempo.

Os valores $\Delta N$ e $N_{0}$ usados foram obtidos a partir dos ficheiros (DN50.txt, LAT.txt, LON.txt e N050.txt) fornecidos pela recomendação UITR P.452-16. O valor $\beta_{0}$ foi obtido a partir do procedimento fornecido pela recomendação. Logo a partir do valor de $\Delta N$ obtido é encontrado o raio efetivo da Terra $\left(a_{e}\right.$ e $\left.a_{\beta}\right)$ parâmetros necessários para o analise do percurso e para a aplicação da metodologia de predição da interferência em condições de céu claro resumidos nas seguintes seções.

\section{A.3}

\section{Análise do perfil do percurso}

Certos parâmetros relacionados com o percurso são necessários para a aplicação da metodologia usada neste trabalho, os quais são obtidos a partir do analise do perfil do percurso como é descrito no apêndice 2 do anexo 1 da recomendação UIT-R P.452-16 e resumido neste apêndice. A partir do analise do perfil do percurso são obtidos:

- $d$ : distância total do percurso $[\mathrm{km}]$

- $d_{i}$ : distância ao i-ésimo ponto a partir da estação interferente [km]

- $h_{i}$ : altura do i-ésimo ponto do terreno sobre o nível do mar [m]

- $h_{t s}$ : altura da antena interferente sobre o nível do mar [m]

- $h_{r s}$ : altura da antena interferida sobre o nível do mar [m]

- $\theta_{t}$ : trajeto transhorizonte - ângulo de elevação do horizonte em relação ao horizonte local (mrad) medido desde a antena interferente, trajeto visibilidade direita - elevação na direção da antena interferida [mrad]

- $\theta_{r}$ : trajeto transhorizonte - ângulo de elevação do horizonte em relação ao horizonte local (mrad) medido desde a antena interferida, trajeto visibilidade direita - elevação na direção da antena interferente [mrad]

- $d_{l t}$ : trajeto transhorizonte - distância desde a antena interferente a seu horizonte, trajeto visibilidade direita - distância desde a antena interferente ao ponto do perfil identificado como o obstaculo principal $[\mathrm{km}]$

- $d_{l r}$ : trajeto transhorizonte - distância desde a antena interferida a seu horizonte, trajeto visibilidade direita - distância desde a antena interferida ao ponto do perfil identificado como o obstaculo principal [km]

- $\theta$ : distancia angular do percurso [mrad]

- $h_{s t}$ : altura da superfície no modelo de Terra lisa na posição da antena interferente $[\mathrm{m}]$ 
Apêndice A. Procedimento para determinar o valor $L$ da perda de propagação que não é excedido durante $P \%$ do tempo.

- $h_{s r}$ : altura da superfície no modelo de Terra lisa na posição da antena interferida $[\mathrm{m}]$

- $h_{s t d}$ : altura efetiva da antena interferente para o modelo de difração [m]

- $h_{\text {srd }}$ : altura efetiva da antena interferida para o modelo de difração [m]

- $h_{t e}$ : altura efetiva da antena interferente para o modelo de propagação por dutos $[\mathrm{m}]$

- $h_{r e}$ : altura efetiva da antena interferida para o modelo de propagação por dutos $[\mathrm{m}]$

$-h_{m}$ : rugosidade do terreno $[\mathrm{m}]$

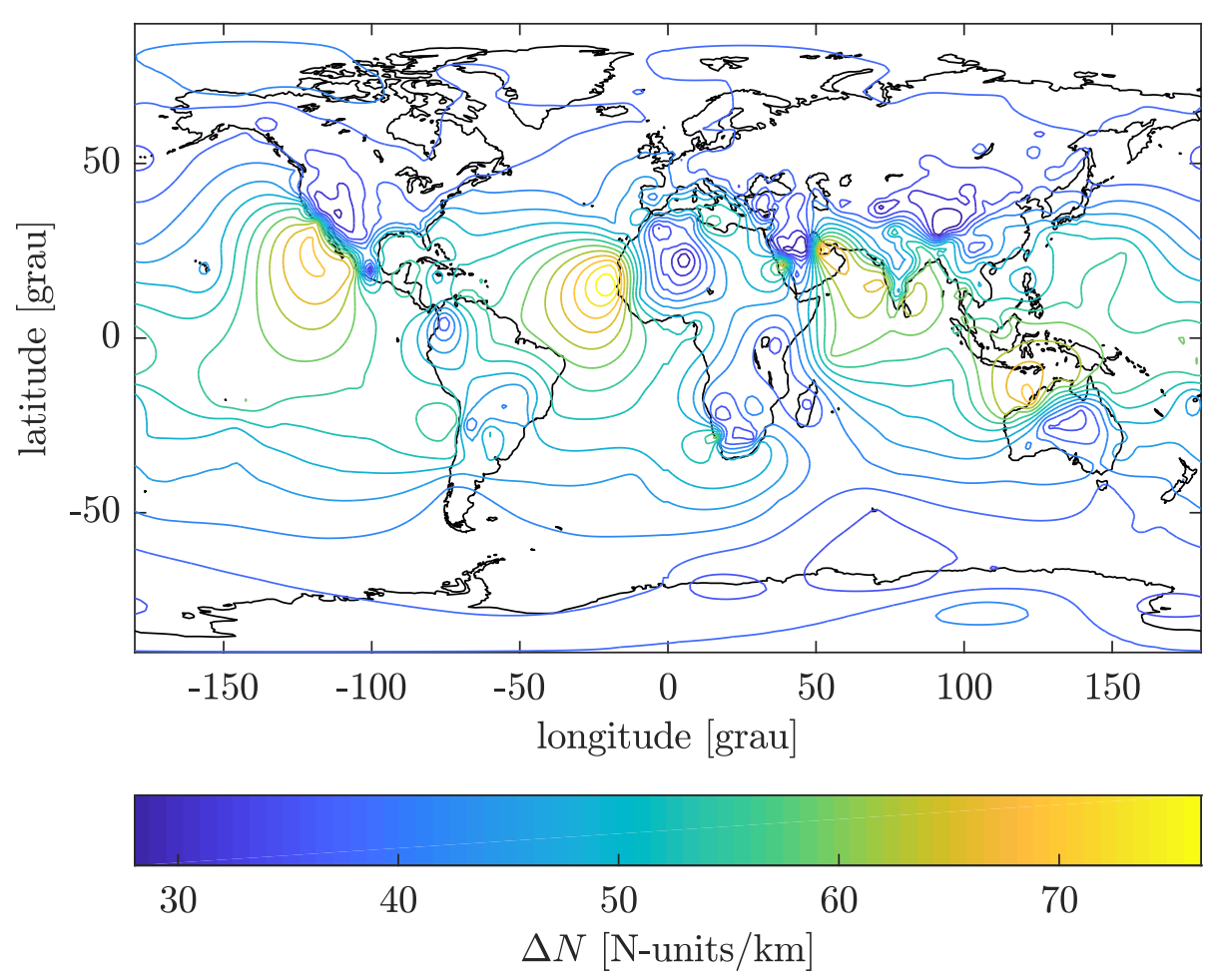

Figura A.3: Valor anual médio de $\Delta N$ (proporção de variação do índice de refracção no primeiro quilômetro da atmosfera).

A recomendação considera o ponto do perfil do percurso na estação interferente como ponto zero e o ponto na estação interferida como ponto $n$, assim o perfil do percurso se compone de $n+1$ pontos. A Figura A. 5 fornece um exemplo de um perfil do percurso do sinal transmitido, sendo apresentados alguns dos parâmetros requeridos.

O conhecimento das coordenadas geográficas das estações envolvidas, o raio efetivo da Terra $\left(a_{e}\right)$, as alturas sobre o nível do solo das antenas, a 
Apêndice A. Procedimento para determinar o valor $L$ da perda de propagação que não é excedido durante $P \%$ do tempo.

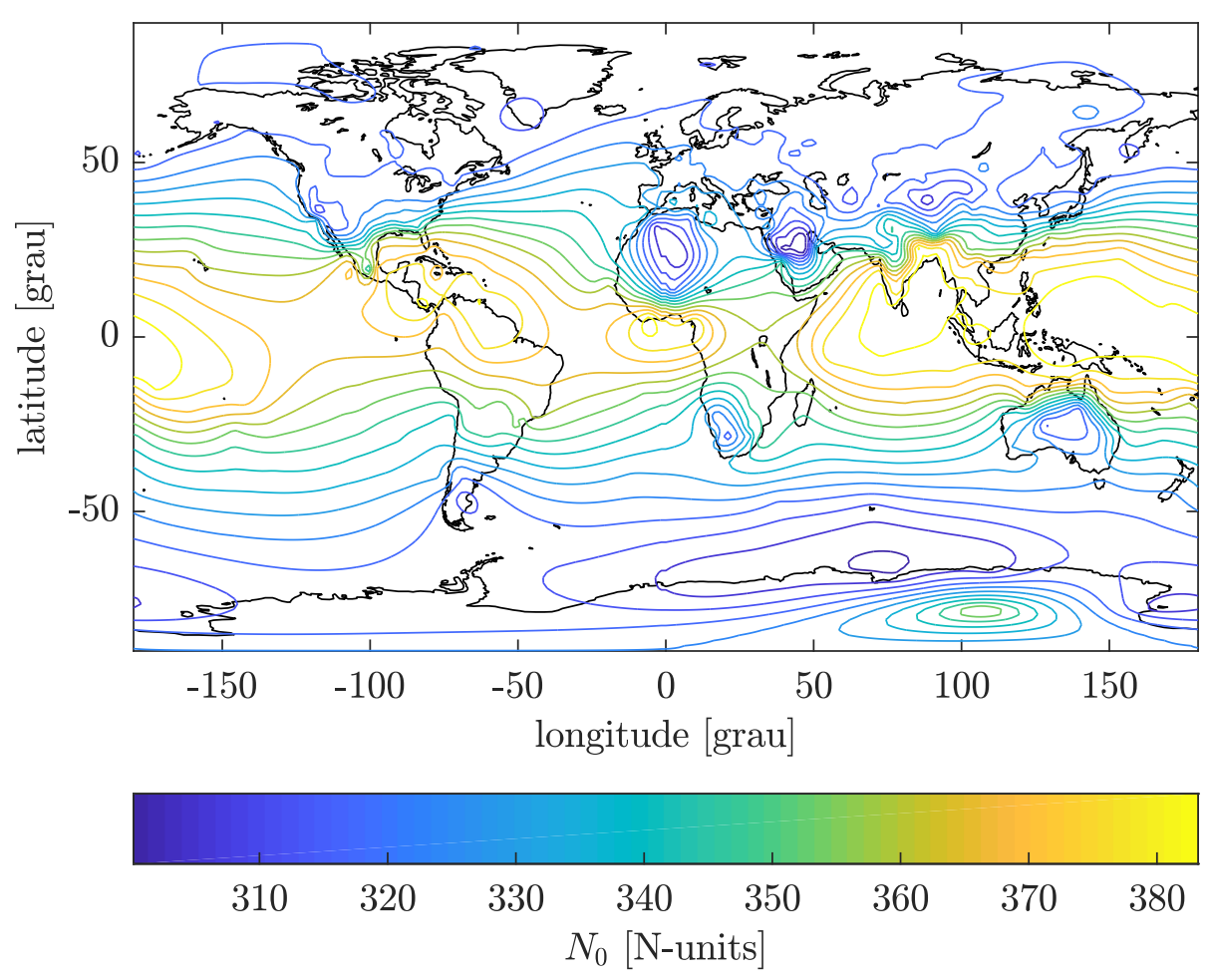

Figura A.4: Valor meio da refracção na superfície ao nevei do mar $N_{0}$.

frequência da sinal unido a utilização de uma base de dados topográfica é o que se precisa para realizar o analise do perfil do percurso.

O perfil do percurso foi obtido a partir da base de dados disponibilizada para uso publico no site http://dds.cr.usgs.gov/srtm/version2_1. Esta base de dados foi desenvolvida pela agência espacial americana (NASA) por meio do programa Shuttle Radar Topography Mission (SRTM). Cobrindo a superfície da Terra desde $60^{\circ} \mathrm{N}$ a $56^{\circ} \mathrm{S}$, a base é disponibilizada em matrizes quadradas equivalentes a $1^{\circ} \times 1^{\circ}$, contendo os valores de elevação em metros, sendo disponibilizados em dois tipos de resolução, 1 arco-segundo (30m) e 3 arco-segundo $(90 \mathrm{~m})$, a resolução disponível para a região usada neste trabalho foi de 3 arco-segundo (90m).

A formula do semiverseno (haversine formula) foi utilizada para o calculo das distâncias no grande circulo entre a antena interferente e a antena interferida e as distâncias ao transmissor dos $n$ pontos intermédios do perfil do percurso. $\theta_{\max }>\theta_{t d}$

O procedimento para a determinação dos parâmetros acima pode ser resumido da forma que mostra a Figura A.6, onde o primeiro passo é a determinação do tipo de percurso em transhorizonte ou visibilidade direita, 
Apêndice A. Procedimento para determinar o valor $L$ da perda de propagação que não é excedido durante $P \%$ do tempo.

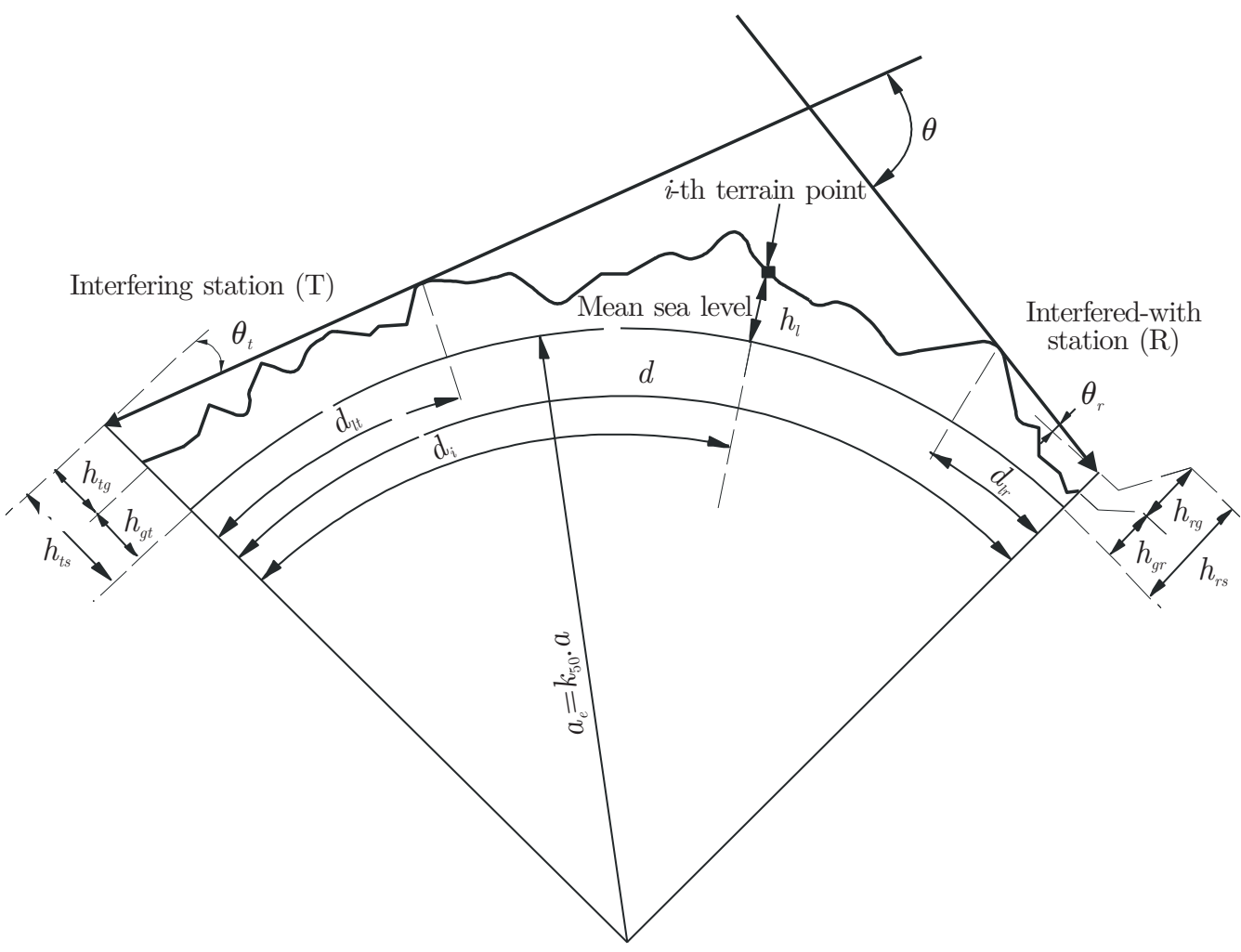

Figura A.5: Exemplo de um perfil de percurso transhorizonte

para assim determinar os parâmetros $\theta_{t}, \theta_{r}, d_{l t}$ e $d_{l r}$ conforme corresponda.

\section{A.4 \\ Predição da interferência em céu claro}

\section{A.4.1}

\section{Propagação em visibilidade direita (incluídos os efeitos a curto prazo)}

Avaliada tanto no caso de visibilidade direita como no caso de percurso transhorizonte, nesta seção do método são estimadas as perdas básicas de transmissão devida a propagação em espaço livre e atenuação por gases atmosféricos a qual é fornecida na recomendação UIT-R P.676, logo são feitas duas correções pelos efeitos de enfoque e multipercurso nos porcentagens de tempo $p$ e $\beta_{0}$. Obtendo-se como resultado duas quantidades: a perda básica de transmissão não excedida durante o $p \%$ do tempo,

$$
L_{b 0 p}=L_{b f s g}+E_{s p}
$$

e a perda básica de transmissão não excedida durante o $\beta \%$ do tempo

$$
L_{b 0 \beta}=L_{b f s g}+E_{s \beta}
$$


Apêndice A. Procedimento para determinar o valor $L$ da perda de propagação que não é excedido durante $P \%$ do tempo.

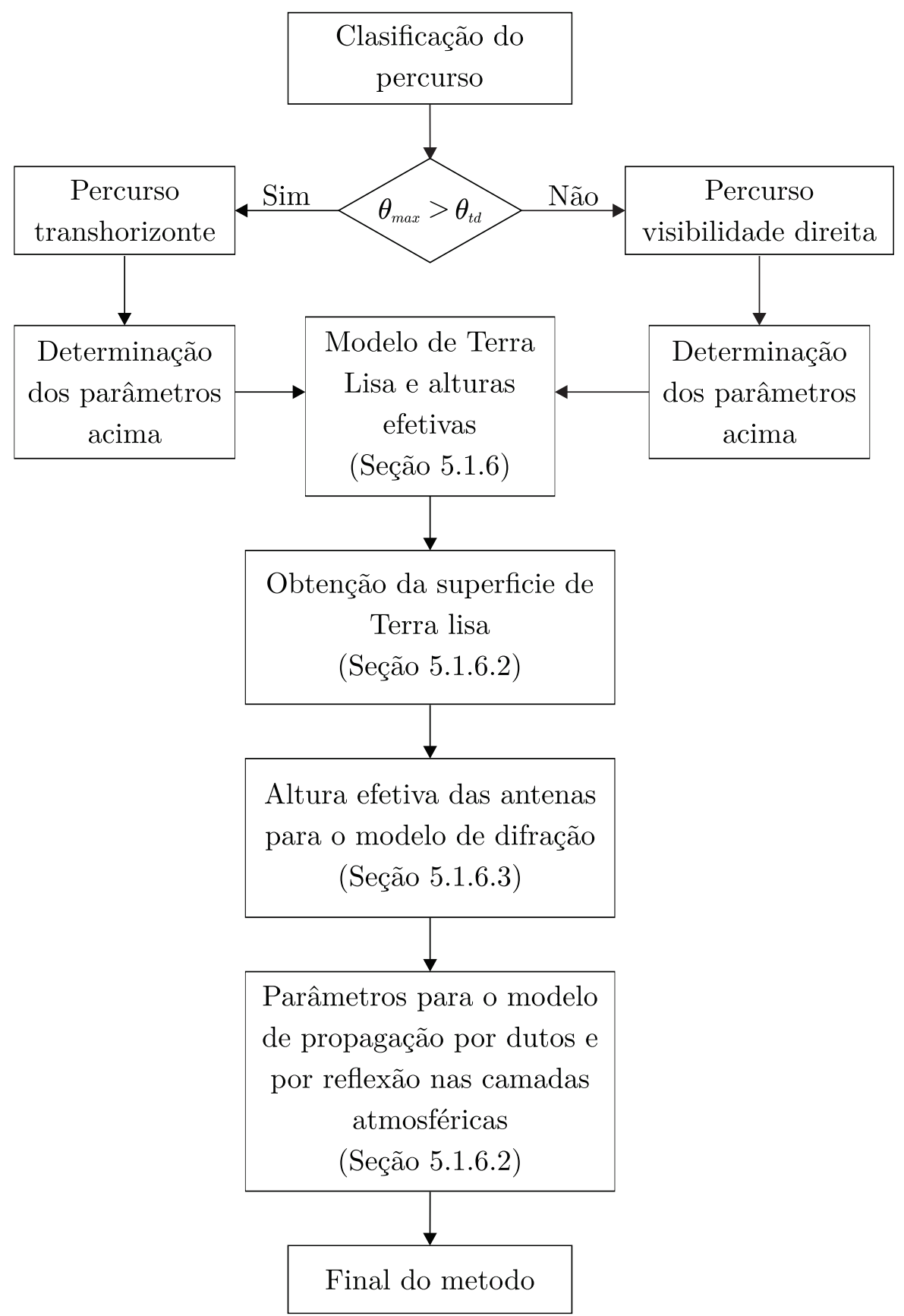

Figura A.6: Metodologia geral para a determinação dos parâmetros obtidos a partir do perfil do percurso

\section{A.4.2}

Difração

As perdas por difração calcula-se mediante um método que combina a construção de Bullington e a difração em uma Terra esférica. A parte do método correspondente a construção de Bullington é usada em duas ocasiões: para o perfil real do percurso e para um trajeto liso de altura zero com altura modificada da antena, o que é conhecido como altura efetiva da antena. A 
Apêndice A. Procedimento para determinar o valor $L$ da perda de propagação que não é excedido durante $P \%$ do tempo.

altura efetiva da antena também é usada para calcular a perda por difração de uma Terra esférica.

O resultado final obtém-se mediante uma combinação das três perdas calculadas, o método permite fazer uma estimação da perda de difração para todos os tipos de percursos, com inclusão de trajetos sobre mar o sobre superfícies interiores o litorais costeiros, e independentemente do fato de que a superfície seja plana o acidentada e de si a propagação é com visibilidade ou transhorizonte, na Figura A.7 é mostrado um diagrama em fluxos geral do método usado para obter as perdas devido a difração. Obtendo-se como resultado: as perdas por difração $L_{d p}$, não excedidas durante o $p \%$ do tempo,

$$
L_{d p}=L_{d 50}+F_{i}\left(L_{d \beta}-L_{d 50}\right)
$$

o valor mediano das perdas de transmissão básicas correspondentes à difração, $L_{b d 50}$,

$$
L_{b d 50}=L_{b f s g}+L_{d 50}
$$

e as perdas de transmissão básicas correspondentes à difração não excedidas durante o $p \%$ do tempo,

$$
L_{b d}=L_{b 0 p}+L_{d p}
$$

\section{A.4.3 \\ Dispersão troposférica}

O modelo de dispersão troposférica adotado pela recomendação é uma generalização empírica do conceito de dispersão troposférica o qual também abarca efeitos de propagação secundaria, pode ser obtido então de maneira coerente a predição das perdas básicas de transmissão na gama de porcentagens de tempo desde $0.001 \%$ ao $50 \%$, ligando de esta maneira o modelo de propagação por dutos e reflexão nas camadas durante pequenos porcentagens de tempo com o modo de "dispersão troposférica real ", foi obtido nesta seção a perda básica de transmissão devida à dispersão troposférica, $L_{b s}$ não excedida durante qualquer porcentagem de tempo $p$ inferior ao 50\%:

$$
L_{b s}=190+L_{f}+20 \log (d)+0.573 \theta-0.15 N_{0}+L_{c}+A_{g}-10.1[-\log (p / 50)]^{0.7}
$$

\section{A.4.4}

\section{Propagação por dutos e por reflexão nas camadas}

São estimadas as perdas básicas de transmissão, $L_{b a}$ geradas durante períodos de propagação anômala (propagação por dutos e por reflexão nas camadas), a expressão usada para a predição e a seguinte: 
Apêndice A. Procedimento para determinar o valor $L$ da perda de propagação que não é excedido durante $P \%$ do tempo.

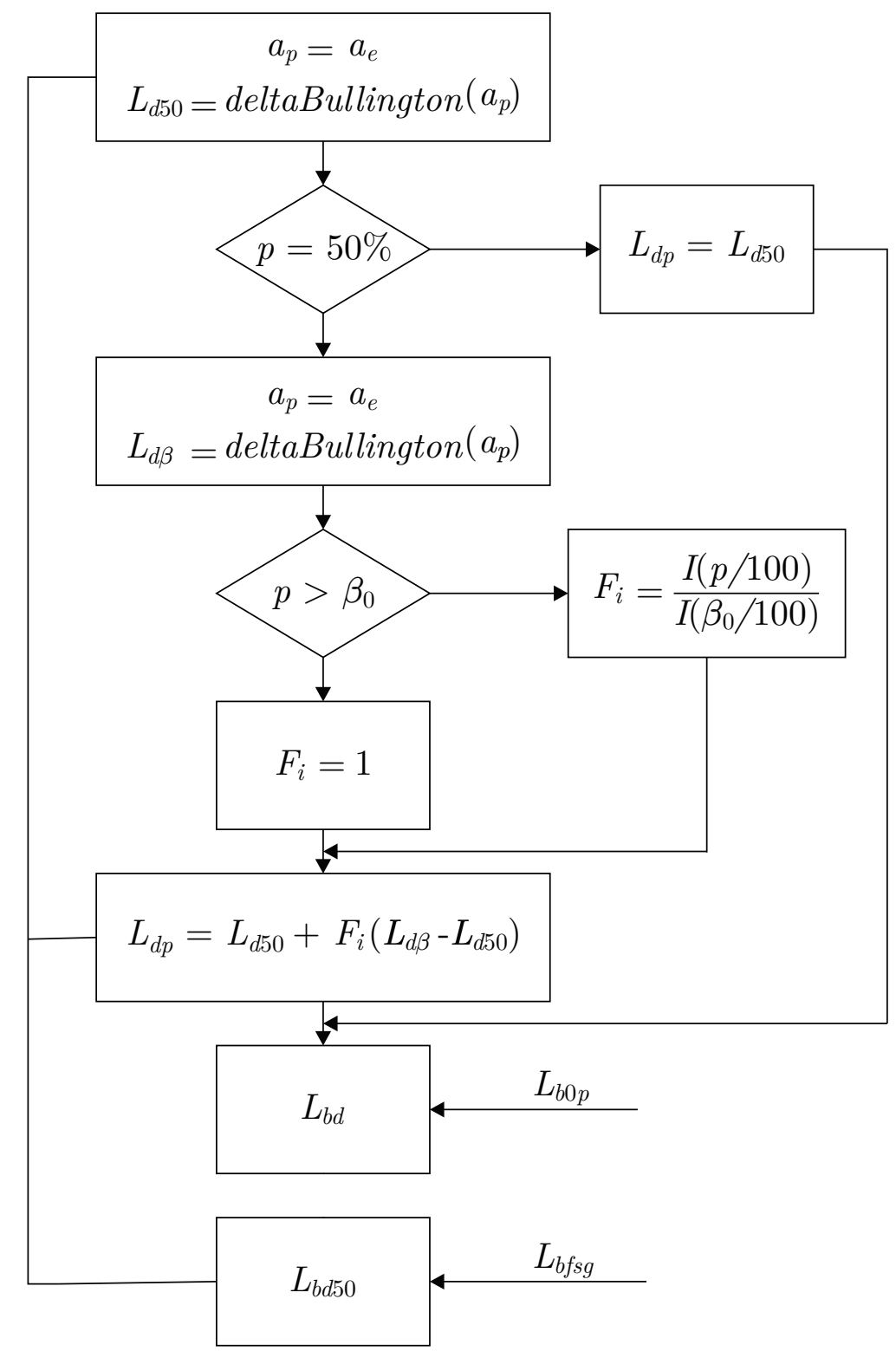

Figura A.7: Metodologia geral para a determinação das perdas devido a difração

$$
L_{b a}=A_{f}+A_{d}(p)+A_{g}
$$

\section{A.4.5}

\section{Perdas adicionais devidas à ocupação do solo}

Este tipo de perdas são apropriadas em termos de proteção de interferência, quando as antenas das estações receptoras estão localizadas em terrenos perto de ambientes saturados (edificações e florestas). Neste trabalho o terreno escolhido não entra nesta descrição por o que não foi tida em conta para o análise feito neste trabalho das perdas básicas de transmissão não excedidas. 
Apêndice A. Procedimento para determinar o valor $L$ da perda de propagação que não é excedido durante $P \%$ do tempo.

\section{A.4.6 \\ Predição Geral das perdas básicas de transmissão não excedidas durante o p do tempo}

A partir dos valores aportados por cada um das seções anteriores é possível aplicar o método de predição da perda de transmissão básica não excedida durante o $p \%$ do tempo como é abordado na seção 4.6 da recomendação UIT-R P.452-16. a expressão usada para determinar $L_{b}$,

$$
L_{b}=-5 \log \left(10^{-0.2 L_{b s}}+10^{-0.2 L_{b a m}}\right)
$$

\section{A.5 \\ Exemplo do uso da metodologia}

Um exemplo para avaliação da metodologia foi realizado no estado do Rio de Janeiro envolvendo duas estações: a estação interferente localizada na PUC e a estação vitima localizada no Museu Bélico (Forte São Luiz) no outro lado da Baía de Guanabara como pode ser visto na Figura A.8.

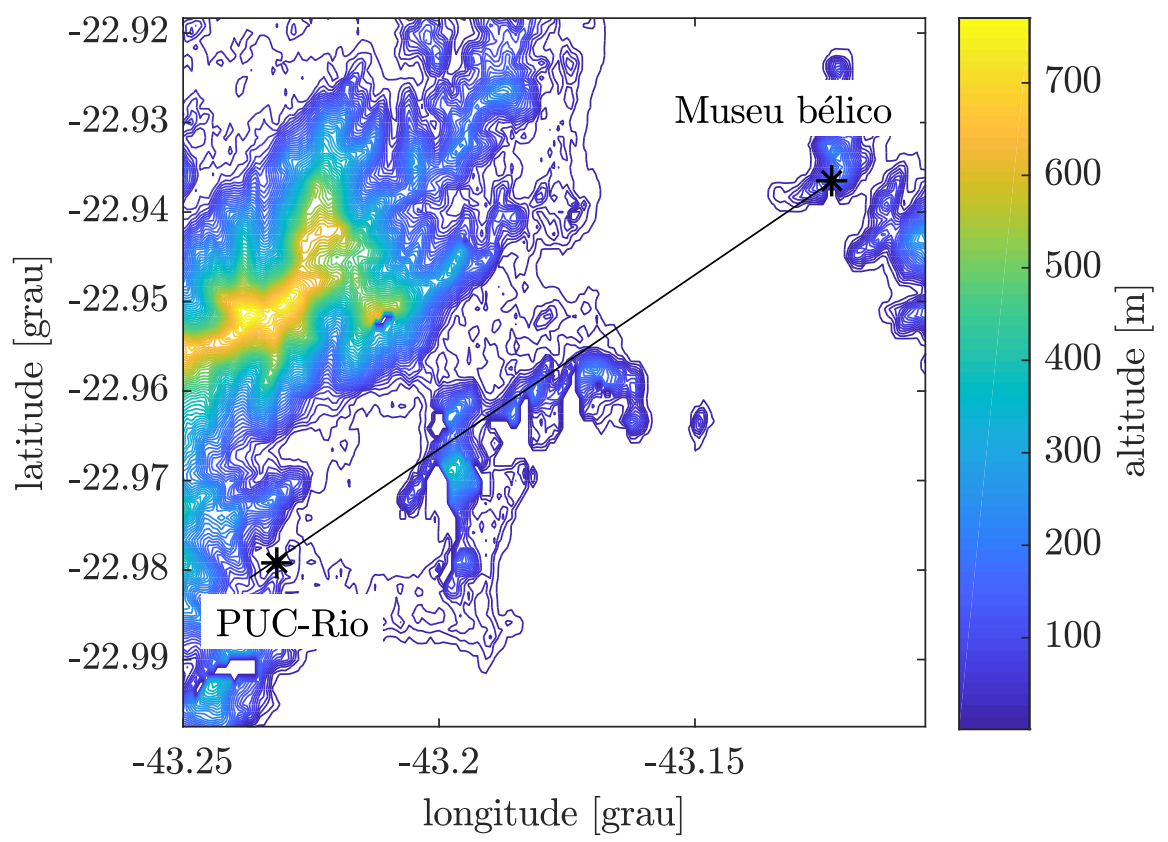

Figura A.8: Exemplo na região metropolitana de Rio de Janeiro, transmissor localizado na PUC-Rio no bairro da Gavea e receptor no Museu Bélico localizado Niteroi.

A partir das coordenadas geográficas, a frequência do sinal e altura das antenas foi obtido o perfil do percurso com uma resolução de $90 \mathrm{~m}$, e a função acumulativa de probabilidade das perdas de propagação $F_{l p}(L p)$ para $p$ valido desde $0.001 \%<p<50 \%$, os dados usados foram os seguintes: 
Apêndice A. Procedimento para determinar o valor $L$ da perda de propagação que não é excedido durante $P \%$ do tempo.

$-\varphi_{t}:-22.9792$ graus

$-\psi_{t}:-43.2317$ graus

$-\varphi_{r}:-22.9365$ graus

$-\psi_{r}:-43.1233$ graus

$-h_{t g}: 10 \mathrm{~m}$

$-h_{r g}: 20 \mathrm{~m}$

O perfil obtido, é mostrado na Figura A.9 podendo-se observar a existência de algumas elevações pequenas, tramo sobre a Baía de Guanabara, é interessante observar que o tramo sobre a Lagoa não têm altitude zero pois a lagoa encontra-se uns 6 metros sobre o nível da mar.

A FDP obtida para esta distância é altura das antenas foi a que se mostra na Figura A.10 estando as perdas não excedidas da acordo a distância e alturas de antenas selecionadas pode ser observado também do perfil do percurso que as estações não têm visibilidade direita

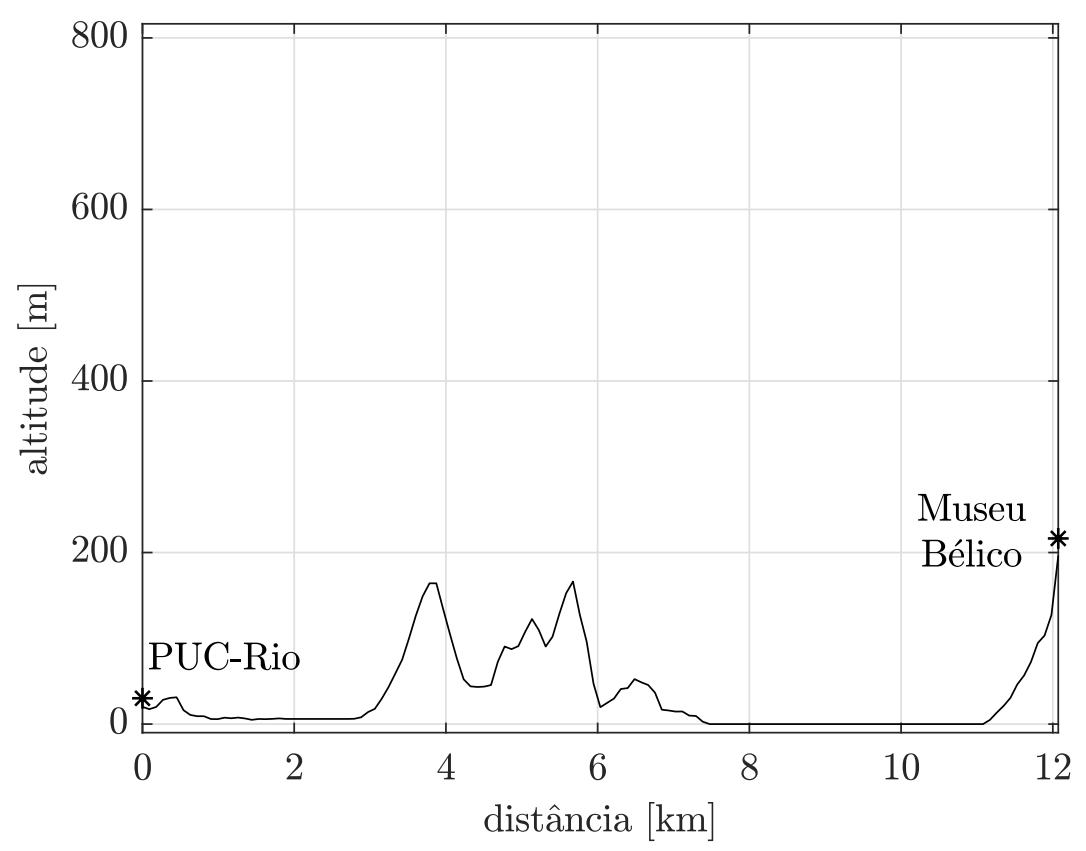

Figura A.9: Perfil do percurso do exemplo da zona sul do Rio de Janeiro, transmissor localizado na PUC-Rio no bairro da Gavea e receptor no Museu Bélico localizado Niteroi. 
Apêndice A. Procedimento para determinar o valor $L$ da perda de propagação que não é excedido durante $P \%$ do tempo.

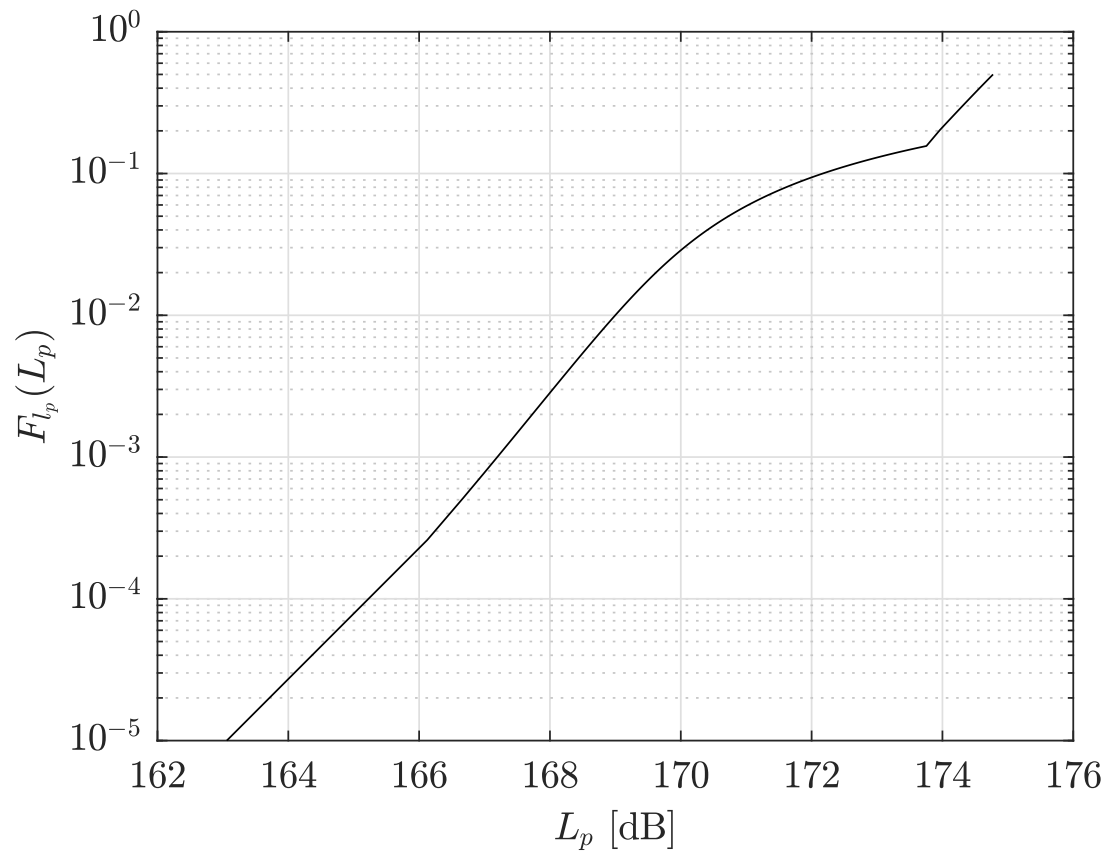

Figura A.10: Função acumulativa da perda básica de transmissão $F_{l p}\left(L_{p}\right)$ entre uma estação na PUC-Rio no bairro da Gavea e outra estação no Museu Bélico em Niteroi. 


\section{B \\ Nível máximo admissível da densidade de potencia da antena transmissora (ESIM) a partir da Recomendação ITU-R S.524.}

Na recomendação ITU-R S.524-9 são estabelecidos níveis máximos admissíveis da densidade e.i.r.p. off-axis, que deverão ser utilizadas por estações terrenas operando com satélites da orbita geostacionária operando no serviço fixo por satélite transmitindo nas bandas de frequência de $6 \mathrm{GHz}, 13 \mathrm{GHz}, 14$ $\mathrm{GHz}$ e $30 \mathrm{GHz}$ buscando limitar a potência interferente em redes de satélites geostacionários (GSO) vizinhos operando na mesma faixa de frequência.

A recomendação ITU-R S.524-9 estabelece que, estações terrenas operando em redes de satélites geostacionários (GSO) no serviço FSS, na banda de frequência de $30 \mathrm{GHz}$, são desenhadas de forma tal, para quaisquer ângulo, $\varphi$, maior a $2^{\circ}$ fora do eixo do lóbulo principal da antena transmissora da estação terrena, a densidade de e.i.r.p. em qualquer direção dentro dos $3^{\circ}$ não deverá exceder os valores seguintes,

$$
\begin{array}{cll}
\text { e.i.r.p.maximo para } 40 \mathrm{KHz} & & \text { Angulo (off-axis) } \\
(19-25 \log \varphi) \mathrm{dB}(\mathrm{W} / 40 \mathrm{KHz}) & ; 2^{\circ} \leq \varphi \leq 7^{\circ} \\
-2 \mathrm{~dB}(\mathrm{~W} / 40 \mathrm{KHz}) & ; 7^{\circ}<\varphi \leq 9.2^{\circ} \\
(22-25 \log \varphi) \mathrm{dB}(\mathrm{W} / 40 \mathrm{KHz}) & ; & 9.2^{\circ}<\varphi \leq 48^{\circ} \\
-10 \mathrm{~dB}(\mathrm{~W} / 40 \mathrm{KHz}) & ; & 48^{\circ}<\varphi \leq 180^{\circ}
\end{array}
$$

em qualquer direção na região fora dos $3^{\circ}$ da orbita geostacionaria (GSO), os níveis listados acima podem ser excedidos por no mais de $3 \mathrm{~dB}$.

Para que a densidade e.i.r.p transmitida pelas ESIM satisfaçam ao limite máximo permitido na Recomendação ITU-R S.524-9 [16], os valores das curvas correspondentes ao diagrama de radiação usado na caracterização da antena transmissora das ESIM mais a densidade de potência, isto é,

$$
\text { e.i.r. } p_{\mathrm{ESIM}}(\varphi)=p_{t}+g_{t}(\varphi)
$$

não deverão ultrapassar os valores correspondentes à curva obtida a partir de (B-1). Assim os níveis de densidade de potência de transmissão de uma antena de diâmetro 0,5 metros foi determinado como sendo o maior valor de potência $p_{t}$ que satisfaz à condição,

$$
p_{t}+g_{t}(\varphi) \leq L_{524}(\varphi) \quad \forall \varphi \in\left[2^{\circ}, 180^{\circ}\right]
$$


onde $L_{524}(\varphi)$ representa valores dos níveis máximos admissíveis da densidade e.i.r.p. estabelecidas na recomendação ITU-R S.524-9. Uma ilustração da condição dada em (B-3) é amostrada na Figura B-3.

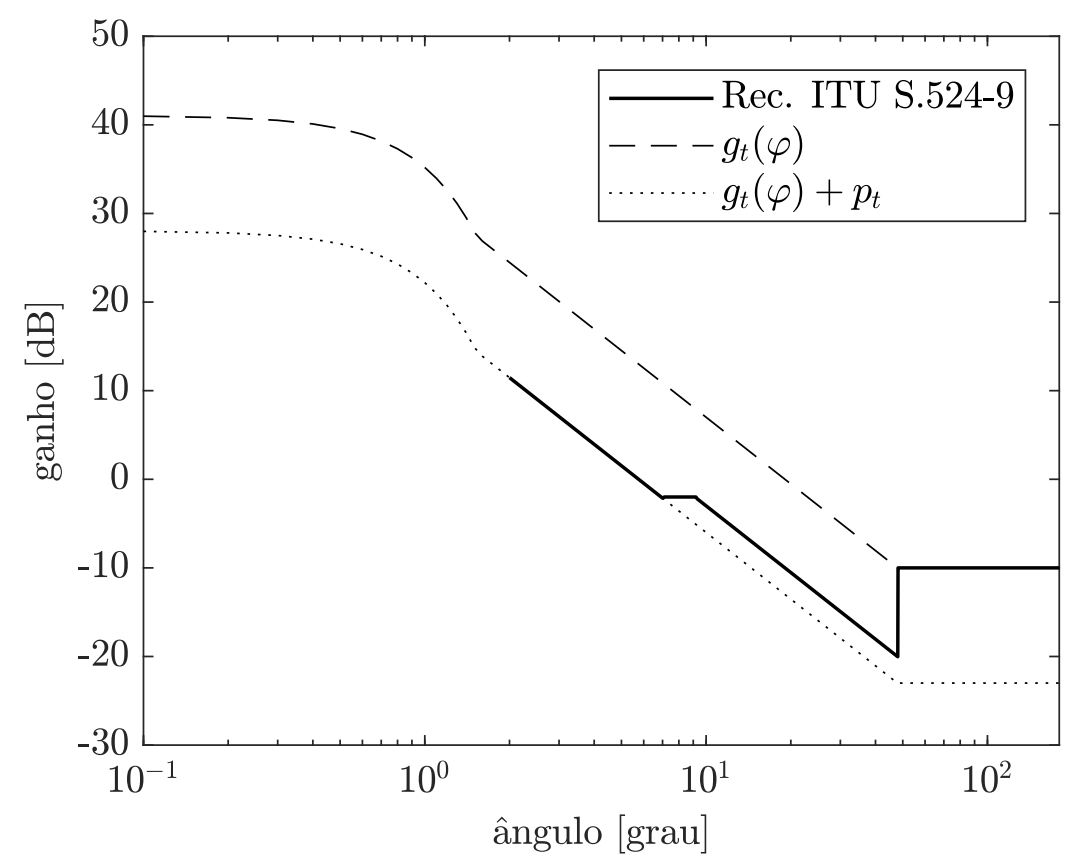

Figura B.1: Condição em (B-3), são ilustrados o diagrama de radiação (Recomendação ITU-R F-1245-2 e ITU-R S.465-6) e o nível máximo admissível da densidade e.i.r.p. (Recomendação ITU-R S.524-9) em dB(W/40KHz), considerando $D=0,5 \mathrm{~m}$. 
Apêndice B. Nível máximo admissível da densidade de potencia da antena transmissora (ESIM) a partir da Recomendação ITU-R S.524.

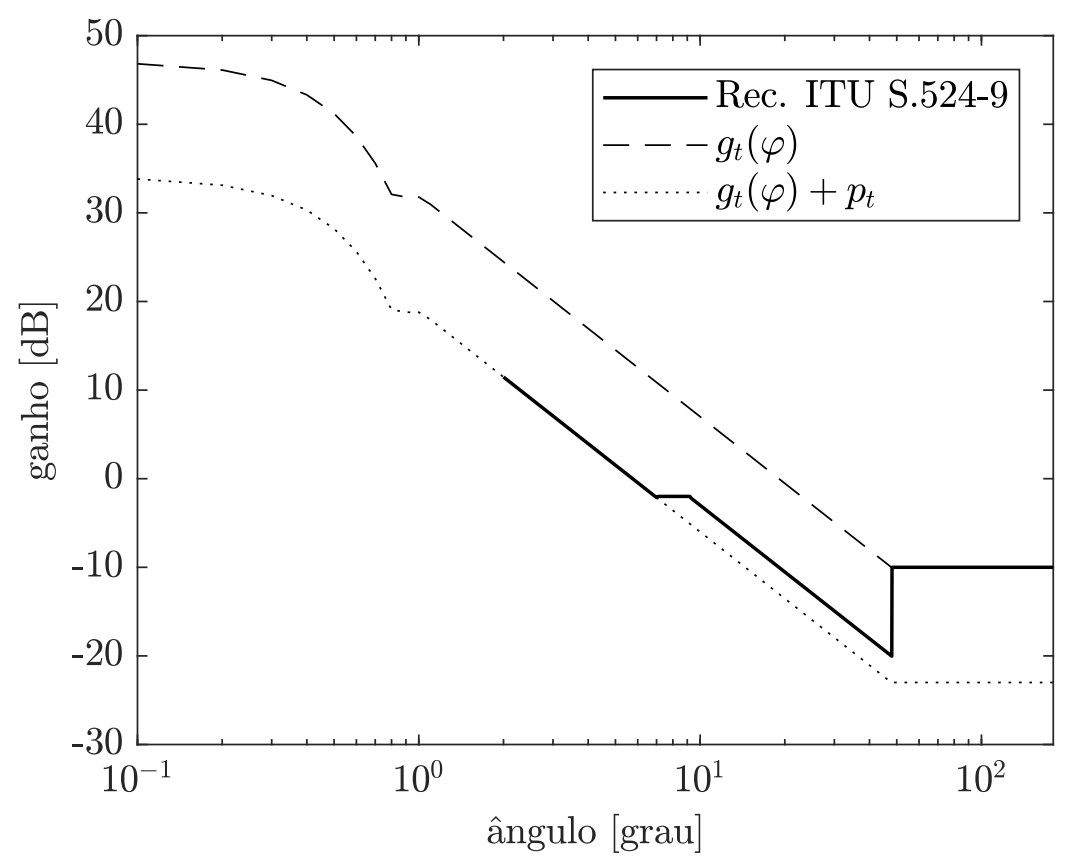

Figura B.2: Condição em (B-3), são ilustrados o diagrama de radiação (Recomendação ITU-R F-1245-2 e ITU-R S.465-6) e o nível máximo admissível da densidade e.i.r.p. (Recomendação ITU-R S.524-9) em dB(W/40KHz), considerando $D=1 \mathrm{~m}$. 